\title{
May I have your attention, please? : A neuroscientific study into message attention for health information
}

Citation for published version (APA):

Kessels, L. (2010). May I have your attention, please? : A neuroscientific study into message attention for health information. [Doctoral Thesis, Maastricht University]. Maastricht University.

https://doi.org/10.26481/dis.20101119lk

Document status and date:

Published: 01/01/2010

DOI:

10.26481/dis.20101119lk

Document Version:

Publisher's PDF, also known as Version of record

\section{Please check the document version of this publication:}

- A submitted manuscript is the version of the article upon submission and before peer-review. There can be important differences between the submitted version and the official published version of record.

People interested in the research are advised to contact the author for the final version of the publication, or visit the DOI to the publisher's website.

- The final author version and the galley proof are versions of the publication after peer review.

- The final published version features the final layout of the paper including the volume, issue and page numbers.

Link to publication

\footnotetext{
General rights rights.

- You may freely distribute the URL identifying the publication in the public portal. please follow below link for the End User Agreement:

www.umlib.nl/taverne-license

Take down policy

If you believe that this document breaches copyright please contact us at:

repository@maastrichtuniversity.nl

providing details and we will investigate your claim.
}

Copyright and moral rights for the publications made accessible in the public portal are retained by the authors and/or other copyright owners and it is a condition of accessing publications that users recognise and abide by the legal requirements associated with these

- Users may download and print one copy of any publication from the public portal for the purpose of private study or research.

- You may not further distribute the material or use it for any profit-making activity or commercial gain

If the publication is distributed under the terms of Article $25 \mathrm{fa}$ of the Dutch Copyright Act, indicated by the "Taverne" license above, 
May I have your attention please?

A neuroscientific study into message attention for health information 


\section{Colophon}

Graphic design: Loes Kessels

Cover design: Alexander van Dongen, www.nul-twintig.nl

Production: Datawyse | Universitaire Pers Maastricht

ISBN 9789052789767

\section{(C) 2010 Loes Kessels, Maastricht 2010}

All rights are reserved. No part of this book may be reproduced or transmitted in any form or by any means, without written permission from the author or, when appropriate, the publisher of the article. 


\section{May I have your attention please?}

A neuroscientific study into message attention for health information

\section{PROEFSCHRIFT}

Ter verkrijging van de graad van doctor aan de Universiteit Maastricht, op gezag van de Rector Magnificus, Prof. mr. G. P. M. F. Mols, volgens het besluit van het College van Decanen, in het openbaar te verdedigen op vrijdag 19 november 2010 om 12.00 uur

door Loes Theodora Elisabeth Kessels

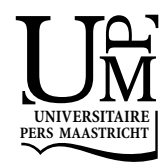




\section{Promotor}

Prof. dr. G. Kok

\section{Copromotores}

Dr. R. A. C. Ruiter

Dr. V. van de Ven

\section{Beoordelingscommissie}

Prof. dr. F. R. H. Zijlstra (voorzitter)

Prof. dr. H. Aarts (Utrecht University)

Dr. S.L. Brown (University of Liverpool)

Prof. dr. R. Goebel

Dr. A. van der Lugt 


\section{Contents}

Chapter 1

Chapter 2

Chapter 3

Chapter 4

Chapter 5

Chapter 6

Chapter 7
General Introduction

11

Increased attention for computer-tailored health communications:

An event-related potential study

Studying the combined effects of tailored and

threatening health information on message attention using event-related brain potentials

Increased attention but more efficient disengagement:

Neuroscientific evidence for defensive processing of threatening health information

Explicit and implicit neural mechanisms for the processing of threatening smoking pictures among smokers and non-smokers:

A functional magnetic resonance imaging study

I spy with my little eye for help, not for threat: Attention for health messages on cigarette packages

General Discussion

References

Summary

Samenvatting

Curriculum Vitae
57 73

133

27 

Dankwoord 
Na ruim vier jaar is het proefschrift eindelijk af! Ik wil graag iedereen bedanken die heeft bijgedragen aan de totstandkoming van dit boekje.

Allereerst een bijzonder woord van dank aan mijn begeleider Rob. Bedankt voor de goede dagelijkse begeleiding tijdens het hele project. Naast je deskundigheid heb je me altijd veel vetrouwen gegeven als onderzoeker. De snelle feedback, de goede overleggen en dat ik altijd bij je binnen kon lopen, heb ik erg gewaardeerd. Daarnaast wil ik Vincent, Bernadette en Gerjo bedanken voor jullie visie en expertise die onmisbaar waren gedurende mijn project. Speciaal dank aan Vincent voor je begeleiding bij de fMRI-studie.

Ook woorden van dank gaan uit naar mijn stagiaires en student-assistenten, Astrid, Els, Esther, Janaica, Kelly, Saman en Sara. Bedankt voor de hulp bij het opzetten en uitvoeren van verschillende studies!

Collega's van psychologie, bedankt voor de leuke werksfeer. Door jullie kwam ik elke dag met plezier naar mijn werk. Speciaal dank aan de lieve meiden die zorgden voor veel gezelligheid op de uns 40 en buiten het werk: Carolien, Ellen, Esther, Jill, en Saskia! Door jullie voelde ik me gelijk thuis op de uns 40. Thanks! Jill, jammer dat je hier niet meer werkt, gelukkig ben je niet ver weg. Bedankt voor de vroege thee-pauzes op de uns 5 en de gezellige lunches. Saar en Hans, dat jullie mijn paranimfen willen zijn, zegt al genoeg. Niet alleen op de uni, maar ook daarbuiten hebben we het vaak erg gezellig. Saar, bedankt voor je optimisime en je enthousiasme. Wat fijn dat je weer terug bent uit The States. Hans, bedankt voor het zijn van zo'n fijne, lieve en relaxte kamergenoot! Jammer genoeg heb je de uns 5 waarschijnlijk verlaten als dit boekje is gedrukt. Ik zal onze gesprekken en de 'koekjes'-momenten erg missen.

Studievriendinnen van Maastricht: Els, Kim en Lonneke. Els, bedankt voor de gezellige momenten als we elkaar na lange tijd weer zien. Kim, bedankt voor de leuke reis in Amerika. Lonneke, heerlijk om met jou zo'n fijne gesprekken te hebben. Bedankt voor je vriendschap.

Dan is er natuurlijk de vriendengroep 'SF'! Anke, Barry, Geert, Gerwin, Janneke, Jeroen C., Jeroen H., Jessie, Jolanda, Marc, Martijn, Paul, Robert, en Thom. Bedankt voor de leuke (dronken) stapavonden, feestjes, JBB-bezoekjes, spellenavonden, weekendjes-weg en vakanties.

Mijn schoonfamilie, Karel, Els en Rudy, dank ik voor jullie gastvrijheid en interesse. Bedankt dat jullie altijd voor ons klaarstaan. 
Mijn lieve familie, Gerrie, Marcel en Ruud! Speciaal dank voor jullie waardering, steun en liefde! Bedankt mama, voor alles wat je hebt gedaan om mij te kunnen laten studeren. Daarnaast heb je een plek gecreëerd waar ik me altijd thuis voel. Thanks!

Lieve Marc! Tijdens het hele project heb je altijd in me geloofd en me veel vertrouwen gegeven. Bedankt dat je me zo vrij laat in alles wat ik doe, dat je er altijd voor me bent en voor zo veel meer! 



\section{Chapter 1}

General Introduction 
Health education messages have the goal to encourage and motivate people to engage in health promoting and disease preventive behaviours and thus reduce health problems and costs in our society. Evidence shows however that health messages often fail to bring about a successful behavioural change (Parrott, 1995). Changing people's health-related behaviour is a difficult and complex task (Joffe, 2000; Lawrence, 1999; Norton, 1998; Whitehead \& Russell, 2004). Partly, this failure can be attributed to the ways that people process the information they have been exposed to (Levy \& Windahl, 1985).

Dual process models like the Elaboration Likelihood Model (ELM; Petty \& Cacioppo, 1986) or the Heuristic Systematic Model (HSM; Chaicken, Liberman, \& Eagly, 1989) have been used to explain the limited effectiveness of health education messages by studying different ways of information processing resulting in weaker and stronger persuasive outcomes. The ELM distinguishes between central and peripheral processing. The central processing route evokes cognitive change based on consideration of presented arguments incorporating both cognitive and affective components. In the heuristic based peripheral processing route cognitive change occurs due to other characteristics of the message than its contents, such as expertise of the source (Petty \& Cacioppo, 1986). In general, central route processing leads to attitude changes that are more stable and predictive of behaviour and more resistant to counterarguments (Chaicken \& Trope, 1999; Eagly \& Chaicken, 1993). In the heuristic-systematic model, or HSM, (Chaicken et al., 1989) information is either processed in a high-involvement and high-effort systematic way, or information is processed through shortcuts known as heuristics. In this approach, heuristics include our own emotions as we ask 'How do I feel about this?' The primary consequence of systematic processing, as in the central route of the ELM, is that attitudes and judgments reached tend to be more stable and more tied to subsequent behaviour than attitudes and judgments reached via heuristic processing.

Within both ELM and HSM message involvement is an important determinant of the specific route of information processing an individual will follow to come to an attitudinal judgement (Chaicken, 1980; Darley \& Lim, 1991; Petty, Cacioppo, \& Schumann, 1983). High involvement with the information is hypothesized to lead to a more thoughtful evaluation of the message arguments, employing central route or systematic processing, than low involvement with the information (Chaicken, 1980). Consequently, high involvement with the information leads to high attitude-behaviour consistency (Darley \& Lim, 1991; Leippe \& Elkin, 1987; Sivacek \& Crano, 1982).

The goal of health education practitioners is to create health education messages that result in attitude changes that are stable and predictive of behaviour and more resistant to counterarguments. One way to stimulate systematic or central route processing is thus to heighten message involvement. Two frequently used health education methods that have been assumed to increase message involvement and thus promote systematic processing are the presentation of threatening health information and message tailoring (Baron, Logan, Lilly, Inman, \& Brennan, 1994; Brug, Oenema, \& Campbell, 
2003; Kreuter \& Holt, 2001). Both methods are central to this thesis and will therefore be discussed more thoroughly in this chapter.

\section{Threatening health information}

In health education threatening health information is used to arouse fear in order to promote precautionary motivation and self-protective action such as not smoking, using seat belts and having a healthy diet (Rogers, 1983). A recent example is the advice of the European Union Commission for Health and Consumer Protection to the EU member states to add shocking graphic pictures to existing health warnings on cigarette packages. These pictures include hard-hitting photographs of, for example, black lungs and an open tumor on the throat that should motivate smokers to quit smoking (European Union, http://www.europa.eu.int, retrieved May 14, 2005).

Several theoretical models have been formulated to explain the effects of threatening health messages on persuasion. The Parallel Response Model (PRM; Leventhal, 1970), for example, emphasized the cognitive antecedents of self-protective action. The PRM suggests that threatening health messages cause distinct motivational and coping responses, particularly fear control and danger control. Fear control entails emotionfocused coping (Lazarus \& Folkman, 1984), that generates reassurance through denial of the threat or derogation of the message (Ruiter, Abraham, \& Kok, 2001). Fear control attempts to control fear generated by the threat and is thus maladaptive because it does not avert the perceived threat (Leventhal, 1971; Witte, 1992). Danger control can be thought of as a cognitive evaluation process oriented towards the presented threat rather than the evoked fear, to stimulate protective action. Danger control thus attempts to control the presented threat. Although fear control and danger control processes are thought to operate independently one may dominate the other (Leventhal, 1970, 1971). According to PRM, fear arousal should precede the danger control processes that underpin precautionary motivation. On the other hand, fear can also activate emotion-focussed processes that may reduce precautionary motivation (Leventhal, 1971; Ruiter, Abraham et al., 2001).

Leventhal's PRM was further elaborated by Rogers resulting in the Protection Motivation Theory (PMT; Rogers, 1975). According to PMT, danger control in reaction to threatening health messages constitutes two mediating cognitive processes: threat appraisal and coping appraisal. Threat appraisal consists of evaluations of threat seriousness and personal susceptibility (i.e., severity and susceptibility). Coping appraisal consists of evaluations of the effectiveness of potential responses and one's ability to undertake these successfully (i.e, response efficacy and self-efficacy). Threat and coping appraisal generate protection motivation defined as "an intervening variable that has the typical characteristics of a motive: it arouses, sustains, and directs activity" (Rogers, 1975, p. 98). 
According to PRM and PMT the chance of accepting the recommendation is more likely when threat increases, but only if the recommendation is judged to be an effective and feasible way to reduce the threat. Individuals will not take protective actions that are supposed to be ineffective in averting the negative consequences. PMT, for example, suggests that protection motivation will arise when becoming conscious of the severity of a threat that one is susceptible to. However, the nature of this motivation is dependent on coping appraisal (i.e., response efficacy and self-efficacy). If the recommended protective action is seen as ineffective in preventing the threat or people feel unable to carry out the recommended action, then people will have no intention to act. In the organization of threatening health messages, subdivided in threat information and coping information, coping beliefs thus have a large influence on subsequent health promoting behaviour. Research also showed that the perception of threat, without high self-efficacy and response efficacy, activates maladaptive fear control coping rather than danger control in the form of preparation for action (Abraham, Sheeran, Abrams, \& Spears, 1994; Rippetoe \& Rogers, 1987; Witte, Berkowitz, Cameron, \& McKeon, 1998). For example, Rippetoe and Rogers (1987) reported that while threat information motivates both adaptive (e.g., intentions to perform breast self-examination) and maladaptive (e.g., avoid thinking about breast cancer) precautionary action, coping information determines whether the action is directed to the threat (adaptive) or to the unpleasant emotion of fear (maladaptive). In other words, the presentation of threat information alone is not sufficient for stimulating adaptive action; a positive coping appraisal process is required to motivate people to change risk behaviour and adopt safer behavioural alternatives (Abraham et al., 1994; Rippetoe \& Rogers, 1987; Witte et al., 1998). Therefore, an effective threatening persuasive message comprises of threat information that describes the severity of the threat and the person's susceptibility to it (e.g., "Lung cancer is a deadly disease and those who smoke may acquire it"), accompanied by coping information outlining the feasibility and effectiveness of a recommended action (e.g., "Quitting smoking may help you in preventing lung cancer").

Combining PRM and PMT, Witte proposed the extended parallel process model (EPPM; Witte, 1992). The EPPM explains both successes and failures of fear appeals through incorporating both fear control and danger control processes. When perceiving threat, danger control processes will initially be activated. Recommended actions will be judged on their effectiveness and feasibility. Judging the response as effective and feasible will motivate the recipient to undertake the recommended action. Judging the recommended action as ineffective or impossible however will lead to negative emotions and fear arousal in particular if threat perception continues. At this moment, fear control processes are instigated leading to denial and avoidance coping. According to EPPM, threat perceptions thus contributes to the extent of a response to a fear appeal (i.e., how strong the danger or fear control responses are), whereas perceived efficacy (or lack 
thereof) contributes to the nature of the response (whether danger of fear control responses are elicited; Witte, 1992).

Consistent with these assumptions, a meta-analysis (Milne, Sheeran, \& Orbell, 2000) indicated that threat appraisal (i.e., severity and susceptibility) and response efficacy measures, have small associations with concurrent behaviour, and do not predict future behaviour. Self-efficacy on the other hand is a strong predictor of concurrent and future behaviour. In line with the larger domain of attitude-behaviour research, efficacy components are stronger determinants of protective action than threat perceptions (see also Floyd, Prentice-Dunn, \& Rogers, 2000; Godin \& Kok, 1996). For the creation of threatening health messages, presenting coping information is thus important because it can enhance self-efficacy (Moriarty \& Stryker, 2008).

Besides the theoretical social cognitive models described in previous sections, interpretations of the impact of fear appeals are also explained by dual-process models of persuasion. While the social cognitive models of threatening health messages were explicitly developed to explain the role of fear arousal in persuasion, the dual-process models like the elaboration likelihood model (ELM) and the heuristic systematic model (HSM), seek to explain the role of any factor in persuasion. The ELM and HSM suggest that threat perception and fear arousal will increase the relevance of threat-relevant information, and, therefore, result in systematic processing of threat-relevant persuasive information (Das, de Wit, \& Stroebe, 2003; Ruiter, Abraham et al., 2001). The increased message involvement leading to systematic processing will initiate attitude changes that are more stable and predictive of behaviour and more resistant to counterargumentation (Chaicken \& Trope, 1999; Eagly \& Chaicken, 1993). For example, Baron and colleagues (1994) found that people with high threat attitudes towards dental hygiene were more positive after reading a persuasive message containing strong arguments than after reading a persuasive message containing weak arguments (Baron et al., 1994). In the low threat conditions, this effect of argument strength on attitude was not reported. Based on these findings it was concluded that fear, or at least perceived threat, promotes systematic processing of threat-relevant persuasive information. Extending these findings, Das and colleagues (2003) hypothesized that inducing vulnerability to a severe health threat communication will cause biased and systematic processing of the action recommendation or coping. Individuals who are vulnerable to a health risk will attempt to make the recommendation appear highly effective by means of biased search for arguments supporting the effectiveness of the protective action and through biased evaluation of these arguments (Das et al., 2003). The results provided support for their hypotheses, with high-vulnerability participants reporting more thoughts and also more positive (but not negative) thoughts about the recommended action, suggesting increases rather than decreases in the depth of processing and a biased evaluation of the evidences presented (Das et al., 2003). Other studies also investigated the effect of fear on the extent of systematic processing with mixed results (Baron, Inman, Kao, \& Logan, 1992; Baron et al., 
1994; Gleicher \& Petty, 1992; Hale, Lemieux, \& Mongeau, 1995; Jepson \& Chaiken, 1990; Kuppens, de Wit, \& Stroebe, 1996; Meijnders, Midden, \& Wilke, 2001; Ruiter, Abraham et al., 2001; Wilder \& Shapiro, 1989).

\section{Defensive processing of threatening information}

Based on the fear appeal models and parallel process models it is assumed that fear appeals, including high threat information and positive coping information, can lead to more adaptive behaviour change. Although threat information is assumed to lead to more systematic but biased processing of information containing recommended actions, empirical findings have also detected defensive responses towards the threat information itself. A considerable body of experimental studies suggest a negative effect of threatening health information on message acceptance, especially among those for whom the health threat is high as opposed to low self-relevant (Brown \& Locker, 2009; Croyle, Sun, \& Hart, 1997; Ditto \& Croyle, 1995; Freeman, Hennessy, \& Marzullo, 2001; Harris \& Napper, 2005; Keller, 1999; Keller \& Block, 1999; Liberman \& Chaiken, 1992; Sherman, Nelson, \& Steele, 2000; Taubman - Ben-Ari, Florian, \& Mikulincer, 2000).

For example, Liberman and Chaicken (1992) presented coffee-drinking and noncoffee drinking participants with threatening information linking coffee-drinking to the development of fibrocystic disease (a precursor of breast cancer). The findings based on self-report questionnaires showed that female coffee-drinkers, for whom the message was highly relevant, were less persuaded of the link between caffeine and fibrocystic disease than female non-coffee drinkers. More importantly, coffee-drinkers seemed to have systematically processed the threatening parts of the message, in a defensive, biased manner. Compared with non-coffee drinkers, they were less critical of information supporting the link. Thus, people for whom the health message had high personal relevance seemed to process the threat information more defensively than people who already followed the recommendations. Also Keller (1999, Experiment 1) in the context of AIDS prevention research, provided evidence that fear appeals seem to be least effective for those that are most at risk. Among the participants who used a condom whenever they engaged in vaginal sex in the past six months, those who were exposed to a moderate fear message about the health consequences of unsafe sex (e.g., AIDS related cancers, syphilis, death) had more positive intentions to use a condom and showed less message discounting than those who received a low fear-arousing message. In contrast, among those who did not have consistently safe sex during the past six months the low rather than the moderate fear message resulted in more persuasion and less message discounting, again based on questionnaires. Freeman and colleagues (2001) replicated Keller's (1999) finding that fear-arousing persuasive messages seem to be less effective for those who perform risky behaviours. They exposed regular smokers to anti-smoking 
videos and found that they evaluated the video contents as less effective than nonsmokers.

Empirical findings thus support the hypothesis that self-relevant health messages are received with more defensive reaction to the extent that they more vividly present the negative consequences of risky health behaviour. Sherman and colleagues (2000) hypothesized that this defensive motivation stems from the anticipation that threatening information will damage self-image. Two experimental studies suggested that defensive processing may help to maintain a positive self-image. Among respondents for whom the presented threat was highly relevant, those who maintained a positive self-image through self-affirmation techniques were less defensive and more accepting of health information than those whose central values were not affirmed (Harris, Mayle, Mabbott, \& Napper, 2007; Harris \& Napper, 2005; Sherman et al., 2000; Van Koningsbruggen \& Das, 2009; Van Koningsbruggen, Das, \& Roskos-Ewoldsen, 2009). Theoretically, these findings can be explained in cognitive dissonance theory (Festinger, 1957) and Kunda's (1990) argument for motivated reasoning: Individuals experiencing dissonance because their self-image is threatened (e.g., smokers exposed to threatening health commercials about smoking) are motivated to reduce it by changing one of the implicated cognitive or behavioural elements, for example through biased processing of presented information (e.g., Liberman \& Chaiken, 1992) or message derogation (e.g., Keller, 1999).

Overall, based on self-report measures and measures of response times and reading times it has been concluded that people for whom the health message had high personal relevance seemed to process the threat information more defensively than people who already followed the recommendations (see also Harris et al., 2007; Harris \& Napper, 2005; Noar, Benac, \& Harris, 2007; Sherman et al., 2000).

In the light of these defensive results, the important question arises whether threat information leads to more message involvement and thus more systematic processing of the persuasive information as was assumed by the presented models or leads to less message involvement and more defensive reactions, especially among those for whom the information is self-relevant.

\section{Message tailoring}

Another frequently used technique that intends to increase message involvement and promotes systematic processing of persuasive messages is the method of message tailoring. Message tailoring can be defined as any combination of information or change strategies intended to reach one specific person, based on characteristics that are unique to that person, related to the outcome of interest, and have been derived from an individual assessment (Kreuter, Bull, Clark, \& Oswald, 1999; Kreuter, Farrell, Olevitch, \& Brennan, 2000). A message is thus created that closely responds to the needs of the targeted individual based on an earlier individual assessment. Nowadays, tailoring is 
often applied by using an interactive technology. In such computer-tailoring, the combined expertise of health educators is translated into a computer expert system (see Dijkstra \& De Vries, 1999). Evidence shows that message tailoring is associated with better behaviour change effects than generic health education, especially in nutrition education interventions (Brug et al., 2003; Kreuter, Farrell et al., 2000; Kroeze, Werkman, \& Brug, 2006; Noar et al., 2007; Rimer \& Glassman, 1999; Skinner, Campbell, Rimer, Curry, \& Prochaska, 1999). Research in the Netherlands showed that computer-tailored nutrition interventions resulted in a $5.4 \%$ lower fat intake, compared with a $1.4 \%$ drop in a general nutrition information control group (Brug et al., 2003).

Although the underlying mechanisms for the increased effectiveness of message tailoring compared to general nutrition information are not fully explored yet, message tailoring is often used by health educators to increase personal relevance of the health information and thus motivate people into more self-protective action (for a review, see Brug \& De Vries, 1999). A theoretical rationale for message tailoring is provided by dual process models of persuasion such as the earlier discussed Elaboration Likelihood Model and Heuristic Systematic Model. As was mentioned earlier, more active and thoughtful processing of the information (i.e., central-route processing) will occur if people are motivated and able to do so. Message tailoring is assumed to increase motivation for active processing because the information is perceived as personally relevant, which is one of the most important determinants of message motivation (Kreuter \& Holt, 2001).

Based on the theoretical explanation of the ELM, Kreuter \& Holt (2001) expected that a comparison of tailored and non-tailored health education messages would show that tailored messages elicit (a) greater attention, (b) greater comprehension, (c) greater likelihood of discussing the content with other people, (d) greater intention to change the behaviours addressed by the content, and (e) greater likelihood of behaviour change. Recent studies showed consistent findings with these expectations. Tailored messages are more likely to be read and remembered (Skinner, Strecher, \& Hospers, 1994), saved (Brug, Steenhuis, Van Assema, \& De Vries, 1996), discussed with other people (Brug, Glanz, Van Assema, Kok, \& Van Breukelen, 1998), and perceived by readers as interesting (Campbell et al., 1994), personally relevant, and having been written especially for them (Brug et al., 1996) than non-tailored messages. Furthermore, health-education materials showed greater impact when they are perceived as a better "fit" by participants (Kreuter, Oswald, Bull, \& Clark, 2000).

\section{Understanding Underlying Processes}

Both persuasion methods (fear appeals and message tailoring) assume more message involvement and thus heightened attention for the information (Baron et al., 1994; Brug et al., 2003; Kreuter \& Holt, 2001). However, the few studies that investigated underlying working mechanisms showed contrasting results. While message tailoring leads to better 
exposure for the message, fear appeals cause defensive reactions among those for whom the information is most self-relevant. Although these studies tried to investigate whether the presented information caused more systematic processing, thus assuming more attention allocated to the health message, the direct effects of health message on processes of attention allocation have not been studied systematically yet.

Measuring attention processes for health education messages is crucial because attention for the information is a prerequisite for effective health education (Blumberg, 2000; McGuire, 1985). McGuire's (1985) persuasion-communication model states that people should first be exposed to the stimulus message and then attend to it, followed by accurate comprehension of the presented information and integration of new information with previous knowledge to arrive at an attitudinal judgment. According to this model, a prerequisite for effective health education is that people allocate sufficient attention resources to the persuasive message they are exposed to (Blumberg, 2000; McGuire, 1985). Health messages can thus already fail in the early process of message attention. Remarkably, persuasion research has largely ignored attention as a dependent variable in evaluation studies.

The few studies investigating attention processes for health education messages were limited to indirect measures of attention. For example, self-report measures of cognitive effort (Liberman \& Chaiken, 1992) and more implicit measures of reading time (Brown \& Locker, 2009) and response time (W. M. P. Klein \& Harris, 2009) have been used to provide an index of the amount of attention that was allocated to threatening health information. However, by definition these measures do not allow a direct observation of the amount of attention that is allocated to the threatening information during message processing. At best, the procedures reflect relatively late information processing stages that feed higher order cognitive processes such as biased processing and not the early stage of attention allocation.

A major limitation of self-report measures is that they require introspection from the participants while people may not be aware of motives that drive their behaviour (Wilson, 2002; Wilson \& Dunn, 2004). Furthermore, participants may respond with social desirable statements. With regard to the earlier mentioned warning messages on tobacco packages, Ruiter and Kok (2005) argued that campaign effects of fear arousal on smoking behaviour based on self-reports are not consistent with objectively measured effects. People are full of good intention, especially when being confronted with significant health threats, but seldom act towards these intentions. Therefore, caution should be used when interpreting self-report measures. From a scientific point of view, but also a practical point of view, it is important to identify the conditions that determine whether people attend to health messages or not. The present thesis therefore investigates early attention processes when people are exposed to tailored and threatening health information. 
Attention

Attention is a widely researched psychology phenomenon within the fields of cognitive psychology and cognitive neuroscience. Defining the term 'attention' often leads to very diverse descriptions. A century ago William James (1890) had the following definition of attention: Everyone knows what attention is. It is the taking possession by the mind, in clear and vivid form, of one out of what seem several simultaneously possible objects or trains of thought (1890, p.403). While the definition of James is subjective, it is often said that there is no better definition of attention (Posner, 2004). In more cognitive terms, attention can also be described as the sustained focus of cognitive resources on information while filtering or ignoring extraneous information (Anderson, 2004, p. 519).

Central to this definition is the mechanism of selective attention. With selective attention some locations or objects receive priority over others by shifting attention. Shifting of attention is necessary because the human brain has limitations in the amount of information that can be processed (Gazzaniga, Ivry, \& Mangun, 2002). Through shifting attention we can redirect our attention to aspects of the environment we want to focus on, and subsequently process. The shifts of attention can help facilitate the processing of multiple stimuli (Eysenck \& Keane, 2005).

How visual attention is shifted can be explained by the moving-spotlight theory (LaBerge, Carlson, Williams, \& Bunney, 1997; Sperling \& Weichselgartner, 1995). According to the moving-spotlight theory attention can be seen as a movable spotlight that is directed towards intended targets, focusing on each target in a serial manner. When the spotlight illuminates information, or when the information is attended, information processing will proceed more efficiently. However, during spatial shifts of attention, the spotlight is turned off while attention shifts to the next attended location (LaBerge et al., 1997; Sperling \& Weichselgartner, 1995).

The orienting of attention can be subdivided in three mental sub-processes (Posner, Walker, Friedrich, \& Rafal, 1984). When orienting to a new location, disengagement is necessary, that is attention has to be taken away from the current focus. Next, a shift of attention from one location to another occurs. Finally, attention is focused at this new location, also called attention engagement.

Attention shifting can occur overtly or covertly. Overt attention refers to shifts in gaze direction (in terms of eye movements or head movements, or both) that can be seen by an external observer (R. M. Klein, 2004). Covert orienting entails attention shifts without an overt movement, thus the eyes remain fixated. These covert shifts cannot be noticed directly by an external observer, and must be inferred from performance (R. M. Klein, 2004).

The research field of psychology started a long time ago with measuring selective attention (Eriksen \& Yeh, 1985; Hoffman \& Nelson, 1981; Posner, 1980). More recently, new imaging techniques have enabled neuroscientist to investigate attention processes in the human brain (Reynolds, 2004). In studying less observable cognitive processes, such 
as the amount of attention given to certain health information, it is crucial to select appropriate and objective outcome measures. In order to objectively study attention processes for different persuasive methods we therefore used the techniques of electroencephalogram (EEG), functional magnetic resonance imaging (fMRI), eye tracking and reaction times (RT). The research techniques of EEG, $\mathrm{fMRI}$ and eye tracking will be introduced in this chapter.

\section{EEG}

The measure of electroencephalogram (EEG) is used to record electrical brain activity. A primary motivation to use EEG is the excellent (millisecond) temporal resolution resulting in measures of the time course of cognitive processes with great precision. From the continuous measure of brain activity (EEG) event-related potentials (ERPs) are generated. ERPs are the electric potentials that are specifically time locked to an internal or external event. By measuring ERPs the chronology of mental processes can be linked to the neural activations occurring after a sensory stimulus (Srinivasan, 2004).

The EEG is measured by attaching electrodes to the scalp at various locations. While performing an experiment, the ongoing EEG reflects thousand of simultaneously ongoing brain processes. The brain response to a single stimulus or event of interest is hardly detectable in the EEG recording of a single trial. By conducting many trials $( \pm 100)$ and averaging the samples of the EEG that are time-locked to the repeated trials, random brain activity is canceled out and the relevant ERP remains.

The ERP consist of positive and negative peaks, occurring at fixed moments after a certain event. These different components are believed to reflect synchronized postsynaptic activity in large populations of neurons. The labels of the different components usually indicate their latency and polarity. The latency thus reflects the time course of different sensory, motor or cognitive processes. The polarity of the different components indicates either positive or negative amplitudes of the peaks according to a pre-stimulus baseline. While a positive amplitude reflects an increase of activity that is related to synchronization of neural firing, a negative amplitude reflects a decrease of activity that is related to desynchronization of neural firing (Fabiani, Gratton, \& Coles, 2000).

An ERP component that is of special interest in the present study is the P300. The P300 refers to a positive peak with a modal latency of $300 \mathrm{msec}$ (Fabiani et al., 2000) and is strongly influenced by the task demands that are laid on the participants. The P300, frequently measured in attention paradigms, is functionally related to late conscious, decisional and premotor response related stages. The P300 which is usually strongest at central-parietal scalp sites, reflects relatively late en more controlled attention processes and as such provides an index for a cognitively driven allocation of attention and an update of stimulus processing with working memory information (e.g., Coull, 1998; Hillyard, Mangun, Woldorff, \& Luck, 1995; Näätänen, 1992). The P300 is typically elicited by novel 
and low probability (rare) stimuli, but is also sensitive to other parameters such as task relevance.

\section{fMRI}

Functional magnetic resonance imaging ( $\mathrm{fMRI}$ ) is a noninvasive neuroimaging technique with a high spatial resolution. $\mathrm{fMRI}$ works by detecting the changes in blood oxygenation (BOLD) and flow that occur in response to neural activity. BOLD FMRI is based on the principle that the blood flowing to an active region is more oxygenated than blood elsewhere, and oxygenated blood has different magnetic properties than deoxygenated blood. Activation maps show which parts of the brain are more or less active in a particular mental process. fMRI can detect the spatial location of these different magnetic properties and reconstruct where blood was flowing to in large detailedness. This high spatial resolution is caused by the measurement of the whole brain or parts of the brain in an extremely large set of three-dimensional (3D) spatial units (voxels) of a few millimeter in each dimension (for an introduction to fMRI see Huettel, Song, \& McCarthy, 2004).

In the present thesis, we wanted to explore the activated brain mechanisms when people are confronted with health related information, in particular threatening health information. Cognitive neuroscience research dealing with processing emotional information has particularly focused on the role of the amygdala (Ewbank, Barnard, Croucher, Ramponi, \& Calder, 2009; Lieberman, 2010). A meta-analysis modelling the probability of amygdala activation during the processing of emotional stimuli as a function of multiple experimental characteristics indicated that all emotions were more likely to activate the amygdala than neutral stimuli (Costafreda, Brammer, David, \& Fu, 2008). Furthermore, the amygdala is thought to have an important role in directing attention to emotional stimuli (Compton, 2003).

\section{Eye movements}

Eye-movement registration enables us to measure the course of overt attention over longer periods of time, thus which parts are viewed by participants and for how long (Thomsen \& Fulton, 2007). In marketing research the technique is often used to measure the amount of attention people have for the brand name. For health education practitioners this technique could be used for the evaluation of visually presented materials, for example posters.

Eye movements, as important indicators of visual attention (Krugman, Fox, Fletcher, \& Fischer, 1994; Wedel \& Pieters, 2000), comprise of a sequence of fixations (i.e., discrete periods of immobility of the eye) and saccades (i.e., quick jumps between fixation locations). During fixating, attention is paid to the stimulus and information is extracted, whereas during saccades vision is basically suppressed (Rayner, 1998; Wedel \& Pieters, 
2000). In eye-tracking studies the number of fixations is related to the amount of information extracted from a stimulus (Rayner, 1998; Wedel \& Pieters, 2000). Besides the number of fixations, dwell time can also be used as an indicator of the amount of attention paid to a stimulus. Dwell-time represents the total duration (in $\mathrm{ms}$ ) of time that was spent looking at a stimulus (Thomsen \& Fulton, 2007).

\section{Current thesis}

The aim of the present thesis is to investigate underlying working mechanisms of persuasive health messages during message exposure. Early (neural) attention processes were measured for the persuasive methods of message tailoring and threatening health information. Although these methods are hypothesized to heightened attention for health information, no previous research has investigated the effects of these methods on processes of attention allocation during message processing.

Previous research suggest that self-relevance heightens attention for the information, but only if this information is non-threatening. When the information contains high threat information, less attention will be paid to the self-relevant health information. We investigated these attention processes in several studies.

In our first study we explored the effects of self-relevance on attention. No threat information was presented. The method of message tailoring was used to create the factor of self-relevance. Based on the assumption that message tailoring increases personal relevance and thus motivates into more systematic processing, we hypothesized that tailored information will receive more attention from the reader than non-tailored information (Brug et al., 2003; Kreuter \& Holt, 2001). In the following four studies we investigated attention effects for self-relevant health information in combination with threatening health information. In our second study tailored health information was combined with either high or low threatening health information. In the other three studies the factors of self-relevance and threat were created through presenting threatening health information to persons who already follow the recommended behaviour (i.e., non-smokers) or who not follow the recommended behaviour (i.e., smokers). Based on previous studies, showing defensive reactions for threatening health information that is self-relevant, we hypothesized that threatening health information will attract less attention among those for whom the information is most self-relevant (Brown \& Locker, 2009; Croyle et al., 1997; Ditto \& Croyle, 1995; Freeman et al., 2001; Harris et al., 2007; Harris \& Napper, 2005; Keller, 1999; Keller \& Block, 1999; Liberman \& Chaiken, 1992; Sherman et al., 2000; Taubman - Ben-Ari et al., 2000). 
Experimental studies

In this thesis, five experimental studies will be presented in which attention processes for tailored and threatening health information are investigated. The five experimental studies reported on different types of health behaviours (i.e., nutrition and smoking), presented different experimental tasks (i.e., oddball task, cueing task), and used different research methods (e.g., ERPs, RTs, fMRI and eye tracking).

In the first two studies (chapter 2 and 3 ) attention processes were examined by measuring ERPs and RTs. The main aim of study 1 was to investigate attention processes for tailored versus non-tailored nutrition education messages in a between-subjects design. In study 2, tailored and non-tailored nutrition education messages were presented in a within-subjects design. Both messages were supplemented with high threat or low threat nutrition information in order to investigate the effects of message tailoring in combination with health threat information on attention allocation processes. In a dualprocessing task, participants were reading nutrition education messages and at the same time attention had to be paid to specific odd auditory stimuli in a sequence of frequent auditory stimuli (odd ball paradigm). The amount of attention allocation was measured by recording event-related brain potentials and reaction times to the auditory task. We assumed that the observed auditory attention effects in the ERPs and reaction times could be used as an inverted index of the amount of perceptual and cognitive attention resources allocated to the reading of the nutrition advice. Due to limited attention resources it was hypothesized that there should be more auditory attention paid to the target tones during the reading of the non-tailored nutrition advice than during the reading of the tailored nutrition advice. Furthermore, more auditory attention was expected for the target tones during reading of high threat tailored information than during reading of the low threat tailored information.

The third study (chapter 4) aimed to measure specific covert attention engagement and disengagement processes for high threat versus low threat smoking pictures among participant for whom the information was self-relevant (i.e., smokers) or non-selfrelevant (i.e., non-smokers). We used a variant of the Posner's cueing task in combination with the high temporal resolution method of event-related brain potentials (ERPs) and reaction times to test whether smokers showed more efficient disengagement from high versus low threatening smoking pictures than non-smokers.

In the cueing task participants reacted to a target (two horizontal or two vertical dots) presented at the left or right visual field. This target was preceded by a cue (i.e., high and low threat smoking pictures) at either the target location (valid trials; 82\%) or at the opposite location (invalid trials; 18\%). In invalid trials, reflecting attention disengagement processes, attention must be disengaged from the incorrect location and has to be reallocated towards the target position. We expected that people react defensively to self-relevant threatening health information by disengaging from it. In other words, 
smokers will more easily disengage attention from high threat smoking pictures than will those less affected by the health threat (non-smokers).

In the following study (chapter 5), we wanted to explore whether defensive reactions to self-relevant threatening health information are detectable in brain processes by using $\mathrm{fMRI}$ as research method. High threat and low threat smoking related pictures were presented while smokers and non-smokers made explicit and implicit judgments of the stimuli. Brain activation and reaction times were measured while making the judgments. In the explicit threat processing task, participants were asked to indicate if they perceived a smoke picture as a high or low threat. In the implicit threat processing task, participants saw the same stimuli but were asked to detect if the stimulus display contained a nonthreat target object (the presence or absence of a hand). It was hypothesized that high threat picture processing increase activation in the amygdala and other brain areas of the emotion network, compared to low threat pictures (i.e., threat modulation of brain activity) irrespective of smoking status. Furthermore, we expected that the overall threat effect in the amygdala is modulated by self-relevance. Smokers compared to nonsmokers, are expected to show defensive reactions towards self-relevant threat information reflected in smaller threat modulation in the amygdala for smokers than for nonsmokers. Finally, we expected this smaller threat modulation for smokers compared to non-smokers at an explicit level, but not at an implicit level.

In the last study (chapter 6) the technique of eye tracking was used to measure dwell time and the number of eye fixations for different smoking cigarette packages. Selfcreated smoking cigarette packages contained either high threat information about the negative consequences of smoking, coping information referring smokers to ways to effectively quit smoking or low threat information about smoking. Eye movements were recorded while smokers and non-smokers viewed different smoking cigarette packages. The aim of this study was to investigate which kind of (written) information (low risk, coping information or high risk) attracts most overt attention from smokers and nonsmokers. We hypothesized that smokers will pay less attention - reflected in fewer fixations and dwell time - to the high risk messages about the negative consequences of smoking than non-smokers. We did not expect that smokers will react defensively to the coping information as the information does not contain any threat information. Since self-relevant information is expected to attract attention from the reader we expected that coping messages will attract more attention - reflected in more fixations and dwell time - from smokers than from non-smokers.

Finally, because the general purpose of the present thesis is to invest early attention processes for different kinds of health information, the last chapter (chapter 7) aimed to summarize and discuss the main findings of the empirical studies. Furthermore, suggestions for future research and implications for health communication practice are provided. 



\section{Chapter 2}

\section{Increased attention for computer-tailored health communications: An event-related potential study}

A manuscript partly based on this chapter is published as: Kessels, L., Ruiter, R., Brug, J., \& Jansma, B. (2004). De effecten van een voedingsadvies-op-maat op aandacht: Een ERP benadering. In D. Wigboldus, M. Dechesne, E. Gordijn, \& E. Kluwer (Red.), Jaarboek Sociale Psychologie 2003: Associatie van Sociaal Psychologische Onderzoekers (ASPO). Grongingen: ASPO Pers.

Published as: Ruiter, R.A.C., Kessels, L.T.E., Jansma, B.M., \& Brug, J. (2006). Increased attention for computer-tailored health communications: An event-related potential study. Health Psychology, 25, 300-306. 
Introduction

In health education, tailoring has been defined as "any combination of information or change strategies intended to reach one specific person, based on characteristics that are unique to that person, related to the outcome of interest, and have been derived from an individual assessment" (Kreuter, Farrell et al., 2000, p. 5). Today it is possible to apply tailoring by using interactive technology. In such computer-tailoring, the combined expertise of health educators is translated into a computer expert system (see Dijkstra \& De Vries, 1999). Empirical studies have found evidence for the hypothesis that persuasive health messages that are 'computer-tailored' are more effective in motivating people to self-protective action than non-tailored health messages (for a review, see Brug \& De Vries, 1999). Higher personal relevance, and thus higher attention, as well as stronger cognitive processing of the health messages have been proposed as important mechanisms for the increased effectiveness of computer-tailored education over traditional non-tailored interventions (e.g., Brug et al., 2003). However, evidence for these working mechanisms is based on self reports derived after exposure to the message (e.g., Brug et al., 1998).

A major limitation of these explicit measures is that they require introspection from the participants while people may not be aware of motives that drive their behaviour (Wilson, 2002). Furthermore, participants may respond with social desirable statements. In studying less observable cognitive processes, such as the amount of attention given to personally relevant health information, the use of implicit measures such as reaction times, as well as the high temporal resolution method of event-related brain potentials (ERPs) that enables assessment of attention processes on-line within milliseconds after stimulus onset (for an introduction, see Fabiani et al., 2000), has important advantages. In the present study, we employed reaction time and ERPs measurements, which are generated from a continuous measure of brain activity by means of an electroencephalogram (EEG), to study attention during the exposure to computer-tailored or non-tailored nutrition education messages.

\section{Attention and ERP Analysis}

To study attention we specifically focused on the extent to which participants allocated their attention resources to tailored health communications. In persuasion research it is generally believed that attention is a necessary (but not sufficient) condition for effective communication (McGuire, 1985). However, persuasion research has largely ignored attention as a dependent variable in evaluation studies. In contrast, attention has been extensively studied in cognitive science and neuroscience separately for different modalities, such as visual attention, auditory attention or for cross-modal processing (for reviews, see Mangun \& Hillyard, 1995; Näätänen, 1992). For instance, attention can be 
disengaged from one process and shifted to another. For example, when speaking with the passenger next to you in the car, we can shift or re-allocate attention away from the speaking process towards the road and the driving task whenever the traffic situation requires our attention. This shift of attention has been addressed in numerous ways. Here we will focus on the shift as a re-allocation of attention resources, based on the theory of resource allocation (for extensive reviews and critical discussion, see Kok, 1997; Sanders, 1997).

Resource allocation theory says that we have a limited amount of mental attention resources and whenever we pay more attention to one, we will have less attention for another task (or feature). If attention is directed to one stimulus, this attended stimulus is processed with benefits due to sensory and evaluation gain of the incoming stimuli for the attended compared to the ignored stimulus. This benefit is usually seen in faster reaction times, higher percentage of good performance, and in higher amplitudes of ERPs that are sensitive to divided attention effects.

The relationship between mental resources of attention and ERPs has been discussed especially with regard to two target ERP components, namely the N100 and the P300. Both components show larger amplitudes whenever the target stimulus is attended to compared to when there is less or no attention to the target. The N100 is an early component with negative amplitude that has a maximum peak around $100 \mathrm{~ms}$ after stimulus onset. The $\mathrm{N} 100$ is usually interpreted as reflecting the distribution of perceptual resources to task relevant stimulus processing. The P300, in contrast, is a relatively late positive component that has a maximum peak around $300 \mathrm{~ms}$ after stimulus onset and that is strongly influenced by the task demands that are laid upon the participant. The P300, which usually is strongest at central-parietal scalp sites, reflects relatively (compared to the N100 effects) late and thus more controlled attention processes and as such provides an index for a cognitive attention allocation and update of stimulus processing with working memory information (e.g., Coull, 1998; Hillyard et al., 1995; Näätänen, 1992).

\section{Overview of the Study and Hypothesis}

In a dual task paradigm, participants were reading either computer-tailored nutrition education messages (derived from an existing computer tailoring system, see Brug et al., 1998) or non-tailored general nutrition education messages, and simultaneously listened to sequences of auditory tones. Although participants had to process both streams of information (auditory and textual), they had to focus attention, i.e. allocate the majority of their attention resources, to the auditory task because for this task they carried out an active decision. They were asked to push a button whenever a rare high frequency tone (i.e., target) appeared, and to withhold the response whenever a standard low frequency tone (i.e., non-target) was presented. 
An N100 or P300 effect is defined as the difference between the average ERP of the rare minus the average ERP of standard conditions. Attention re-allocation processes, in turn, are inferred from the reduction of the N100 or P300 effect as a result of greater attention being paid to a secondary task - here, the reading of a nutrition education message (e.g., Kramer, Wickens, \& Donchin, 1985). According to this view, we thus assumed that the observed auditory attention effects in the N100 and P300 ERPs can be used as an inverted index of the amount of perceptual and cognitive attention resources allocated to the reading of the nutrition advice. Therefore, in line with theoretical notions that people attend more to personally relevant information (e.g., Petty \& Cacioppo, 1986), we hypothesized that due to limited resources there should be more auditory attention paid to the target tones during the reading of the non-tailored nutrition advice than during the reading of the tailored nutrition advice. As a result, we predicted that the mean amplitudes of the N100 and P300 effects would be lower and reaction times would be slower for the tailored rather than for the non-tailored intervention group.

\section{Method}

\section{Participants and Experimental Design}

Twenty-nine psychology undergraduate students signed-up for the experiment, nine male and 20 female. They were 17 to 26 years of age $(M=21.38$; $S D=2.15)$, were native speakers of Dutch, were right handed, and reported upon being asked normal or corrected-to-normal vision and normal hearing. Participants were randomly exposed to either a tailored or non-tailored nutrition education messages about fat, vegetable and fruit intake. Participants received course credits or a $€ 15$ (approximately \$18) gift voucher for their participation.

\section{Procedure, Materials and Tasks}

The experiment had two sessions. In the first session, participants filled out written questionnaires that determined their fat, vegetable and fruit intake as well as their attitude, self-efficacy and intentions related to reducing their fat intakes and increasing consumption of fruits and vegetables (for a more elaborate description of the questionnaires, see Brug et al., 1996). The answers of respondents in the tailored intervention group were used by the second author to construct an individually-tailored nutrition advice before the start of a second session approximately one week later.

In the second session, participants carried out a dual task. Next to reading the nutrition education messages, they had to listen to sequences of high and low frequency 
tones, and were asked to push a button whenever they heard the infrequent high frequency tone (i.e., auditory oddball task; e.g., Hillyard et al., 1995). The EEG was recorded during the task. Therefore, after the mounting of an electrode cap, participants were taken to a dimly lit sound-attenuating electrically shielded cabin and seated in a comfortable chair, approximately $80 \mathrm{~cm}$ from the computer screen with the screen's centre situated at eye level. Participants were instructed to stay fixated to the nutrition information presented on the screen while performing the auditory oddball task, and to avoid eye blinks and other body movements as much as possible during presentation of the intervention messages and auditory oddball task. It was also made clear to them that the reading task and oddball task were equally important and both had to be performed accurately.

The participants in the tailored intervention group read the person-related information whereas participants in the non-tailored intervention group received a general advice without any person-related information (see also Brug et al., 1998). For example, a person in the tailored intervention group who ate 100 grams of fat per day read the following sentence: You eat daily 100 gram of fat, whereas 75 gram is sufficient. In the non-tailored intervention group the same sentence was as follows: On average people in the Netherlands eat 95 gram fat per day, whereas 75 gram is sufficient. The non-tailored intervention message counted 1923 words, the tailored intervention messages between 1900 and 2100 words. Both messages had three sections referring to fat, vegetable and fruit intake, respectively.

To minimize eye movements, the intervention messages were presented on the computer screen word by word with an inter-stimulus-interval of $1000 \mathrm{~ms}$. Every word appeared on the screen during $250 \mathrm{~ms}$, followed by a black screen of $750 \mathrm{~ms}$. The words were clearly visible and had a minimum length of 2 letters and a maximum length of 16 letters. In the auditory oddball task high $(1000 \mathrm{~Hz})$ and low $(500 \mathrm{~Hz})$ frequency auditory tones were presented simultaneously with the words of the intervention messages. The tones were presented $150 \mathrm{~ms}$ after word-onset and the tone length was $100 \mathrm{~ms}$. The low and high frequency tones were presented in random order. The high frequency tones (target stimuli) had an occurrence probability of $17 \%$, the low frequency tones (nontarget stimuli) had an occurrence probability of $83 \%$. On hearing a high frequency tone participants were instructed to respond by pressing the button as fast as possible. On hearing a low frequency tone, no overt response was required. The oddball and reading tasks were preceded by a practice round of 50 oddball trials without word presentation, and interrupted by two breaks of each two minutes.

After finishing the dual task participants answered several self-report questions concerning message attention and evaluation and motivation to change. Finally, participants were debriefed, paid and asked not to talk about the objectives and topic of the study with fellow students. The entire second session took about two hours. 
Measures

Reaction times. Button-press responses were measured from high tone onset with a time-out limit of $850 \mathrm{~ms}$.

EEG. The EEG was recorded from 30 scalp sites (extended version of the 10/20 system) using tin electrodes mounted in an electrode cap, referenced to the left mastoid signal. A bipolar montage of two electrodes placed on the right and left external canthus recorded horizontal eye movements. Vertical eye movements and eye blinks were measured by a bipolar montage using two electrodes placed upon the upper and lower orbital ridge of the left eye. The electro-oculogram (EOG) was recorded for later off-line rejection of trials contaminated with eye movements. EEG and EOG signals were digitized at $250 \mathrm{~Hz}$ and amplified by using a 32-channel NeuroScan SynAmps amplifier with a bandpass of $0.05-30 \mathrm{~Hz}$. All electrode impedances (EEG and EOG) were kept below $5 \mathrm{kOhm}$.

N100 and P300 ERP. From the continuous EEG signal epochs of 900 ms were obtained, including a $100 \mathrm{~ms}$ pre-stimulus (tone) baseline. Trials including artifacts were rejected from further analyses (threshold $+/-75 \mu \mathrm{V}$ ). By averaging the remaining artifactfree epochs per participant per condition the ERP waveforms were derived separately for high and low frequency tones in each intervention condition. Next, difference waveforms were computed per participant for each intervention condition by subtracting the ERP to the non-target tones from the ERP to the target tones. The difference waveforms were quantified by mean amplitude measures $(\mu \mathrm{V})$ to assess the N100 effect (in the time window $80 \mathrm{~ms}$ to $150 \mathrm{~ms}$ ) and P300 effect (in the time window $230 \mathrm{~ms}$ to $450 \mathrm{~ms}$ ), respectively. The latency windows were derived from visual inspection of the grand average difference waves at the Fz electrode to determine the latency for the N100 across electrodes, and at the Pz electrode to determine the latency for the P300 across electrodes (see Figure 1, right column). The analyses were restricted to the midline electrodes $\mathrm{Fz}, \mathrm{Cz}$, $\mathrm{Pz}$ as the N100 and P300 effects are generally largest for these midline electrodes. 


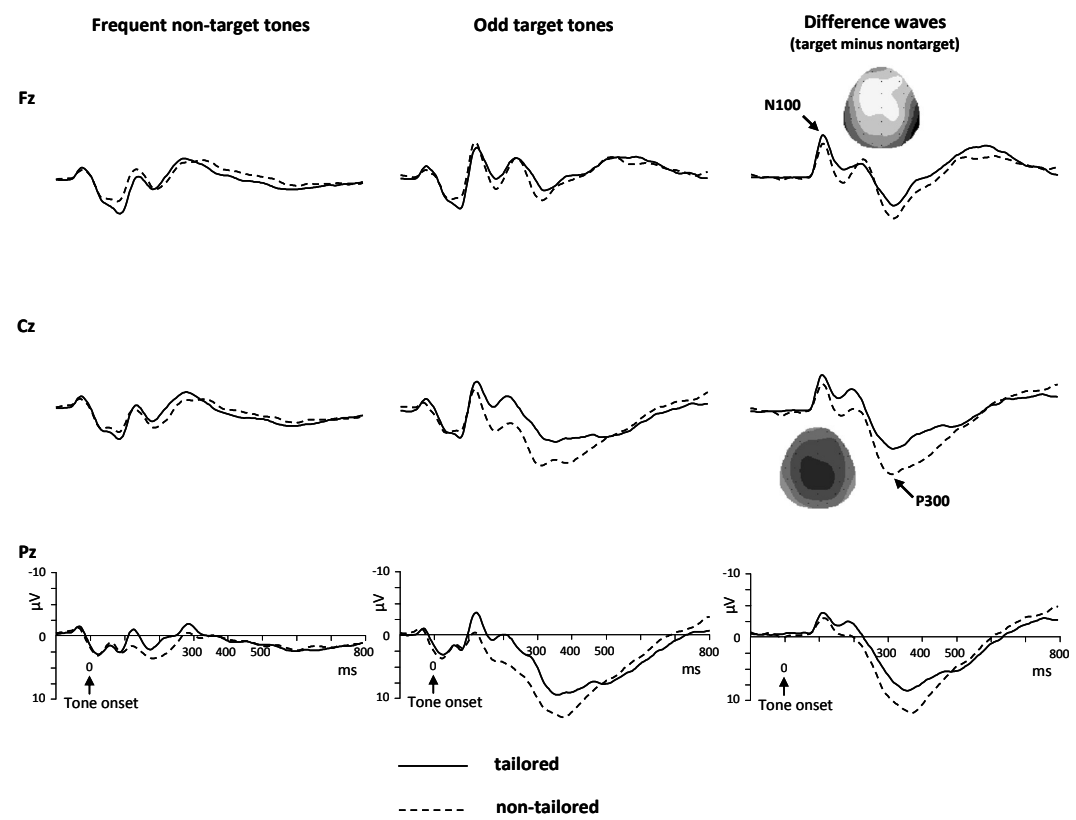

Figure 1. Grand average ERP waveforms for tailored (solid line) and non-tailored (dotted line) intervention groups. Displayed are data for all 24 participants for the midline electrode sites $\mathrm{Fz}$, $\mathrm{Cz}, \mathrm{Pz}$. The left column presents the waveforms for the frequent non-target tones. The center column presents the waveforms for the odd target tones. The right column presents the difference waves (target minus non-target tones). Negative voltage is plotted up. The topographical maps present the signal distributions of the N100 effect at $112 \mathrm{~ms}$ and the P300 effect at $320 \mathrm{~ms}$ after stimulus onset with a maximum of $5 \mu \mathrm{V}$ (dark grey) and a minimum of $-5 \mu \mathrm{V}$ (white).

Self-report. All self-report items used 9-point Likert scales and were based on measures proposed by Brug et al. (1996) and Kreuter et al. (2000). We measured perceived attention (i.e., "to what extent have you read the information carefully", $1=$ not at all, $9=$ very much), perceived difficulty of the information (i.e., "how difficult or easy was the content of the information", 1 = very difficult, 9 = very easy), appreciation of the advice (1 = unpleasant, 9 = pleasant, 1 = unattractive, 9 = attractive, $1=$ uninteresting, $9=$ interest ing; Cronbach's alpha $=.81$ ), and the perceived personal relevance of the nutrition advice ( $1=$ not at all, $9=$ very much). Finally, one item asked participants if they intended to change their diet behaviour based on the information they had read $(0=n o, 1=y e s)$. 
Data Analysis

Independent-samples t-tests were used to compare the two groups on the reaction times (ms) and the answers on the self-report questionnaires (for the dichotomous measure of intention a logistic regression analysis was used). To examine whether the N100 and P300 attention effects were modulated by the intervention conditions mean amplitude measures in the indicated time windows were subjected to repeated measures analyses of variance (ANOVA) that crossed the between-subjects factor Intervention (tailored vs. non-tailored) and within-subjects factor Electrode Sites (Midline Electrodes: $\mathrm{Fz}, \mathrm{Cz}, \mathrm{Pz}$ ). At sites where the $\mathrm{P} 300$ effect has its maximum (anticipated $\mathrm{Cz}, \mathrm{Pz}$ ) planned comparisons (i.e., independent samples t-tests) were conducted to test the effect of Intervention at each electrode site. We also included Fz to show that the effect has a central-parietal and not frontal distribution. Following visual inspection of the signal distribution of the N100 effect a similar procedure was used for testing the effect of Intervention at $\mathrm{Fz}, \mathrm{Cz}, \mathrm{Pz}$ in the 80-150 ms time window. To control for sphericity violations in the ANOVAs, $p$-values with Greenhouse-Geisser correction were reported for F-tests with more than one degree of freedom in the numerator. The reported estimates of the effect size are the partial eta squared $\left(\eta_{p}^{2}\right)$ for the ANOVAs, Cohen's $d$ for the independent samples t-tests, and odd ratio $(O R)$ for the logistic regression analysis.

\section{Results}

Because the data sets of three participants in the tailored intervention group and two participants in the non-tailored intervention group could no be used due to too many artefacts (more than $50 \%$ of the reactions to the high frequency tones rejected) or technical problems, 24 participants remained in the sample and were included in the analyses with 13 participants in the non-tailored intervention group and 11 in the tailored intervention group.

\section{Premeasures}

Analyses showed that the tailored and non-tailored intervention groups did not significantly differ on the measures of attitude, self-efficacy, intention and behaviour regarding fat, vegetables and fruit intake that served as input for the nutrition advices ( $p s>.20$ ), indicating that randomization indeed resulted in equal groups. 


\section{Error Analysis}

Trials in which no response was registered within $850 \mathrm{~ms}$ after presentation of the auditory target tone, or a response was given in reaction to the non-target tone, were left out of the analyses of both the reaction time data and the ERP data. The proportion of rejected trials was not different between participants in the tailored intervention group ( $M$ $=.03 ; S D=.01)$ and those in the non-tailored intervention group $(M=.03 ; S D=.01), t(22)$ $=-0.90, p=.38, d=-0.37(95 \% \mathrm{Cl}:-0.02,0.01)$. Furthermore, we looked at the number of valid responses to the auditory target that could not be analyzed due to eye and other movements that distorted the resulting EEG signal and thus were excluded from further analyses. This number of lost valid responses as proportion of the total number of valid responses did not differ between the non-tailored condition $(M=.05 ; S D=.07)$ and the tailored condition $(M=.05 ; S D=.05), t(22)=-0.08, p=.94, d=-0.03(95 \% \mathrm{Cl}:-0.05,0.05)$.

\section{ERP}

Visual inspection. The grand average waveforms at the midline electrode sites (see Figure 1) indicate that responses to the non-target tones (left column) were similar for both intervention groups, showing that both groups produced a comparable baseline ERP wave. In contrast, responses to the target tones (center column) were stronger for the non-tailored compared to the tailored intervention group. As a result, both groups differed in the strength of the N100 effect and P300 effect, as can be seen in the difference waves (right column). Detailed visual inspection of the difference waveforms shows a P300 effect between approximately $230 \mathrm{~ms}$ and $450 \mathrm{~ms}$ after stimulus onset that is strongest at the central and parietal sites. At these sites the difference wave is more positive in amplitude for the non-tailored than for the tailored intervention group. In addition, a $\mathrm{N} 100$ effect is displayed beginning at about $80 \mathrm{~ms}$ and extending to about $150 \mathrm{~ms}$ after tone onset that is strongest at the frontal and central sites. At these sites, the difference waveform is more negative for the tailored than for the non-tailored intervention group.

Baseline ERP. Statistical analyses of the responses to the non-target tones found no significant differences between the intervention groups in the N100 and P300 time windows ( $p s>.10$ ). This suggests that the two groups were comparable in terms of baseline ERP signals.

P300 effect. Significant main effects of Intervention, $F(1,22)=5.54, p<.05, \eta_{p}^{2}=.20$, and Electrode Sites, $F(2,44)=49.66, p<.001, \eta_{p}^{2}=.69$, and a non significant interaction between both factors, $F(2,44)=2.07, p=.15, \eta_{p}^{2}=.09$, were found on the mean amplitude of the P300 effect. At the three electrode sites, in line with our hypothesis and the visual inspection of the grand average waveforms, larger mean amplitudes of the P300 effect were found for the non-tailored group compared to the tailored group (see Table 
1). Independent samples t-tests and calculated effect sizes at each electrode site suggested that the P300 effect was significantly modulated by the Intervention at $\mathrm{Cz}, t(22)=$ 2.46, $p<.05, d=1.00$ (95\% Cl: 0.55, 6.58), and Pz, $t(22)=2.02, p=.03$ (one-tailed), $d=$ 0.84 (95\% Cl: $-0.07,5.83)$. Together with a non significant effect at $\mathrm{Fz}, t(22)=1.42, p=$ $.17, d=0.59$ (95\% Cl: $-0.59,3.11)$, these findings indicate a central-parietal distribution of the P300 effect as is also illustrated by the topographical map of the signal distribution of the P300 effect at $320 \mathrm{~ms}$ after stimulus onset (see Figure 1).

Table 1. Mean amplitudes (standard deviations) in $\mu \mathrm{V}$ of the $\mathrm{P} 300$ effect (230-450 ms) for the nontailored and tailored intervention groups at the midline electrodes $\mathrm{Fz}, \mathrm{Cz}, \mathrm{Pz}$

\begin{tabular}{lcccc}
\hline & \multicolumn{2}{c}{ Intervention } & \\
Electrodes & $M$ & $S D$ & $M$ & tailored \\
\hline $\mathrm{Fz}$ & 2.55 & 2.48 & 1.29 & 1.73 \\
$\mathrm{Cz}$ & 7.21 & 3.26 & 3.65 & 3.86 \\
$\mathrm{Pz}$ & 9.11 & 3.78 & 6.24 & 3.07 \\
\hline
\end{tabular}

$N 100$ effect. Significant main effects of Intervention, $F(1,22)=4.59, p<.05, \eta_{p}^{2}=.17$, and Electrode Sites, $F(2,44)=59.22, p<.001, \eta_{p}^{2}=.73$, and a non significant interaction effect, $F(2,44)=2.76, p=.09, \eta_{p}^{2}=.11$, were found on the amplitude of the $N 100$ effect. In line with the topographical map of the signal distribution of the N100 effect at $112 \mathrm{~ms}$ after stimulus onset (see Figure 1), independent samples t-tests showed that the N100 effect was significantly modulated by the Intervention at $\mathrm{Fz}, t(22)=2.32, p<.05, d=0.95$ (95\% Cl: $0.13,2.28)$, and $\mathrm{Cz}, t(22)=2.23, p<.05, d=0.90$ (95\% Cl: $0.09,2.54)$, but not at $\mathrm{Pz}, t(22)=1.50, p=.15, d=0.61(95 \% \mathrm{Cl}:-0.26,1.64)$. Results thus indicate a frontalcentral distribution. However, in contrast to our hypothesis and in support of the visual inspection of the grand average difference waves, the amplitudes of the N100 effect at Fz and $\mathrm{Cz}$ were higher for the tailored intervention group than for the non-tailored intervention group (see Table 2). 
Table 2. Mean amplitudes and standard deviations in $\mu \mathrm{V}$ of the N100 effect (80-150 ms) for the nontailored and tailored intervention groups at the midline electrodes $\mathrm{Fz}, \mathrm{Cz}, \mathrm{Pz}$

\begin{tabular}{lcccc}
\hline & \multicolumn{2}{c}{ Intervention } & \\
Electrodes & $M$ & $S D$ & $M$ & tailored \\
\hline $\mathrm{Fz}$ & -2.77 & 1.22 & -3.97 & 1.31 \\
$\mathrm{Cz}$ & -2.25 & 1.09 & -3.56 & 1.77 \\
$\mathrm{Pz}$ & -1.51 & 0.94 & -2.20 & 1.30 \\
\hline
\end{tabular}

\section{Reaction Times}

The non-tailored intervention group seemed to react faster to the target tones ( $M=343$, $S D=38)$ than the tailored intervention group $(M=363, S D=33)$. However, this difference was not significant, $t(22)=-1.39, p=.18, d=-0.57(95 \% \mathrm{Cl}:-50.25,9.99)$.

\section{Questionnaire Measures}

In line with the objectives of a tailored intervention message, participants in the tailored group evaluated the nutrition information as more personally relevant $(M=4.64 ; S D=$ 1.15) than participants in the non-tailored group ( $M=3.38 ; S D=1.39), t(22)=-2.37, p<$ $.05, d=-0.99(95 \% \mathrm{Cl}:-2.35,-0.16)$. Moreover, a bigger proportion of participants in the tailored $(63 \%)$ as opposed to the non-tailored $(23 \%)$ intervention group intended to change their diet behaviour after reading the intervention message, Wald (1) $=3.77, p=$ .05 (OR $=5.83 ; 95 \% \mathrm{Cl}: 0.98,34.64)$. On the other self-report measures no significant differences between the two groups were found ( $p s>.34$ ).

\section{Discussion}

In an innovative research paradigm for both health education research and cognitive neuroscience we found first ERP support for our hypothesis that personal relevant information motivates people into more attentive information processing. As predicted, the observed P300 attention effects at central-parietal sites, which reflect attention allocation to the auditory task in a relatively late stage of information processing (i.e., at the interface between sensory and memory processing), were higher for the participants who read the non-tailored nutrition advice than for those who read the tailored advice. Based on the assumption of resource allocation (Kok, 1997; Sanders, 1997), these modulations 
of the P300 effect thus suggest that the tailored information received more attention from the participants than the non-tailored information. Support for our hypothesis was also observed in the reaction time data. Although the reaction times did not significantly differ between participants in the tailored intervention group and those in the nontailored intervention group, the means were in the predicted direction (faster for nontailored compared to tailored group - presumably due to attention allocation) and a medium to large effect size (Cohen, 1998) was reported.

We further found a frontally distributed N100 effect. However, and unexpected to us, the observed pattern of this effect, interpreted as reflecting maintenance of early selection (Kok, 1997), was such that the effect was larger for the tailored compared to the non-tailored conditions. We can only speculate here. A possible explanation for the observed N100 pattern could be that participants in the tailoring condition felt more involved with the study because they received personal relevant information, which was also supported on the self-report measure. They, compared to the non-tailored group, may have been more motivated to read the advice thoroughly and perform well on the auditory oddball task, reflected in a higher frontally distributed N100 amplitude. As a consequence of this "better" maintenance of selection, in a later processing stage, i.e. the integration of the selected information and their general knowledge on health behaviour in working memory then needs less effort, usually reflected in a smaller P300. This pattern is exactly what we observed. Alternatively, the increase of the N100 effect in the tailored condition could be the result of a generalized increase of arousal in that condition as compared to the non-tailored condition. Earlier studies of the N100 found increases in amplitude with increases in arousal (see Näätänen, 1992).

In sum, the data give additional and methodological new empirical evidence on previous explanations of the positive effects of computer-tailored health information that referred to the relative gain in attention for individualized health information, but were only indirectly supported by self-report measures that followed exposure to the stimulus information (e.g., Brug et al., 1998). They further support dual process models of attitude change that hold that personal relevant information is more systematically processed than information that is less self-relevant (e.g., Petty \& Cacioppo, 1986). Attentive processing of provided information, in turn, is an essential condition for effective health communication (McGuire, 1985). This is also supported by our finding that in line with previous studies (for a review, see Brug \& De Vries, 1999) participants were more motivated to change their diet behaviour after reading the personalized nutrition advice than after reading the general nutrition advice. Remarkable is that in the present study we did not find a significant difference in subjective estimates of the extent to which respondents read the information carefully. The N100/P300 data may thus point to the gain of using more direct measures of important psychological processes (such as ERP on attention) that are conditional to the effectiveness of health communications. 
Before closing, a number of potential limitations of the present study should be noted. First, the present study used a between-subjects experimental design. Although it provided us the opportunity to include subjective measures of message attention and evaluation and motivation, and data suggested that both groups were similar in baseline ERP signals, the use of a within-subjects design, instead, would have had important advantages as well. A within-subjects design would not only have increased the statistical power of the present study by reducing the inter-person variability, but would also have eased the interpretation of the ERP data in terms of the extent to which the tailored information, relative to the non-tailored information, resulted in drawing attention away from the auditory task.

Furthermore, the relatively small sample size may have rendered the behavioural measure insufficiently sensitive to detect statistically significant differences between experimental conditions. Indeed, the lack of significant support on the reaction time measure despite the relatively large effect size reported may simply indicate a case of Type II error. It should be noted, however, that reaction times are indicative of the complete information process from stimulus processing to execution. It could be the case that in one of those information processing stages attention to the tailored information indeed slowed down the auditory information process whereas this might later be washed out due to executive control effects that might be going into the other direction (cannot be solved by just reaction time information). This indicates that EEG can be extremely informative, because we can look at processing phases prior to execution.

A third limitation concerns the presenting of the intervention text in a word-by-word format. Indeed, normal reading may occur in larger chunks than one word and be faster (or slower) than the speed urged upon participants in the present study. However, the format we applied is widely used in ERP language-processing research, where reading performance is a core target of investigation, as it reduces eye movements and makes data analysis possible in the first place. Of course, the presentation mode might affect sentence integration, for example due to putting more load onto working memory (participants cannot look back in the text), but this should hold for all conditions in the experiment. The self-report data at least showed that participants' appreciation and perceived difficulty of the nutrition advice were not different for the two intervention conditions.

Finally, we would like to point out here that the interpretation of the data is based on the assumption of resource allocation theories, and that our results are only a first step toward a deeper understanding of attentional processing during tailored versus nontailored message encoding. However, considering these limitations, the present study provides first 'on-line' (i.e., during message exposure) empirical evidence that personalized health information may attract more attention than non-tailored health messages, and thus contributes to the further dismantling of the working mechanisms of effective computer-tailored health communications. 



\section{Chapter 3}

\section{Studying the combined effects of tailored and threatening health information on message attention using event-related brain potentials}

Submitted for publication as: Kessels, L.T.E., Ruiter, R.A.C., Brug, J. \& Jansma, B.M. Studying the combined effects of tailored and threatening health information on message attention using event-related brain potentials. 
Introduction

A prerequisite for effective health education is that people have attention for the persuasive message they are exposed to (Blumberg, 2000; McGuire, 1985). The strategy of message tailoring - that is, drafting a message that closely responds to the needs of the targeted individual based on an earlier individual assessment- is often used by health educators to increase personal relevance of the health information and thus motivate people into more attentive processing of the persuasive information about recommended health behaviours. Evidence shows that tailoring is associated with better behaviour change effects than generic health education, especially in nutrition education interventions (Brug et al., 2003; Kroeze et al., 2006; Noar et al., 2007). Brug et al. (2003) suggested that higher personal relevance and thus stronger cognitive processing of the health messages may be important mechanisms for the increased effectiveness (i.e. behaviour change) of computer-tailored education over traditional non-tailored interventions. In a randomized controlled study, we recently confirmed that individually tailored nutrition education messages receive more attention from the reader than non-tailored health communications (Ruiter, Kessels, Jansma, \& Brug, 2006).

Besides message tailoring, a fear appeal (Leventhal, 1971) is often thought as being an effective means to heighten attention for the health information. Several studies have hypothesized that threat perception and fear arousal heighten the relevance of threatrelevant information and, therefore, result in more attentive (systematic) processing of threat-relevant persuasive information (Baron et al., 1994; Gleicher \& Petty, 1992; Ruiter, Abraham et al., 2001; Ruiter, Kok, Verplanken, \& Brug, 2001). The findings concerning the effects of threatening information on the systematic processing of health information are, however, not conclusive. Studies that presented threatening health information to those for whom the health threat was high as opposed to low personally relevant suggest an opposite effect of threatening health information on message attention (Freeman et al., 2001; Harris \& Napper, 2005; Keller, 1999; Keller \& Block, 1999; Liberman \& Chaiken, 1992; Sherman et al., 2000; Taubman - Ben-Ari et al., 2000). For example, Liberman and Chaiken (1992) presented coffee-drinking and non coffee-drinking participants with threatening information linking coffee-drinking to the development of fibrocystic disease (a precursor to breast cancer). The findings showed that female coffee-drinkers, for whom the message was highly relevant, were less persuaded of the link between caffeine and fibrocystic disease than female non-coffee drinkers. More importantly, coffee drinkers seemed to have systematically processed the threatening parts of the message in a defensive manner. Compared to non-coffee drinkers, they were less critical of information questioning the link between caffeine and fibrocystic disease and more critical of information supporting the link. Thus, people for whom the health message had high personal relevance seemed to process the threat information more defensively than 
people who already followed the recommendations (see also Harris et al., 2007; Harris \& Napper, 2005; Noar et al., 2007; Sherman et al., 2000).

The effect of the combined use of message tailoring and health threat information on the extent of message attention has not been tested yet and is subject of the present research. At a more general level, the present study links applied research questions with basic cognitive neuroscience methods to gain more understanding of the cognitive mechanisms that underlie persuasion (cf. S. E. Taylor, 2008).

\section{Study Objective and Hypotheses}

The goal of the present study was to investigate the effect of the combined use of message tailoring and presenting threat information on attention allocation processes. Similar to the attention paradigm and stimulus materials used in a previous study, nutrition education messages were presented in an oddball attention paradigm (Ruiter et al., 2006). In order to measure attention allocation processes in message tailoring, participants processed two streams of information during the experiment: auditory and textual information. Participants were instructed to read the textual information combining the tailoring and threat manipulation from a screen, and at the same time they were asked to push a button whenever they heard a rare high-frequency tone (i.e., a target stimulus) and to withhold the response whenever a standard low-frequency tone (i.e., a non-target stimulus) was presented. Response latencies and event-related brain potentials were recorded to quantify the amount of attention allocation to the auditory task.

Event related potentials (ERPs) are generated from a continuous measure of brain activity by means of an electroencephalogram (EEG) (for an introduction, see Fabiani, Gratton, \& Coles, 2000). The relationship between mental resources of attention and ERPs has been discussed especially with regard to the P300 ERP component (for an overview, see Polich, 2007). The P300 component shows larger amplitudes whenever the target stimulus is attended to, compared to when there is less or no attention to the target. The P300 has a maximum peak around 300 ms after stimulus onset and is functionally related to later conscious, decisional and premotor response related stages (Bentin, Mouchetant-Rostaing, Giard, Echallier, \& Pernier, 1999). The P300, which is usually strongest at parietal scalp sites, reflects more controlled attention processes and as such provides an index for a cognitive attention allocation (Coull, 1998; Näätänen, 1992).

Based on previous findings showing that people attend more to personally relevant information (Petty \& Cacioppo, 1986; Ruiter et al., 2006), we expected that tailored nutrition messages attract more attention than non-tailored messages. This in turn - as predicted by resource allocation theory (Kok, 1997; Pollak \& Tolley-Schell, 2003; Sanders, 1997) - leads to fewer resources left for carrying out the auditory attention task resulting in a smaller auditory attention effect in tailored vs. non-tailored conditions. This main effect of tailoring on attention for the auditory task should be reflected in lower mean 
amplitudes of the P300 ERP component towards the auditory targets for tailored vs. nontailored messages. In addition, we expect slower reaction times in response to the target tones while reading the tailored as opposed to non-tailored nutrition messages.

Recent fear appeal studies suggest that personal relevant health information is defensively processed when the information is high threatening (Freeman et al., 2001; Harris \& Napper, 2005; Keller, 1999; Keller \& Block, 1999; Liberman \& Chaiken, 1992; Sherman et al., 2000; Taubman - Ben-Ari et al., 2000). Based on these findings we predict that high threat information reduces the predicted attention effect of tailoring as compared to low threat information. While tailored messages have been found to receive more attention than non-tailored messages, presenting high threat information in combination with tailored messages will reduce attention for the information resulting in more attention for tailored low threat messages than tailored high threat messages. An interaction effect between tailoring and threat is therefore expected in which the main effect of message tailoring is moderated by an effect of high versus low threat information.

\section{Method}

\section{Participants and Experimental Design}

Forty-one students participated in the experiment. Participants were 19 to 28 years of age (Low Threat Condition: $M=21.30 ; S D=2.54$; High Threat Condition: $M=22.14 ; S D=$ 2.57; $t(29)=1.06, p=.30, d=.39)$. All participants were female and reported normal or corrected-to-normal vision and had no medical history of hearing problems. They received course credits or $€ 15$ gift vouchers for their participation. In the first ERP-study that measured attention processes for tailored information, tailoring was manipulated as a between-subjects factor (Ruiter et al., 2006). In the present study participants received both a tailored and a non-tailored nutrition education message about fat, vegetable and fruit intake in a counter-balanced order. Each participant was further randomly exposed to either high threat or low threat information about the consequences of having unhealthy eating habits (i.e. high fat intakes and low fruit and vegetable intakes). This threat information was intermingled with the nutrition information. Although a within-subjects manipulation of threat would be preferable, this was thought to be ineffective because of the explicit nature of the threat manipulation. Where both tailoring messages were highly similar in content (see below) the differences between both threat messages is much more visible because they describe different consequences of having an unhealthy diet. When reading both threat messages, the participants could simply combine the consequences of both messages to have a more complete picture of the health threat. 


\section{Procedure, Stimulus Materials and Tasks}

The experiment consisted of two sessions. In the first session participants filled out written validated questionnaires to assess the participants' fat, fruit and vegetable intake and their attitude, self-efficacy and intentions related to changing their nutrition behaviour (Brug et al., 1996; van Assema, Brug, Ronda, Steenhuis, \& Oenema, 2002). The answers of the respondents were used to construct an individually tailored nutrition message before the start of the second session approximately 1 week later. The content of the tailored messages was a result of three essential strategies of message creation, namely personalization, feedback and content matching (Hawkins, Kreuter, Resnicow, Fishbein, \& Dijkstra, 2008).

In the second session, participants carried out a dual task. In addition to reading tailored and non-tailored nutrition education messages from a computer-screen (with a break of approximately $5 \mathrm{~min}$ in between), they listened to sequences of high- and lowfrequency tones and were asked to push a button whenever they heard the rare highfrequency target tone (Hillyard et al., 1995). The softwaren program ERTSVIPL V 3.32c (Beringer, 1987) was used for stimulus presentation and response time latency measurement. Participants were introduced to the different tones in a practice trial of 50 oddball trials without word presentation. The EEG was recorded during the task. After an electrode cap was mounted on the participant's head, the participant was taken to a dimly lit, sound-attenuating, electrically shielded cabin and seated in a comfortable chair approximately $80 \mathrm{~cm}$ from the computer screen that situated the participant at eye level to the screen's center. Participants were instructed to fixate on the nutrition information presented on the screen while performing the auditory oddball task and to avoid eye blinks and other body movements as much as possible during presentation of the nutrition messages and auditory oddball task. They were instructed that the reading task and oddball task were equally important.

Both tailored and non-tailored messages had three sections referring to fat, vegetable and fruit intake, respectively. Each section contained about 200 to 250 words with either high threat or low threat information about the negative consequences of unhealthy eating. The remainder of each section in the tailored and non-tailored messages contained information about how to improve nutrition behaviour without any threatmanipulation. The tailored message contained between 1550 and 1650 words and the non-tailored message contained 1500 words.

For example, a person who's fat intake was assessed to be 100 grams of fat/day received in the tailored high threat intervention message the following sentence: "You eat approximately an average of 100 gram of fat per day, whereas 75 gram is sufficient. If you eat too much fat at a young age, this will increase your risk of getting heart- and vascular diseases." For the low-threat group the second part of the sentence was presented as follows: "If you eat too much fat, this is not good for your health at later age." In the non-tailored high-threat intervention message the person received the sentence as 
follows: "On average people in the Netherlands eat 95 gram fat per day, whereas 75 gram is sufficient. If people eat too much fat, this increases the risks of getting heart- and vascular diseases at young age." The second part of this sentence was made less threatening in the non-tailored low-threat condition: "If people eat too much fat, this is not good for their health at later age."

In order to measure valid ERP responses, eye movement were minimized by presenting intervention messages on the computer screen word-by-word with an inter-stimulus interval of 1,000 ms. Every word appeared on the screen for $250 \mathrm{~ms}$, followed by a black screen for $750 \mathrm{~ms}$. The words were clearly visible and had a minimum length of 2 letters and a maximum length of 16 letters. In the auditory oddball task, the high- $(1,000 \mathrm{~Hz})$ and low-frequency $(500 \mathrm{~Hz})$ auditory tones were presented. The tones were presented 150 $\mathrm{ms}$ after word onset, and the tone length was $100 \mathrm{~ms}$. The high- and low-frequency tones were presented in random order. The high-frequency tones (target tones) had an occurrence probability of $17 \%$, the low-frequency tones (non-target tones) had an occurrence probability of $83 \%$. On hearing a target tone, participants responded as instructed by pressing the button as fast as possible. On hearing a non-target tone, no overt response was required. A practice round of 50 oddball trials without word presentation preceded the experimental task.

After finishing the dual task participants answered several self-report questions about the information received. Finally, participants were debriefed, paid and asked not to talk about the objectives and topic of the study with fellow students. The entire second session took about $2.5 \mathrm{hr}$.

\section{Measures}

Self-report Measures. To measure different dimensions of message evaluation, we used self-report items based on previous research into the effectiveness of message tailoring (cf. Brug et al., 1996; Kreuter, Farrell et al., 2000). For the tailored and nontailored nutrition education messages we measured perceived personal relevance of the message ( $1=$ not at all, $7=$ very much), the appreciation of the message on scales from 1 = unpleasant, to $7=$ pleasant $1=$ unattractive, to $7=$ attractive; $1=$ uninteresting, to $7=$ interesting (tailored: Cronbach's $\alpha=.78$; non-tailored: Cronbach's $\alpha=.85$ ), the newness and difficulty of the message ( 1 = not at all, 7 = very much), and the estimated amount of attention allocated (subjective attention) to the message (i.e., "to what extent have you read the information carefully"; $1=$ not at all, to 7 = very much). We further used six items to measure the extent to which participants felt scared, worried, concerned, anxious, nervous and threatened while reading the information about the health consequences of bad nutrition behaviour on a scale from 1 (not at all) to 7 (very much). The scores on these items were averaged to form highly reliable indices (tailored: Cronbach's $\alpha=.94$; non-tailored: Cronbach's $\alpha=.92$ ) of fear arousal. 
Reaction times. Button-press responses were measured from high tone onset, with a time-out limit of 850 milliseconds (ms). Errors in which no response was registered within $850 \mathrm{~ms}$ after presentation of the auditory target tone, or in which a response was given in reaction to the non-target tone were left out of the analyses of both the reaction time data and the ERP data.

EEG. The EEG was recorded from 30 scalp sites (an extended version of the 10/20 system) with tin electrodes mounted in an electrode cap, with the electrodes referenced online to the left mastoid signal. A bipolar montage with electrodes placed on the right and left external canthus, recorded horizontal eye movements. Vertical eye movements and eye blinks were measured by a bipolar montage of electrodes placed on the upper and lower orbital ridge of the left eye. The electro-oculogram was recorded for later offline rejection of trials contaminated with eye movements. EEG and electro-oculogram signals were digitized at $250 \mathrm{~Hz}$ and amplified by using a 32-channel NeuroScan SynAmps amplifier with a bandpass of $0.05-30 \mathrm{~Hz}$. All electrode impedances (EEG and electrooculogram) were kept below $5 \mathrm{k} \Omega$.

ERP effects. From the continuous EEG signal epochs of $900 \mathrm{~ms}$ were obtained, including a $100 \mathrm{~ms}$ pre-stimulus (tone) baseline. Trials with artifacts, including eye movements, were rejected from further analyses (threshold $+/-75 \mu \mathrm{V}$ ). By averaging the remaining artifact-free epochs per participant per condition, we derived the ERP waveforms separately for target and non-target tones from all experimental conditions. The ERP signal was further examined in terms of deviant-standard difference waveforms that we computed by subtracting the ERP signal elicited by the non-target tones from that of target tones (separately for each subject, condition and electrode). The difference waveforms were quantified by mean amplitude measures $(\mu \mathrm{V})$, in the time window derived from visual inspection of the grand average (difference) waves. The following three groups of electrodes were used for examining the effects at frontal, central and parietal sites on the scalp: frontal (Fp1, FPz, FP2, F3, Fz and F4), central (FC3, FCz, FC4, C3, Cz, and $C 4$ ) and parietal (CP3, CPz, CP4, P3, Pz, and P4).

\section{Analyses}

Mixed model analyses of variance (ANOVA) were used with the within-subjects factor tailoring (tailored vs. non-tailored) and the between-subjects factor threat (high vs. low threat) to compare the four groups on the self-report measures, reaction times and errors. 
The P300 ERP results were subjected to separate mixed ANOVAs for the frontal, central and parietal sites that crossed the within-subjects factors tailoring (tailored vs. non-tailored) and the between-subjects factor threat (high vs. low threat).

To control for sphericity violations in the analyses of variance, we reported probability values with Greenhouse-Geisser correction for F-tests with more than one degree of freedom in the numerator. The reported estimates of the effect size are the partial eta squared $\left(\eta_{p}^{2}\right)$ for the analyses of variance, eta squared $\left(\eta^{2}\right)$ for the paired-samples t-tests and Cohen's $d$ for the independent-samples t-tests.

\section{Results}

Because the data sets of four participants in the high threat condition and three participants in the low threat condition could not be used because of technical problems or too many mistakes, 34 participants remained in the sample and were included in the analyses with 17 participants in the high threat condition and 17 in the low threat condition.

\section{Premeasures}

Analyses showed that the high and low threat conditions did not differ on the measures of attitude, self-efficacy, intention, and behaviour regarding fat, vegetables, and fruit intake that served as input for the nutrition message, $t s<1.93, n s, d s<.66$.

\section{Self-report measures}

An overview of the mean scores on the self-report measures can be found in Table 1. Significant main effects of tailoring were found on the measures of perceived personal relevance, $F(1,32)=83.55, p<.001, \eta_{p}^{2}=.72$, message appreciation, $F(1,32)=34.68, p<$ $.001, \eta_{p}^{2}=.52$, and newness of the information, $F(1,32)=10.22, p<.01, \eta_{p}^{2}=.24$. That is, participants perceived the tailored nutrition information as more personally relevant than the non-tailored nutrition information, appreciated the tailored information more, and rated the tailored message as newer. A significant interaction effect of tailoring and threat was found on the perceived difficulty of the nutrition messages, $F(1,33)=5.23, p<$ $.05, \eta_{p}^{2}=.14$. Independent-samples $t-$

tests showed that the low threat non-tailored message was rated as more difficult to read than the high threat non-tailored message, $t(32)=2.66, p<.05, d=.92$. No effect of threat was found in the tailored messages, $t(32)=-.34, p=.73, d=.12$. In addition, paired-samples t-tests revealed no effects of tailoring in the high and low threat conditions, $t s<1.73, n s, \eta^{2} s<.16$. 
A significant main effect of threat on the measure of fear arousal indicated that the threat manipulation was successful, $F(1,32)=6.24, p<.05, \eta_{p}^{2}=.16$. Participants who read the high threat information reported more fear arousal than those that read the low threat information. The main effect of tailoring was also significant, $F(1,32)=4.24, p<$ $.05, \eta_{p}^{2}=.12$. The tailored high and low threatening parts were judged as being more feararousing than the non-tailored high and low threatening parts.

Finally, no differences were found among the four conditions on participants' reports of the estimated amount of attention that was allocated to the nutrition messages, Fs < 2.42, ns, $\eta_{p}^{2} s<.07$.

Table 1. Mean scores and standard deviations on Self-Report Measures of Personal Relevance, Appreciation, Newness, Difficulty, Fear arousal and Attention for the Non-tailored and Tailored Intervention Messages by levels of Threat

\begin{tabular}{lcccccccc}
\hline & \multicolumn{4}{c}{ Non-tailored } & \multicolumn{3}{c}{ Intervention } & \multicolumn{3}{c}{ Tailored } \\
& \multicolumn{4}{c}{ Low Threat } & High Threat & Low Threat & \multicolumn{1}{c}{ High Threat } \\
& $M$ & $S D$ & $M$ & $S D$ & $M$ & $S D$ & $M$ & $S D$ \\
\hline Relevance & 2.51 & 1.33 & 2.51 & 1.12 & 5.59 & 0.98 & 4.78 & 1.70 \\
Appreciation & 4.84 & 1.19 & 4.55 & 1.09 & 5.76 & 0.85 & 5.57 & 0.64 \\
Newness & 1.69 & 0.83 & 2.18 & 0.93 & 2.33 & 1.25 & 2.86 & 1.41 \\
Difficulty & 1.71 & 0.85 & 1.12 & 0.33 & 1.41 & 0.51 & 1.35 & 0.49 \\
Fear & 1.88 & 0.88 & 2.58 & 1.07 & 2.12 & 1.07 & 3.05 & 1.24 \\
Attention & 6.12 & 0.93 & 5.82 & 0.88 & 6.35 & 0.61 & 5.88 & 1.05 \\
\hline
\end{tabular}

\section{Error Analysis}

False alarms, misses and responses slower than $850 \mathrm{~ms}$ were removed from the ERPs and reaction time data (overall mean $=7.88 \%$; $S D=3.79 \%$; no differences among conditions, $\left.F_{s}<1.24, n s, \eta_{p}^{2}<<.04\right)$. Furthermore, trials with EEG artifacts were rejected from the data (overall mean $=3.73 \%$; SD $3.12 \%$; no differences among conditions, $F<.59, n s, \eta_{p}^{2} s<.02$ ).

\section{Reaction Times}

Table 2 illustrates mean reaction times for detecting the deviants in the stimulus sequence of auditory tones for all four conditions. In line with our expectations, the mixed ANOVA revealed a significant main effect of tailoring, $F(1,32)=4.38, p<.05, \eta_{p}^{2}=.12$. 
Average reaction times to the target tones were faster for the non-tailored conditions than for the tailored conditions. Although the reaction times to the target tones seemed to be faster for the high threat conditions than for the low threat conditions, no significant support for the main effect of threat or the interaction between threat and tailoring was found, $F \mathrm{~s}<1.79, n s, \eta_{p}^{2} s<.05$.

Table 2. Mean reaction times (ms) and mean amplitudes $(\mu \mathrm{V})$ of the P300 effect (350 ms $-450 \mathrm{~ms}$ for the Non-tailored and Tailored Conditions by Level of Threat at Frontal, Central and Parietal Sites

\begin{tabular}{lcccccccc}
\hline & \multicolumn{9}{c}{ Non-tailored } & \multicolumn{3}{c}{ Intervention } & \multicolumn{3}{c}{ Tailored } \\
& \multicolumn{4}{c}{ Low Threat } & High Threat & Low Threat & High Threat \\
& $M$ & $S D$ & $M$ & $S D$ & $M$ & $S D$ & $M$ & $S D$ \\
\hline RT & 414.33 & 42.07 & 393.64 & 39.70 & 420.97 & 41.38 & 405.22 & 43.41 \\
P300 & & & & & & & & \\
Frontal Site & 0.14 & 3.74 & 1.87 & 2.87 & -0.28 & 3.80 & 1.66 & 2.36 \\
Central Site & 3.34 & 4.54 & 5.64 & 2.73 & 2.62 & 3.54 & 5.44 & 2.58 \\
Parietal Site & 8.13 & 3.28 & 9.68 & 2.50 & 7.15 & 2.23 & 9.36 & 2.93 \\
\hline
\end{tabular}

\section{Visual Inspection of the Grand Average ERP Waves}

The grand average waveforms for the four conditions (see Figure 1) indicated larger P300 ERP amplitudes in reactions to the target tones than in reactions to the non-target tones, starting around $300 \mathrm{~ms}$ after tone presentation. Further inspection of the differences waves indicated effects of tailoring and threat on the P300 ERP component. Between 350 and $450 \mathrm{~ms}$ after stimulus presentation, the difference waves showed more positive amplitudes for the non-tailored conditions than for the tailored conditions (see Figure 2) and more positive amplitudes for the high threat conditions than for the low threat conditions (see Figure 3 ) at the central and parietal sites (for efficiency reasons, waveforms are presented for midline electrodes $\mathrm{Fz}, \mathrm{Cz}$ and $\mathrm{Pz}$ only). 


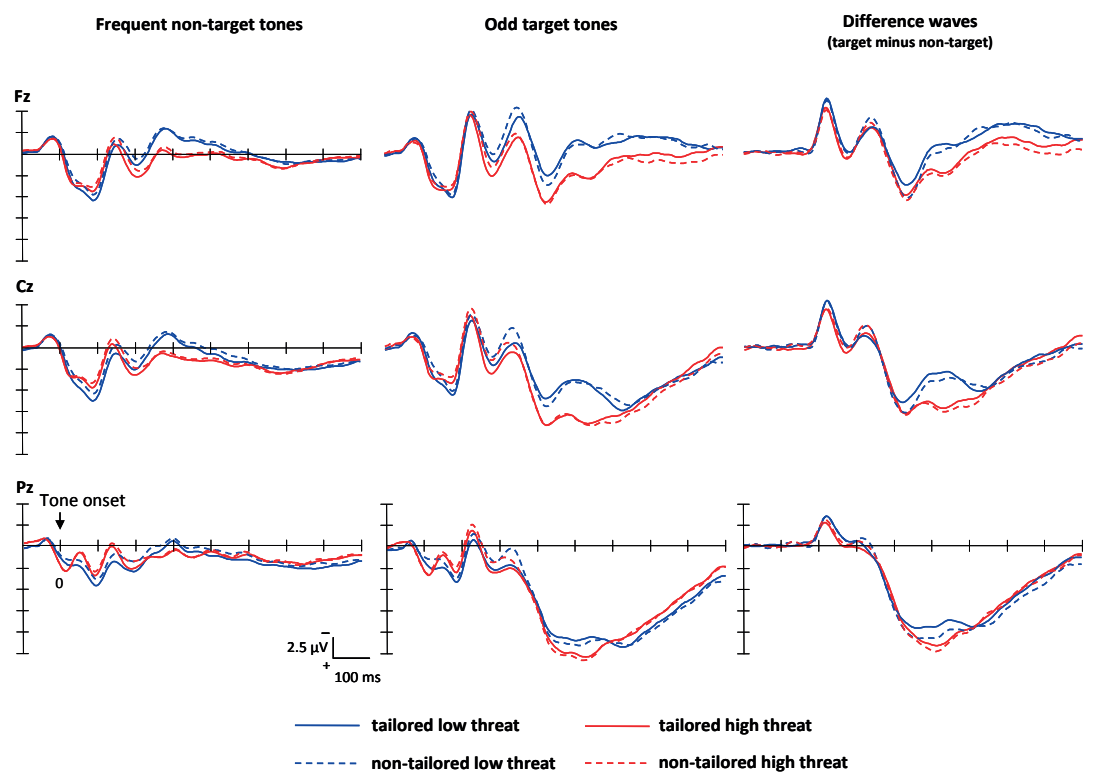

Figure 1. Grand average event-related potentials waveforms for the non-tailored and tailored intervention by level of threat. Data are displayed for all 34 participants for the midline electrodes $\mathrm{Fz}, \mathrm{Cz}$, and $\mathrm{Pz}$. The left column presents the waveforms for the frequent non-target tones. The center column presents the waveforms for the odd target tones. The right column presents the difference waves (target minus non-target tones). Negative voltage is plotted up.

\section{Mean Amplitude Analyses}

Separate mixed ANOVAs and calculated effect sizes at each electrode site suggested that the P300 effect was significantly modulated by tailoring at the parietal site, $F(1,32)=$ $4.05, p<.05, \eta_{p}^{2}=.11$. This effect of tailoring was not replicated at the frontal site, $F(1,32)$ $=1.25, p=.27, \eta_{p}^{2}=.04$, and the central site, $F(1,32)=1.90, p=.18, \eta_{p}^{2}=.06$. Larger mean amplitudes were found for the non-tailored conditions compared to the tailored conditions at the parietal site (see Table 2). These findings indicate a parietal distribution of the tailoring effect, as is also illustrated by the topographical map of the signal distribution around $400 \mathrm{~ms}$ after stimulus presentation (see Figure 2). 
Difference Waves - Tailoring Effect (target minus non-target)
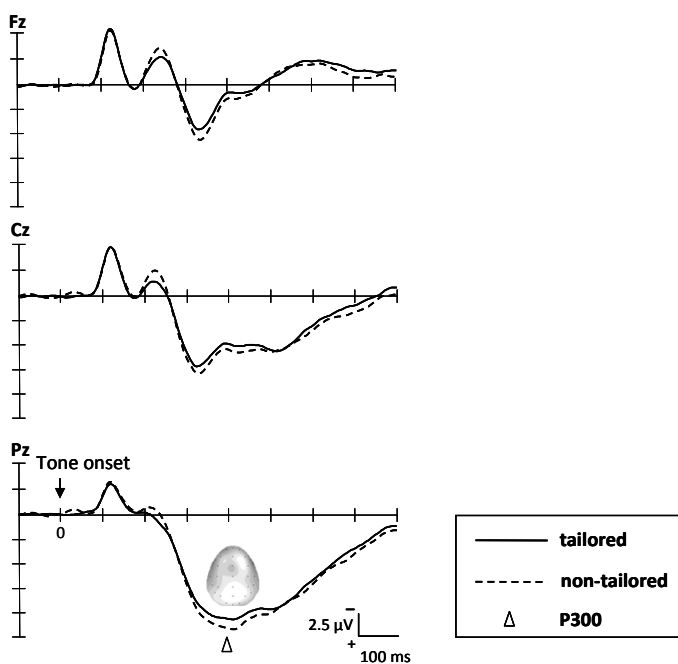

Figure 2. Difference waves (target minus non-target tones) for the tailored condition and the nontailored conditions across threat conditions. The topographical map presents the signal distribution of the P300 tailoring effect (tailored minus non-tailored) between 350-450 ms after tone onset with a maximum of $1 \mu \mathrm{V}$ (black) and a minimum of $-1 \mu \mathrm{V}$ (white). Negative voltage is plotted up.

Besides the tailoring effect, the same separate mixed ANOVAs showed a significant main effect of threat at the central site, $F(1,32)=5.11, p<.05, \eta_{p}^{2}=.14$, and the parietal site, $F(1,32)=4.45, p<.05, \eta_{p}^{2}=.12$, but not at the frontal site, $F(1,32)=2.89, p=.10$, $\eta_{p}^{2}=.08$. Larger mean amplitudes of the $P 300$ effect were found for the high threat conditions compared to the low threat conditions (see Table 2). These findings indicate a central-parietal distribution of the P300 threat effect, which is illustrated by the topographical map of the signal distribution around $400 \mathrm{~ms}$ after stimulus presentation (see Figure $3)$.

No significant support was found for the expected interaction effects between threat and tailoring at the three different sites, $F s<1.06, n s, \eta_{p}^{2}<.03$. 


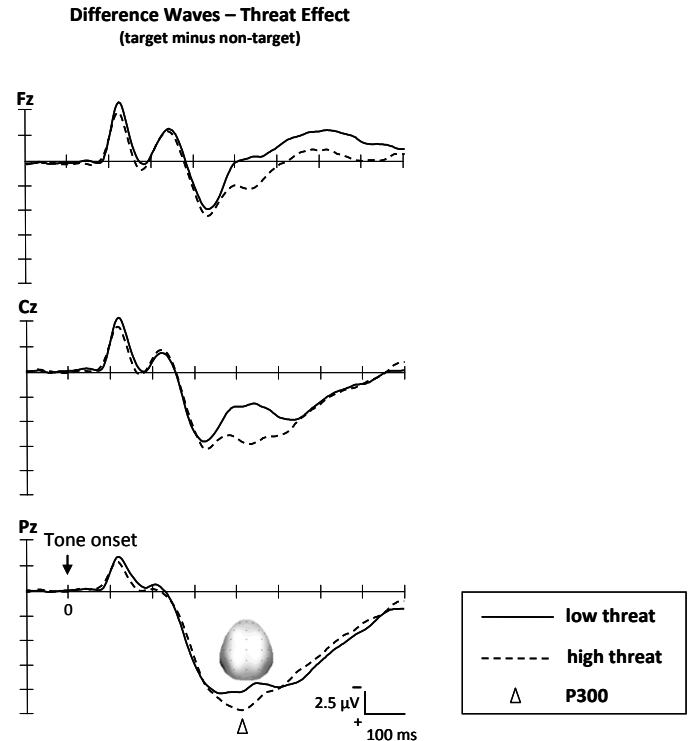

Figure 3. Difference waves (target minus non-target tones) for the low threat condition and the high threat condition across tailoring conditions. The topographical map presents the signal distribution of the P300 threat effect (low threat minus high threat) between 350-450 ms after tone onset with a maximum of $4 \mu \mathrm{V}$ (black) and a minimum of $-4 \mu \mathrm{V}$ (white). Negative voltage is plotted up.

\section{Discussion}

In the present study we examined the effects of combining the methods of tailoring and threat information on attention processes for the information. The ERP results showed that tailored nutrition information as well as low threat nutrition information motivates people into more attentive information processing. In addition to a first ERP-study (Ruiter et al., 2006), the attention enhancement for the tailored nutrition information was not only shown for the P300, but also for the reaction times. Furthermore, we were able to replicate previous ERP-findings on tailoring by manipulating message tailoring within participants instead of between participants which is normally done.

The P300 attention effects for the tones were higher when participants were reading the non-tailored and high threat nutrition information than when they were reading the tailored and low threat nutrition information. In line with assumptions of the attention 
resource theory (Kok, 1997; Sanders, 1997), we interpret the moderation of the P300 effect by presenting tailored vs. non-tailored information and low threat vs. high threat information as a reallocation of attention away from the auditory task toward the encoding of the nutrition information suggesting that the tailored as well as the low threat information received more attention resources from the participant than the non-tailored and high threat information (Coull, 1998; Näätänen, 1992).

The reaction time data, showing faster reaction times for the non-tailored condition compared to the tailored condition, provided further support for the hypothesis that tailored information receives more attention than non-tailored information. In the first ERP-study that measured attention processes for tailored information a nonsignificant pattern in the expected direction was found (Ruiter et al., 2006). We assume that the significant result in the present study was caused by the reduced between-subjects variation as a result of manipulating message tailoring as a within-subjects factor instead of a between-subjects factor.

This positive attention effect of tailored information was further supported by the self-report measures. Participants perceived the tailored information as more personally relevant than the non-tailored information, appreciated the tailored information more, and rated the tailored message as newer.

A recent meta-analysis of tailoring studies suggests that presenting tailored messages that focus on threat perceptions leads to less motivation to health behaviour change than messages that focus on inducing positive attitudes and higher self-efficacy towards the recommended action (Noar et al., 2007). The present study partly supported this finding at the level of message attention with more attention allocated to low threat compared to high threat information for both tailored and non-tailored messages. Despite visible indications of a moderation effect between threat and tailoring information on the ERP difference waves, no empirical support was found for the expected interaction between the threat and tailoring on the amplitude measures of the expected ERPcomponents and on the reaction times.

The self-report results showed that the tailored messages were judged to be more threatening than the non-tailored messages. Tailored messages could create an emotional response such as fear or anxiety (Hawkins et al., 2008), probably because participants become aware of their own nutrition behaviour. Participants felt most threatened by the tailored and the high threat information, but the tailored and the low threat information received the highest attention processes. This suggests that different psychological processes explained the effects of both experimental manipulations. Furthermore, the self-report results showed that tailored messages were rated as newer than the nontailored messages. An explanation could be that participants are more exposed to general nutrition in the media, while they are less familiar with personally tailored messages.

In support of using ERP and reaction time measures in addition to self-report measures, it is further noteworthy that our data did not show a significant difference in subjec- 
tive estimates of the amount of attention participants paid to the different messages. This study thus provides further evidence for the need to use more direct measures when studying important psychological processes that are conditional to the effectiveness of health communications.

Several methodological issues emerged from the present study that should be followed up in future research. First, in the present study, threat was presented as a between-subjects factor because we thought that participants would discover the purpose of the threat manipulation when both high and low threat information was presented to the same participant. To overcome the resulting confounding of an experimental manipulation with interpersonal differences in brain structure and activity, future research might opt for a procedure in which the health topic is varied for the high and low threat condition within participants, and the combination of health topic and threat level is then counterbalanced across participants. Still a between-subjects factor is introduced but this variation is less of influence on the research question that is studied. To avoid complex combinations with message tailoring and given the successful replication of the positive effect of tailoring on message attention, the effect of threat might be studied for only tailored health education messages. Second, while we measured attention processes for different kind of messages, no other measures of defensive reactions were measured, for example overt self-report measures of defensive avoidance. Such a measure could have given us more insight regarding defensive reactions in the tailored high threat condition compared to other conditions. Third, future studies might counterbalance (preferably within subjects) the assignment of high frequency vs. low frequency tones to target vs. standard auditory tones. When the two tones are counterbalanced, any effects on the difference waves would be entirely due to the oddball effect, thus serving as an index of attention resources, and not due to tone frequency, which probably has nothing to do with attention. Fourth, in future research varying gradations of severity of threat could be tested, in order to determine the optimal level at which attention and processing is greatest.

Overall, the present study showed independent gains in attention for individualized and low threat health information. This gain was empirically shown by a multi-method approach measuring ERP (P300) and reaction times. Attentive processing of provided information is an essential condition for effective health communication (Blumberg, 2000). This latter point could be tested in future neurocognitive experiments that incorporate measures of attitude and behaviour change. Note in any case, the findings of processing benefits for tailored as opposed to non-tailored messages and low threat as opposed to high threat messages suggest that threat is not particularly needed to draw attention to relevant health messages and could actually result in a reduction in attention, but that tailoring seems to be an important means to do so. 



\section{Chapter 4}

Increased attention but more efficient disengagement:

Neuroscientific evidence for defensive processing of threatening health information

A manuscript partly based on this chapter is published as: Kessels, L.T.E., Moors, S., Pauwels, K.R, \& Ruiter, R.A.C. (2008). Een ERP-studie naar de effectiviteit van bedreigende rookfoto's op processen van wegkijkgedrag. In J. Karremans, B. Beersma, R. Custers, F. van Harreveld, \& W. van Rijswijk (eds.), Jaarboek Sociale Psychologie 2007: Associatie van Sociaal Psychologische Onderzoekers (ASPO). Groningen: ASPO Pers.

Accepted for publication as: Kessels, L.T.E., Ruiter, R.A.C., Jansma, B.M. (2010). Increased attention but more efficient disengagement: Neuroscientific evidence for defensive processing of threatening health information. Health Psychology, 29, 346-354. 
Introduction

Presenting threatening health information by highlighting the negative consequences of unhealthy behaviour is often used to motivate people into behaving more healthily. A recent example of this practice is the worldwide introduction of graphic warnings labels on cigarette packages, following recommendations of the World Health Organisation's Framework Convention on Tobacco Control and - for member states of the European Union - Directive 2003/641/EC of the European Committee (see also Harris et al., 2007; Ruiter \& Kok, 2005, 2006). Indeed, explanatory models of health behaviour suggest that increased risk perception is an important determinant of people's motivation to adopt safer and healthier behavioural alternatives (Fishbein, Triandis, Kanfer, Becker, \& Middlestadt, 2000; Leventhal, 1970; Maddux \& Rogers, 1983; Witte, 1992).

However, a large body of experimental research suggests that people who are at risk report the least motivation to change and subsequently react defensively to threatening health information (e.g., Brown \& Locker, 2009; Croyle et al., 1997; Ditto \& Croyle, 1995; Freeman et al., 2001; Keller, 1999; Keller \& Block, 1999; Liberman \& Chaiken, 1992). Early empirical support for counterproductive effects of health messages was found by Liberman and Chaiken (1992). They demonstrated that coffee drinkers were less critical of information questioning the link between caffeine and fibrocystic disease and more critical of information supporting the link than non-coffee drinkers. Similar empirical support for defensive processing of self-relevant threat information has been obtained in recent work on the role of self-affirmation, which demonstrates that defensive reactions can be prevented through strengthening feelings of self-integrity (e.g., Harris et al., 2007; Harris \& Napper, 2005; Sherman et al., 2000; Van Koningsbruggen \& Das, 2009).

\section{Understanding Defensive Reactions}

Theoretically, defensive reactions to threatening health information have been explained primarily with the help of cognitive dissonance theory (Festinger, 1957) and Kunda's (1990) argument for motivated reasoning. That is, individuals experiencing dissonance because their self-image is threatened are motivated to reduce it by changing one of the implicated cognitive or behavioural elements (e.g., perceived risk), for example through biased processing of compromising information (Liberman \& Chaiken, 1992) or message derogation by refuting message claims (e.g., Brown \& Locker, 2009) and evaluating recommendations as not effective (e.g., Keller, 1999).

In addition, self-report measures of cognitive effort (Liberman \& Chaiken, 1992) and more implicit measures of reading time (Brown \& Locker, 2009) and response time (W. M. P. Klein \& Harris, 2009) have been used to provide an index of the amount of attention that is allocated to threatening health information. These studies suggest that people most at risk react defensively to threatening health information by attending away from 
the message (or by avoiding the message). However, by definition these measures do not allow a direct observation of the amount of attention that is allocated to the threatening information during message processing. At best, the procedures reflect relatively late information processing stages that feed higher order cognitive processes such as biased processing and not the early stage of attention allocation. In the present study, we aim to explain people's defensive reactions to threatening health messages by studying attention processes during the exposure to high and low threatening smoking related pictures among smokers (high self-relevance) and non-smokers (low self-relevance).

\section{Attention and ERP Analysis}

In the visual attention system a distinction can be made between attention capture and attention holding processes. Automatic attention capture is usually driven by salient characteristics of the stimuli (for example its valence). The visual attention system also decides whether the stimulus needs to hold attention or whether it is important to shift the attention focus to another place, i.e. attention disengagement (Posner et al., 1984). For example, Koster, Crombez, Van Damme, Verschuere, \& De Houwer (2004) provided evidence that imminent threat causes attention capture and attention holding, caused by the phylogenetically old mechanism that directs attention to imminent threat automatically. In the present study we hypothesized that although threatening health information will automatically causes attention capture because of its obvious survival value, it will also motivate people to reduce their feeling of dissonance when the information undermines self-relevant goals by disengaging attention from it. People for whom the threat information is self-relevant will thus be motivated to avoid this information by disengaging from the threat. The latter is, for example, reflected in the use of less cognitive resources in detecting visual targets presented in other areas of the visual scene than the threatening cue.

Several paradigms have been used to study attention bias for high threat stimuli among which the stroop task, the dot-probe task, the visual search task or the cueing task (MacLeod, Mathews, \& Tata, 1986; Melara \& Algom, 2003; Posner, 1980; Rabbitt, 1982). In the context of investigating attention allocation processes to health threat information only one study is known to us that used such an attention paradigm. Klein and Harris (2009) measured attention processes for threatening components of a persuasive message by using a dot-probe task. The study provided evidence that moderately heavy drinkers who were not self-affirmed show an attention bias away from the threat information. However, the setup of the dot-probe task used in this study had the disadvantage that it could not distinguish between attention processes such as attention capture and attention holding (Koster, Crombez, Verschuere, \& De Houwer, 2004). Therefore, Klein and Harris (2009) cannot conclude what attention processes, less attention capture or less attention holding, caused the attention bias away from the threat among those 
participants who were not self-affirmed. In the present study we therefore used the Posner's (1980) cueing task as it enables us to measure both attention capture and attention holding (disengagement) processes in order to investigate early visual selective attention processes in response to self-relevant health threat information (Koster, Crombez, Van Damme et al., 2004; Posner, 1980).

In measuring attention allocation processes we chose to use the high temporal resolution method of event-related brain potentials (ERP). ERPs are derived from a continuous recording of brain activity by means of an electroencephalogram (EEG; for an introduction, see Handy, 2005) and thus enable the assessment of early attention processes during message processing - within milliseconds after stimulus onset. ERP measures provide additional knowledge about different component processes because they do not rely upon convergence of effects on a single output measure, such as reaction time or self-report questionnaires (Fichtenholtz, Hopfinger, Graham, Detwiler, \& LaBar, 2007). The relationship between attention allocation, cognitive resources and ERP is clearly visible in the P300 ERP component (Polich, 2007). The P300 is a relative late component that is maximal around $300 \mathrm{~ms}$ after stimulus presentation in the central-parietal regions of the brain. The P300 reflects more controlled attention processes and as such provides an index for cognitive attention allocation and the update of stimulus processing with working memory information (Näätänen, 1992). Because the P300 is dependent on the task requirements of the participant it reflects the amount of resources necessary for attending (Polich, 2007). ERP studies using Posner's cueing paradigm (Posner, 1980) have reported P300 increases when disengagement was more difficult, reflecting increased resources required to disengage from previously cued stimuli (Correa, Lupiáñez, Madrid, \& Tudela, 2006; Fichtenholtz et al., 2007; Pollak \& Tolley-Schell, 2003).

\section{Overview of the Study and Hypotheses}

In general, the effects of message features and personal characteristics on processes of attention allocation have not been addressed systematically in persuasion research (for an exception, see Ruiter et al., 2006; see also Blumburg, 2000; McGuire, 1985). As such, important information about the detailed process of attention allocation as a function of health threat and self-relevance of the persuasive message is missing. In the present study we sought evidence for the hypothesis that although high threat information might cause more attention capture than neutral information because of its evolutionary value (e.g., Koster, Crombez, Van Damme et al., 2004), people for whom the high threat information is self-relevant (i.e. smokers) will be better able to disengage themselves from this negative information than those for whom the negative information is less self-relevant (i.e. non-smokers). The latter prediction is in line with Kunda's argument of motivated reasoning and with recent experimental findings (alluded to earlier) that show that peo- 
ple for whom the health message is self-relevant produce an attentional bias away from threatening health information when affirmation resources are missing (W. M. P. Klein \& Harris, 2009) and tend to spend less time reading the high threat message (Brown \& Locker, 2009).

We investigated the early visual selective attention processes in response to selfrelevant health threat information by using Posner's (1980) cueing paradigm. More specifically, we used a variant of Posner's cueing paradigm in which participants reacted to a target (here two horizontal or two vertical dots) presented at the left or right visual field. This target was preceded by a cue (i.e., high and low threat smoking pictures) at either the target location (valid trials; $82 \%$ ) or at the opposite location (invalid trials; $18 \%$ ). In this paradigm, valid trials encourage rapid behavioural responses because the presented cue directs the attention immediately to the correct location. In invalid trials, attention must be disengaged from the incorrect location and has to be reallocated towards the target position. Reactions to the valid trials thus reflect attention capture processes and reactions to the invalid trials reflect attention holding (disengagement) processes (Koster, Crombez, Van Damme et al., 2004; Posner et al., 1984). We tested smokers and nonsmokers to introduce the factor of self-relevance (high vs. low) of the health threat information.

Our main hypotheses focused on the reactions to the targets in the invalid trials, reflecting disengagement processes. We expected that people react defensively to selfrelevant threatening health information by disengaging from it. In other words, smokers will more easily disengage attention from high threat smoking pictures than will those less affected by the health threat (non-smokers). Therefore, we hypothesized that smokers would need fewer resources to disengage their attention from the cued location to the invalid target location in the high as opposed to low threat conditions. Because the use of less attention resources is reflected in lower P300 amplitudes and faster reaction times, we expect lower P300 amplitudes and faster reaction times for the high threat invalid trials than for the low threat invalid trials. For non-smokers, we did not expect these effects because of the absence of defensive responses.

For the reactions to the targets in the valid trials, reflecting attention capture processes, we expected the same pattern of results for smokers and non-smokers. Attention will be directed to imminent threat automatically because of its survival value resulting in more attention capture preferences for high threat as opposed to low threat smoking pictures for both smokers and non-smokers. Because the use of more attention resources is reflected in higher P300 amplitudes and faster reaction times, this general attention bias for high threat smoking stimuli above neutral stimuli (e.g., Koster, Crombez, Van Damme et al., 2004) will result in faster reaction times and higher P300 amplitudes for the high threat than for the low threat valid trials (cf. Ito, Larsen, Smith, \& Cacioppo, 1998). 
Method

\section{Participants and Experimental Design}

Thirty psychology undergraduate students took part in the experiment, fifteen daily smoking ( 7 women) and fifteen non-smoking students ( 8 women). A self-report measure of smoking behaviour (i.e., "How many cigarettes do you smoke a day?") showed that smoking participants smoked on average $6.75(S D=4.93)$ cigarettes a day. Non-smoking participants reported never having smoked. Smoking and non-smoking students were 18 to 25 years of age $(M=21 ; S D=1.5)$, right handed, and reported having normal or corrected-to-normal vision. Participants were recruited from various public places at the university and took part for course credits. The experiment varied the level of threat of the smoking pictures (low vs. high) and validity of the trials (valid vs. invalid) as withinsubjects factors and included smoking status (smoker vs. non-smoker) as a betweensubjects factor. Because the data set of one female smoking participant could not be used because of too many movement artifacts and eye movements, 29 participants remained in the sample and were included in the analyses.

\section{Materials}

Thirty colored smoking-related pictures with a high or a low threatening content were used as cues in the cueing task. The high threat stimuli contained pictures with black lungs, children near smoking cigarettes, skeletons with a smoking cigarette and other images that illustrate the negative health consequences of smoking. The low threat pictures showed smoking cigarettes, packages of cigarettes, people smoking a cigarette and other images that do not directly focus on the negative health consequences of smoking (see Figure 1 for examples). The selection of the thirty smoking pictures was based on a pilot study where we presented 120 smoking pictures among 16 smoking and 16 nonsmoking undergraduate students. They had to rate on 9-point scales the perceived level of threat ( $1=$ not at all, $9=$ very much) and arousal $(1=$ calm, $9=$ excited $)$ for each smoking picture. Finally, we made a selection of fifteen high threat smoking pictures with a minimum score of 4.5 on both scales and fifteen low threat smoking pictures with a maximum score of 3 on both scales. The thirty selected pictures were used as stimulus material for the main experiment. The pictures $(11.8$ by $8.5 \mathrm{~cm})$ were presented at the left or right side of the midpoint of a 17 inch computer screen (distance: $8 \mathrm{~cm}$ ). The target stimuli were either two horizontal (. .) or two vertical (:) dots. Throughout the whole experiment a fixation cross was presented in the middle of the computer screen (see Figure 2 for an outline of the cueing task). 

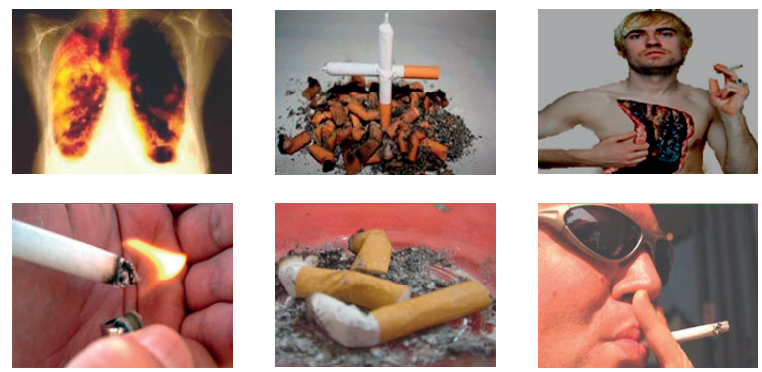

Figure 1. Examples of three high threat pictures (top row) and three low threat pictures (bottom row) used as cues in the present study.

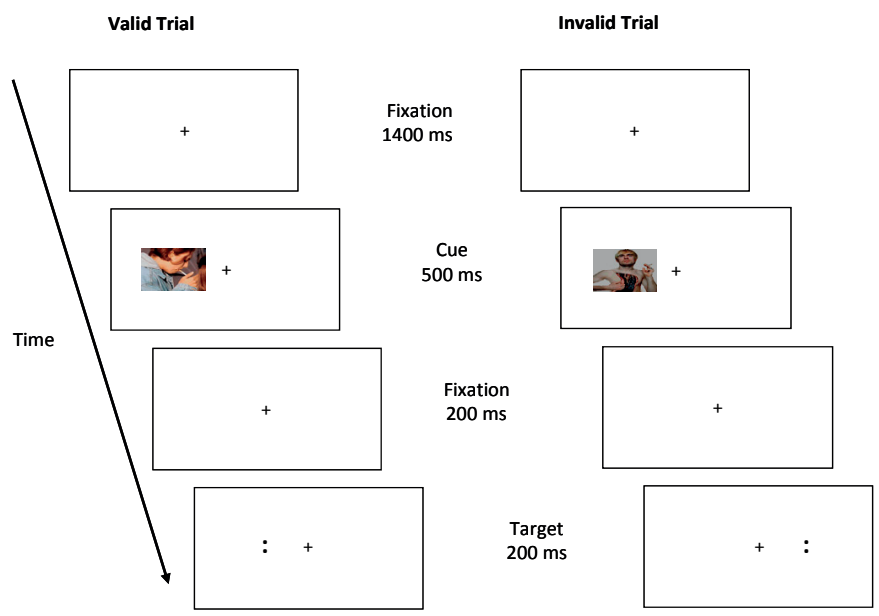

Figure 2. Illustration of the experiment. The valid trial shows an example of the low threat smoking pictures and the invalid trial shows an example of the high threat smoking pictures.

\section{Procedure}

The study took place in a dimly lit, sound-attenuating, electrically shielded cabin. After the electrode cap was mounted the participants sat in a chair approximately $80 \mathrm{~cm}$ from the monitor displaying the stimuli and the experimental task was explained to them. In each trial of the cueing task a fixation period of $1400 \mathrm{~ms}$ was followed by a high or low threatening cue for $500 \mathrm{~ms}$ (see Figure 2). After a second fixation period of $200 \mathrm{~ms}$, a 
target stimulus was presented for $200 \mathrm{~ms}$, either on the same side of the screen as the cue (valid trial) or on the opposite side of the screen (invalid trial). In the valid condition ( $82 \%$ of trials) the cue correctly indicated the position of the upcoming target. In the invalid condition ( $18 \%$ of trials), the cue appeared on the field opposite to the subsequent target. The inter-trial interval was 2300 ms. The cue-target combinations were intermingled randomly within each experimental run. Participants were instructed to keep their eyes fixated on the fixation cross and to press as quickly as possible the left button when two horizontal dots were presented as target and to press the right button when two vertical dots were presented.

Before the start of the experiment, participants were told that the probability of a valid trial was larger than the probability of an invalid trial. A practice block of two minutes trained participants to respond correctly to the target while keeping their gaze fixed to the fixation cross. The experimental session consisted of 1320 trials (cue and target) with 1080 valid trials and 240 invalid trials. Within the valid and invalid trials, type and presentation side of the two different targets (horizontal and vertical dots) were counterbalanced. Following the cueing task, participants had to evaluate each smoking picture on the perceived level of threat $(1=$ not at all, $9=$ very much $)$ and arousal $(1=$ calm, $9=$ excited). The whole experiment lasted about 2 hours including the mounting and removal of the electrode cap.

\section{Measures}

Reaction times and errors. Button-press responses were measured from target onset. Errors consisted of mistakes (pressed right for horizontal dots and pressed left for vertical dots), misses (no button press), and reactions faster than $120 \mathrm{~ms}$.

EEG and ERPs. The EEG was recorded from 30 scalp sites (an extended version of the $10 / 20$ system) with tin electrodes mounted in an electrode cap, with the electrodes referenced online to the left mastoid signal. A bipolar montage, with electrodes placed on the right and left external canthus, recorded horizontal eye movements. Vertical eye movements and eye blinks were measured by a bipolar montage of electrodes placed on the upper and lower orbital ridge of the left eye. The electro-oculogram was recorded for later off-line rejection of trials contaminated with eye movements. All electrode impedances (EEG and electro-oculogram) were kept below $5 \mathrm{k} \Omega$.

EEG and electro-oculogram signals were digitized at $250 \mathrm{~Hz}$ sampling rate and amplified by using a 32-channel NeuroScan SynAmps amplifier. The continuous EEG was filtered off-line with a bandpass filter of 0.05 to $30 \mathrm{~Hz}$. For ERP analysis, epochs of $1500 \mathrm{~ms}$ were obtained from the continuous EEG signal, starting $100 \mathrm{~ms}$ before onset of the cue and ending $700 \mathrm{~ms}$ after target offset. The $100 \mathrm{~ms}$ pre-cue interval was used as a baseline. Epochs containing artifacts, including eye movements, beyond -100 and $100 \mu \mathrm{V}$ were 
removed before analysis; the overall rejection rate of the analyzed trials was $21 \%$. Finally, ERPs were derived by averaging for each participant the EEG sequences for each combination of threat, validity, and electrode site. Subsequently, a grand average of these individual ERP data for each experimental condition and electrodes site was calculated per smoking status group.

\section{Analyses}

Reaction times and errors were subjected to mixed ANOVAs with the within-subjects factors threat (high vs. low) and validity (valid vs. invalid trials) and the between-subjects factor smoking status (smoker vs. non-smoker). ERP analyses were restricted to the midline electrodes $\mathrm{Fz}, \mathrm{FCz}, \mathrm{Cz}, \mathrm{CPz}$, and $\mathrm{Pz}$ because the peak amplitudes were largest for these midline electrodes and the expected attention effects are generally largest for the midline electrodes (Johnson, 1993; Polich, 2007). Because of the unequal distribution of the number of valid and invalid trials, different ERP response patterns on reactions to the target stimuli were expected as a function of validity. Therefore separate mixed ANOVA analyses were performed for the reactions on the valid and the invalid targets with threat (high vs. low) and electrodes (5) as within-subjects factors and smoking status (smokers vs. non-smokers) as between-subjects factor. Significant interactions were followed by simple effect analyses. To control for sphericity violations in the mixed ANOVAs, we report probability values with Greenhouse-Geisser correction for $F$ tests with more than one degree of freedom in the numerator. The reported estimates of the effect size are partial eta squared $\left(\eta_{p}^{2}\right)$ for the analyses of variance and Cohen's $d$ for the paired samples $t$-tests.

\section{Results}

\section{Error Analysis}

Mean percentages of errors, omissions, premature responses (reactions faster than 120 $\mathrm{ms}$ ) and trials with EEG-artefacts that were removed from the data are presented in Table 1. For the number of errors on the target detection task, a significant interaction between validity and smoking status was found, $F(1,27)=5.03, p<.05, \eta_{p}^{2}=.16$. A paired samples $t$ test showed that smokers made more errors on invalid trials than on valid trials, $t(13)=$ $2.90, p<.05, d=.65$. For non-smokers no difference in the number of errors was detected between the invalid and valid trials, $t(14)=.01, p=.99, d=.01$. No further main effects or interactions involving the factors threat or smoking status were found for the 
proportion of EEG artefacts, the number of omissions, and premature responses, Fs < $3.04, n s, \eta_{p}^{2}<.10$. For the final analyses we used $79 \%$ of the original data.

\section{Reaction Times}

Table 1 presents mean reaction times to the target stimuli (horizontal and vertical dots). The mixed ANOVA revealed a significant main effect of validity, $F(1,27)=141.90, p<$ $.001, \eta_{p}^{2}=.84$. As expected, reaction times to the targets were faster for the valid targets than for the invalid targets. No further main effects or interactions involving the factors threat and smoking status were found, $F s<2.59, n s, \eta_{p}^{2}<.09$.

Table 1. Behavioural Performance Measures as a Function of Trial Validity, Threat and Smoking Status

\begin{tabular}{|c|c|c|c|c|c|c|c|c|}
\hline \multirow[b]{3}{*}{ Variable } & \multicolumn{4}{|c|}{ Valid } & \multicolumn{4}{|c|}{ Invalid } \\
\hline & \multicolumn{2}{|c|}{ High Threat } & \multicolumn{2}{|c|}{ Low Threat } & \multicolumn{2}{|c|}{ High Threat } & \multicolumn{2}{|c|}{ Low Threat } \\
\hline & $M$ & $S D$ & $M$ & $S D$ & $M$ & $S D$ & $M$ & $S D$ \\
\hline \multicolumn{9}{|l|}{ Reaction Time (ms) } \\
\hline Smokers & 470 & 46 & 471 & 47 & 498 & 52 & 493 & 49 \\
\hline Non-smokers & 488 & 56 & 490 & 59 & 514 & 59 & 513 & 55 \\
\hline \multicolumn{9}{|l|}{ Omission } \\
\hline Smokers & 6.84 & 12.13 & 7.00 & 12.79 & 7.62 & 12.88 & 7.44 & 12.68 \\
\hline Non-smokers & 4.52 & 1.03 & 4.41 & 7.66 & 5.11 & 8.09 & 4.72 & 7.58 \\
\hline \multicolumn{9}{|l|}{ Premature } \\
\hline Smokers & 0.04 & 0.15 & 0.03 & 0.10 & 0.00 & 0.00 & 0.00 & 0.00 \\
\hline Non-smokers & 0.01 & 0.05 & 0.00 & 0.00 & 0.00 & 0.00 & 0.06 & 0.22 \\
\hline \multicolumn{9}{|l|}{ Error } \\
\hline Smokers & 1.93 & 1.31 & 1.88 & 1.31 & 3.45 & 2.63 & 2.86 & 2.83 \\
\hline Non-smokers & 2.33 & 1.86 & 2.27 & 1.67 & 2.67 & 2.46 & 1.94 & 1.77 \\
\hline \multicolumn{9}{|l|}{ EEG artifact } \\
\hline Smokers & 8.49 & 9.08 & 11.22 & 12.05 & 6.67 & 7.74 & 8.10 & 9.84 \\
\hline Non-smokers & 10.63 & 9.75 & 13.48 & 13.19 & 9.94 & 8.79 & 11.33 & 10.22 \\
\hline \multicolumn{9}{|l|}{ Total reject } \\
\hline Smokers & 17.30 & 11.96 & 20.12 & 16.66 & 17.74 & 11.82 & 18.39 & 13.17 \\
\hline Non-smokers & 17.49 & 11.07 & 20.16 & 14.56 & 17.72 & 10.18 & 18.05 & 11.96 \\
\hline
\end{tabular}

Note. Unless otherwise indicated, all values are percentages. 


\section{ERP Analyses}

Visual inspection. Visual inspection of the ERP waves on reaction to the target stimuli shows the expected P300 effect between approximately 360 and 560 ms after target presentation (see Figure 3 and 4). For the invalid trials, smokers provided lower peak amplitudes for the high threat trials than for the low threat trials (see Figure 3). For nonsmokers, no difference in peak amplitudes on reaction to the invalid trials is visible (see Figure 3). Reactions to the valid trials show for both groups higher peak amplitudes for the high threat trials than for the low threat trials (see Figure 4).

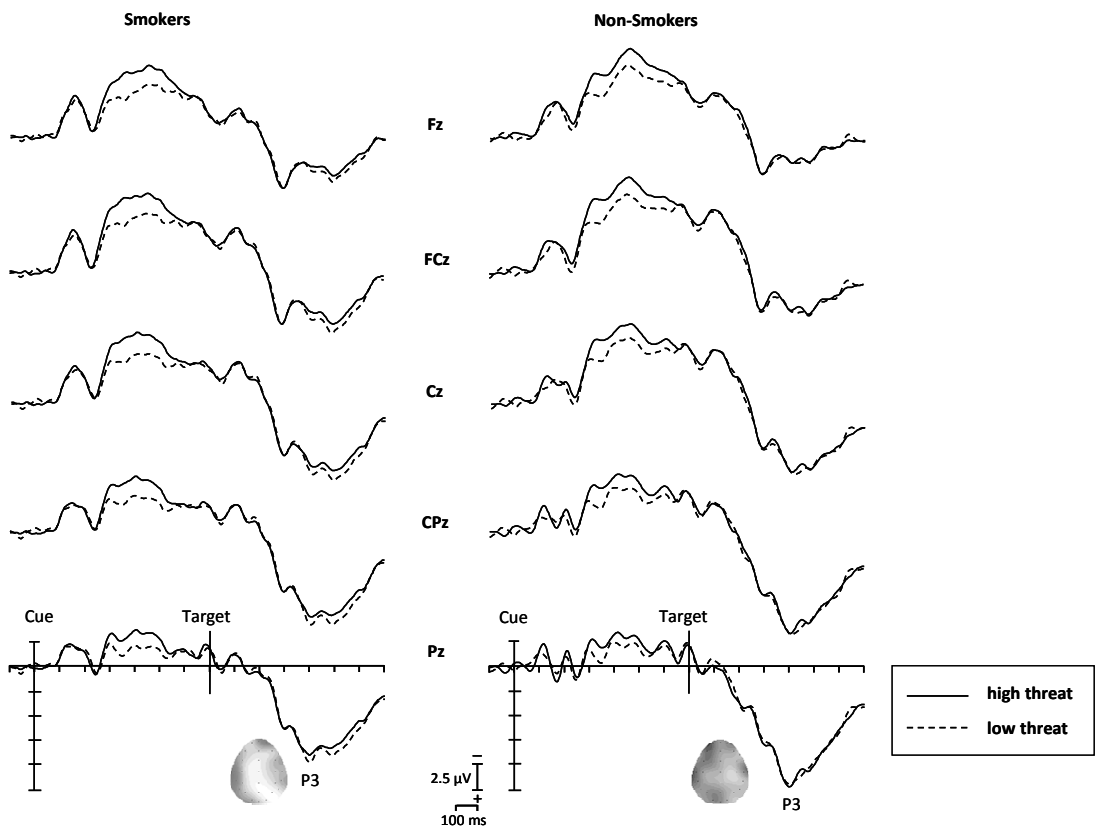

Figure 3. Grand average ERP waveforms by condition and group for the invalid trials. Scalp distribution maps present the signal distribution for the P300 component. For the P300 component, topographical maps were computed by subtracting low from high threat condition for the invalid trials at $392 \mathrm{~ms}$ after target presentation with a maximum of $1 \mu \mathrm{V}$ (dark grey) and a minimum of $-1 \mu \mathrm{V}$ (white). Electrode locations are marked by blocks. 


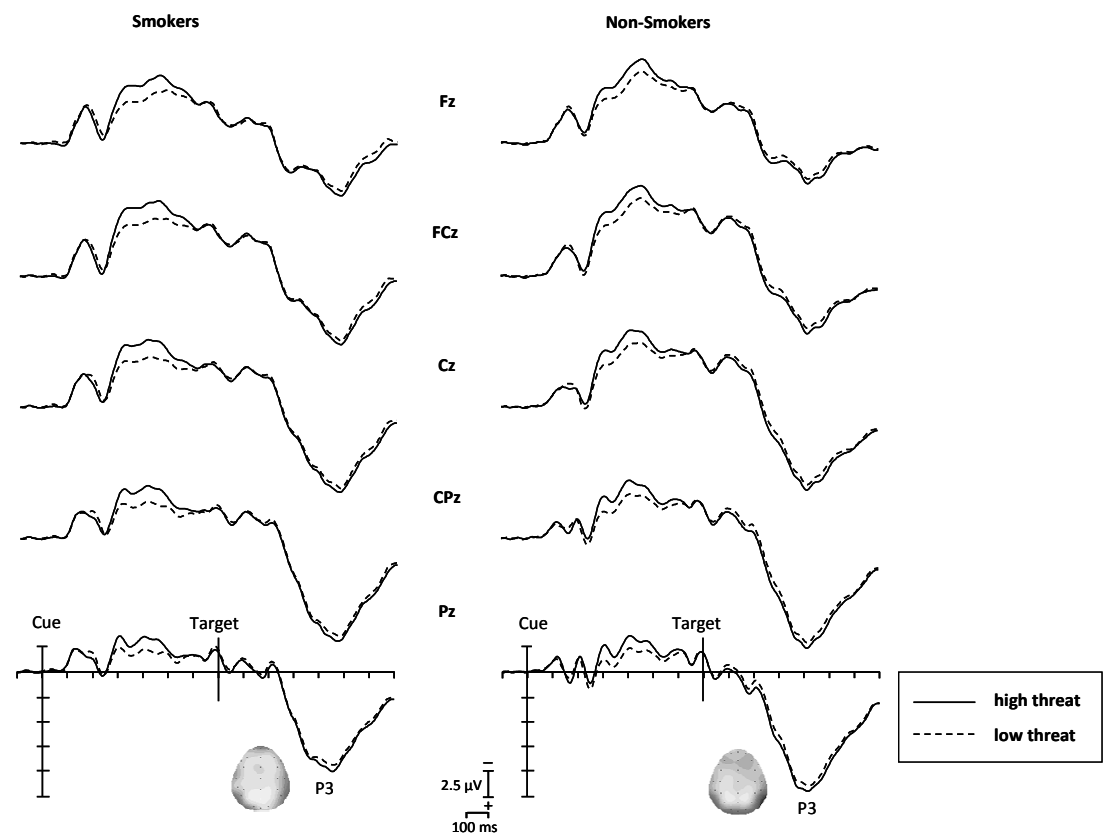

Figure 4. Grand average ERP waveforms by condition and group for the valid trials. Scalp distribution maps present the signal distribution for the P300 component. For the P300 component, maps were computed by subtracting high from low threat condition for the valid trials at $384 \mathrm{~ms}$ after target presentation with a maximum of $1 \mu \mathrm{V}$ (dark grey) and a minimum of $-1 \mu \mathrm{V}$ (white). Electrode locations are marked by blocks.

P300. Mixed ANOVAs for the invalid trials revealed a significant interaction between threat and smoking status, $F(1,27)=4.80, p<.05, \eta_{p}^{2}=.15$, and a significant main effect of electrodes, $F(4,108)=52.92, p<.001, \eta_{p}^{2}=.66$. Separate analyses for each level of smoking status showed for smokers the expected pattern with lower P300 amplitudes for the high threat than for the low threat trials, $F(1,13)=16.22, p<.01, \eta_{p}^{2}=.55$. Although all electrodes showed lower P300 amplitudes for the high as opposed to the low threat trials (see Table 2), the topographical map of the signal distribution indicates that the expected P300 effect was most strongly concentrated at the central-parietal electrodes (See Figure 3 ). For non-smokers, only a main effect of electrodes was found, $F(4,56)=34.27, p<$ $.001, \eta_{p}^{2}=.71$.

For the valid trials the mixed ANOVA revealed a significant main effect of threat, $F(1,27)$ $=21.32, p<.001, \eta_{p}^{2}=.44$, and a main effect of electrodes, $F(4,108)=54.12, p<.001, \eta_{p}^{2}=$ .67. Higher P300 amplitudes were found for the high as opposed to the low threat trials 
across electrode sites and smoking status (see Table 2). The topographical map of the signal distribution showed a central-parietal distribution of the P300 effect in reaction to the valid trials (See Figure 4). ${ }^{1}$

Table 2. Amplitudes ( $\mu \mathrm{Vs}$ ) of the P300 Effect as a Function of Trial Validity, Threat and Smoking Status

\begin{tabular}{|c|c|c|c|c|c|c|c|c|}
\hline \multirow[b]{3}{*}{ Electrode } & \multicolumn{4}{|c|}{ Valid } & \multicolumn{4}{|c|}{ Invalid } \\
\hline & \multicolumn{2}{|c|}{ High Threat } & \multicolumn{2}{|c|}{ Low Threat } & \multicolumn{2}{|c|}{ High Threat } & \multicolumn{2}{|c|}{ Low Threat } \\
\hline & $M$ & $S D$ & $M$ & $S D$ & $M$ & $S D$ & $M$ & $S D$ \\
\hline \multicolumn{9}{|l|}{$\mathrm{Fz}$} \\
\hline Smokers & 6.33 & 4.47 & 5.74 & 4.47 & 5.33 & 4.13 & 6.13 & 4.50 \\
\hline Non-smokers & 5.36 & 3.62 & 4.65 & 3.51 & 5.22 & 4.62 & 5.47 & 4.40 \\
\hline \multicolumn{9}{|l|}{$\mathrm{FCz}$} \\
\hline Smokers & 8.15 & 5.26 & 7.57 & 5.51 & 6.44 & 4.91 & 5.57 & 5.28 \\
\hline Non-smokers & 7.08 & 4.86 & 6.38 & 4.90 & 6.73 & 5.49 & 6.81 & 5.61 \\
\hline \multicolumn{9}{|l|}{$\mathrm{Cz}$} \\
\hline Smokers & 9.95 & 5.18 & 9.43 & 5.43 & 8.53 & 5.28 & 9.53 & 5.49 \\
\hline Non-smokers & 9.61 & 5.48 & 8.95 & 5.62 & 8.91 & 5.59 & 9.09 & 5.89 \\
\hline \multicolumn{9}{|l|}{$\mathrm{CPz}$} \\
\hline Smokers & 11.78 & 4.61 & 11.30 & 4.75 & 9.96 & 4.65 & 11.42 & 4.78 \\
\hline Non-smokers & 12.42 & 5.62 & 11.73 & 5.72 & 11.67 & 5.54 & 12.01 & 5.68 \\
\hline \multicolumn{9}{|l|}{$\mathrm{Pz}$} \\
\hline Smokers & 11.44 & 3.84 & 10.90 & 3.56 & 9.99 & 3.82 & 11.14 & 3.66 \\
\hline Non-smokers & 13.29 & 5.55 & 12.75 & 5.60 & 13.34 & 5.80 & 13.34 & 5.51 \\
\hline
\end{tabular}

${ }^{1}$ Because our hypotheses were focused on processes of attention holding and attention disengagement we restricted the analyses to the responses on the targets in both valid and invalid trials. Visual inspection of the ERP waves in Figures 3 and 4 however clearly shows a late negativity component, peaking between 280 and 500 ms after cue presentation, with more negative amplitudes for the high threat trials than for the low threat trials. Subsequent analyses confirmed this main effect of threat, $F(1,27)=42.14, p<.001, \eta_{p}^{2}=.61$, which was not further qualified by validity of the trials or smoking status of the participants ( $p s>.12, \eta_{p}^{2}<.09$ ). 
Self-report Measures

Mixed ANOVAs showed that, independent of smoking status, the high threat pictures were judged as being more 'threatening' and more 'arousing' than the low threat pictures, $F(1,27)=91.90, p<.001, \eta_{p}^{2}=.77$ and $F(1,27)=102.85, p<.001, \eta_{p}^{2}=.79$, respectively (see Table 3 for the mean scores).

Table 3. Scores on Perceived Threat and Arousal Scales as a Function of Threat

\begin{tabular}{|c|c|c|c|c|}
\hline \multirow[b]{3}{*}{ Variable } & \multicolumn{4}{|c|}{ Threat } \\
\hline & \multicolumn{2}{|c|}{ High } & \multicolumn{2}{|c|}{ Low } \\
\hline & $M$ & $S D$ & $M$ & $S D$ \\
\hline \multicolumn{5}{|l|}{ Threat } \\
\hline Smokers & 5.13 & 1.22 & 2.40 & 1.39 \\
\hline Non-smokers & 4.73 & 2.03 & 2.22 & 0.84 \\
\hline \multicolumn{5}{|l|}{ Arousal } \\
\hline Smokers & 5.51 & 1.28 & 2.60 & 1.17 \\
\hline Non-smokers & 5.31 & 1.69 & 2.80 & 1.29 \\
\hline
\end{tabular}

\section{Discussion}

In an adapted visual selective attention paradigm, investigating the early stage of information processing, we found neuroscientific support for our hypothesis that threatening health information causes more efficient attention disengagement (less attention holding) among those for whom the health threat is self-relevant. As predicted, smokers (but not non-smokers) showed a decreased P300 amplitude in response to high as opposed to low threat smoking stimuli on invalid trials, indicating the use of less attentional resources when disengaging attention from the previously cued (threatening) location. The expectation that this finding would also result in faster reaction times for the high threat compared to the low threat invalid trials was not supported.

For non-smokers no difference in P300 activity was found in reaction to the high versus low threat invalid trials. This finding indicates that non-smokers, for whom the information was supposed to be less self-relevant, have no attention holding (attention disengagement) preferences for high vs. low threat smoking pictures.

Besides our specific attention disengagement hypothesis we predicted, based on the attention preference mechanism for imminent threat, more attention capture for high as opposed to low threat pictures for both smokers and non-smokers (Koster, Crombez, Van 
Damme et al., 2004). Support for our hypothesis was observed in the parietal distributed P300 amplitudes in reaction to the valid targets, with higher amplitudes for the high threat than for the low threat trials. This finding indicates that both smokers and nonsmokers used increased resources to capture attention for high threat smoking information irrespective of whether the information was self-relevant or not. Again the reaction time data did not mirror these ERP data.

Our ERP findings for the smoking participants are in line with the view that people are motivated to reduce feelings of cognitive dissonance (Festinger, 1957; Kunda, 1990). While previous studies used self-report measures or implicit measures of reading time and response time, the present study provided evidence for motivated reasoning through the use of attention measures during message processing (Brown \& Locker, 2009; W. M. P. Klein \& Harris, 2009). The ERP findings showed that smokers disengaged more efficiently from high threat as opposed to low threat health information, implicating that people whose self-image was threatened tried to avoid the high threat information. The ERP findings thus indicate that avoidance responses can already arise at the early process of attention allocation.

Following a previous study from Pollak and Telley-Schell (2003) we used an emotional component in a spatial cueing task. On behavioural measures, the more standard variants of the cueing task normally show reaction times benefits and higher accuracy rates for valid over invalid trials (Pollak \& Tolley-Schell, 2003). The present study partially supported these findings, with faster reaction times for valid instead of invalid trials for both smoking status groups, and a higher accuracy rate in response to valid instead of invalid trials for the group of smokers. Besides this typical validity effect, there were however no further differences between experimental conditions in reaction times. This suggests that at the end of the cognitive process (during motor preparation) any influence of the combined effect of threat level and message relevance on information processing was cancelled out. In contrast, the ERP waves show a fine grained difference in time windows earlier than response preparation. Indeed, the combination of ERP and RT findings in the present study suggest that attention is modulated by message relevance and threat level rather early on in the cognitive processing of health information.

Furthermore, the observation that the RT measures did not support the interaction between the level of threat and smoking status observed in the ERP data for the invalid trials indicates that the ERP measure can be extremely informative. The method of ERP in future health communication research can be a useful tool to measure low-level attention biases that are nonetheless relevant in health communication.

A limitation of the present study is that we did not include a 'no-cue' condition whereby the target stimuli were presented without any previous warning, which could have served as a reference point to investigate the 'validity effect' on the reaction times (Perchet \& Garcia-Larrea, 2000; Posner, Inhoff, Friedrich, \& Cohen, 1987; Posner et al., 1984; Swanson et al., 1991). Using a no-cue condition is common in behavioural studies 


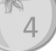

using the cueing task, but less often used when ERP-measures are added as a dependent measure because those trials may introduce another confound, namely that of surprise or unanticipated stimuli (Jonides \& Mack, 1984; Pollak \& Tolley-Schell, 2003). Because we did not include no-cue trials we could not conclude whether the 'validity effect' we found was attributable to a cost associated with an invalid cue or a benefit associated with a valid cue.

The present findings indicate that whether high threat health information attracts and holds attention is dependent upon whether the information is self-relevant or not. In line with previous research, indicating that high threat health information causes denial as a coping strategy (Brown \& Locker, 2009), the use of high threat information may be counterproductive for people performing the risky behaviour. As previous studies proposed, message recipients could be prepared for potentially distressing messages by using prior affirmative experiences (Brown \& Locker, 2009; Harris et al., 2007). While selfaffirmation techniques can enhance attention biases toward threat information (W. M. P. Klein \& Harris, 2009), future studies should explore with online attention measures whether the use of self-affirmation techniques prior to message exposure diminishes attention disengagement processes, for example by using the attention cueing task.

In conclusion, the present study, in which we used a well-validated spatial cueing task, showed that high threat smoking pictures capture more attention processes than low threat smoking pictures both in smokers and non-smokers. At the same time, high threat smoking pictures caused more efficient disengagement processes than low threat smoking pictures, but only in smokers. Neuroscientific support was thus found for previous self-report findings that showed that self-relevant health information leads to more defensive reactions when the message contains high instead of low threat information. 


\section{Chapter 5}

Explicit and implicit neural mechanisms for the processing of threatening smoking pictures among smokers and non-smokers:

A functional magnetic resonance imaging study

The chapter is in preparation for submission as: Kessels L.T.E., Van de Ven, V.G., \& Ruiter, R.A.C. Explicit and implicit neural mechanisms for the processing of threatening smoking pictures among smokers and non-smokers: A functional magnetic resonance imaging study. 
Introduction

Presenting threatening health information by highlighting the negative consequences of unhealthy behaviour is often used to motivate people into behaving more healthily. A recent example of this practice is the worldwide introduction of graphic warnings labels on cigarette packages, following recommendations of the World Health Organisation's Framework Convention on Tobacco Control and - for member states of the European Union - Directive 2003/641/EC of the European Committee (see also Harris et al., 2007; Ruiter \& Kok, 2005, 2006).

Several studies have hypothesized that threat perception and fear arousal heighten the relevance of threat-relevant information and, therefore, result in more attentive (systematic) processing of threat-relevant persuasive information (Baron et al., 1994; Gleicher \& Petty, 1992; Ruiter, Abraham et al., 2001; Ruiter, Kok et al., 2001). The findings concerning the effects of threatening information on the systematic processing of health information are, however, not conclusive. Studies that presented threatening health information to those for whom the health threat was high as opposed to low self-relevant suggest an opposite effect of threatening health information on message attention (Freeman et al., 2001; Harris \& Napper, 2005; Keller, 1999; Keller \& Block, 1999; Liberman \& Chaiken, 1992; Sherman et al., 2000; Taubman - Ben-Ari et al., 2000). In particular, people for whom the health message had high personal relevance seemed to process the threat information more defensively than people who already followed the recommendations (see also Harris et al., 2007; Harris \& Napper, 2005; Noar et al., 2007; Sherman et al., 2000). Experimental findings show that people for whom the health message is selfrelevant produce an attention bias away from threatening health information when affirmation resources are missing, reflected in slower response times to message-relevant threatening stimuli and less reading time of threatening health information (Brown \& Locker, 2009).

Evidence for the defensive processing of self-relevant threatening health information has also been found at the neural level. In a recent study, we investigated whether reduced acceptance of self-relevant health risk information is already visible in early attention processes, i.e. attention disengagement processes (Kessels, Ruiter, \& Jansma, in press). In an adapted visual selective attention paradigm combined with measures of event-related potentials (ERPs), we found that both smokers and non-smokers responded more efficiently to a target appearing on the same location as a preceding picture when this picture was a high threat smoking picture than a when this picture was a low threat smoking picture, thus demonstrating a general attention capture effect of threatening health information. However, we also found that smokers responded more easily to a differently located target when this target was preceded by a high threat smoking picture than by a low threat smoking picture. This effect was not observed in non-smokers. The latter finding supports our hypothesis that threatening health information causes more 
efficient attention disengagement among those for whom the health threat is selfrelevant (Kessels et al., in press).

Although the ERP results provided detailed timing information about attention processes for self-relevant health risk information, no information was obtained about which brain areas were involved in these attention processes. Therefore, the present study used functional magnetic resonance imaging (fMRI) to measure with relatively high spatial resolution widespread (whole brain) neural correlates involved in the processing of selfrelevant high and low threatening health information. The brain responses of participants to threatening health messages were investigated by studying brain activation during the exposure to high and low threatening smoking pictures among smokers (high selfrelevance) and non-smokers (low self-relevance).

At a more general level, the present study uses cognitive neuroscience methods to address applied research questions to gain a better understanding of the cognitive mechanisms that underlie persuasion (cf. S. E. Taylor, 2008). Thus far, no published neuroimaging studies have investigated the neural effects of self-relevant threatening stimuli. Existing fMRI studies of the neural basis of processing self-relevant threatening visual stimuli are restricted to non self-relevant emotional stimuli (Habel et al., 2007; Ochsner et al., 2009; Wright et al., 2008) or to non-emotional self-relevant stimuli (Rameson, Satpute, \& Lieberman, 2010).

\section{The neural basis of processing self-relevant emotional information}

Neuroimaging studies investigating emotion processing most often use two different types of stimuli, e.g., expressive faces and complex evocative pictures to induce affective processing (Britton, Taylor, Sudheimer, \& Liberzon, 2006). Both emotional stimulus types activate similar structures involved in emotion processing, including the amygdala (Breiter et al., 1996; Liberzon, Phan, Decker, \& Taylor, 2003; Morris et al., 1996), hippocampus (Gur, Schroeder et al., 2002; Lane et al., 1997), insula (Phan et al., 2004; Phillips et al., 1997), anterior cingulated cortex (ACC, Killgore \& Yurgelun-Todd, 2004; Morris et al., 1998), medial prefrontal cortex (mPFC, Kim, Somerville, Johnstone, Alexander, \& Whalen, 2003; S. F. Taylor, Phan, Decker, \& Liberzon, 2003; Winston, O'Doherty, \& Dolan, 2003), ventromedial prefrontal cortex (VMPFC, Phan et al., 2004), orbitofrontal cortex (OFC, Blair, Morris, Frith, Perrett, \& Dolan, 1999), and visual cortex (Liberzon et al., 2003; Morris et al., 1998). A neuroimaging study directly comparing brain activation patterns to emotional facial expressions and to complex emotional pictures showed similar activation patterns in the amygdala, posterior hippocampus, vMPFC, and visual cortex (Britton et al., 2006). Furthermore, a recent meta-analysis associated processing of fearful faces with activation in bilateral amygdala and fusiform gyrus, right cerebellum, left inferior parietal lobule, left inferior frontal and right medial frontal gyrus (Fusar-Poli et al., 2009). The neural correlates of emotion processes thus include a network of cortical and subcortical 
structures, with a central role for the amygdala (Habel et al., 2007; Vuilleumier, 2005). The amygdala may serve a critical role in the emotion network. The amygdala is able to prompt fast and automatic responses and is often called the 'gateway to the emotions' (Aggleton \& Mishkin, 1986). A meta-analysis modelling the probability of amygdala activation during the processing of different types of emotional stimuli (e.g., fear, disgust, happiness, humour) indicated that, while all types of emotional stimuli were more likely to activate the amygdala than neutral stimuli, fear and disgust were the most likely emotions to result in amygdala activation (Costafreda et al., 2008).

Amygdala activation was also detected in neuroimaging studies investigating neural correlates for self-relevant non-emotional stimuli (Rameson et al., 2010). The activation in the amygdala suggested that participant processed the otherwise neutral information in an affective manner because of its self-relevance. However, no previous studies investigated neural correlates for self-relevant stimuli with an emotional content.

\section{Present study}

Previous behaviour and ERP research has indicated that self-relevant emotional information may induce defensive responses in early attention processes (Freeman et al., 2001; Harris \& Napper, 2005; Kessels et al., in press). The current study explored the neural correlates involved in the processing of self-relevant threatening health information. Our goal was to investigate the neural mechanisms of defensive reactions while processing self-relevant threatening health information. The factor of self-relevance was created through testing smokers and non-smokers, and we used functional magnetic resonance imaging (fMRI) to investigate the processing of smoking pictures at different levels of perceived health threat in these two subject groups. The threatening smoking pictures were thought to be self-relevant for smokers because they reflect their own smoking behaviour or the consequences of their own smoking behaviour; these pictures were not personally relevant to non-smokers.

Pictures were presented to the participants in two different contexts. In the explicit threat processing task, participants were asked to indicate if they perceived a smoke picture as a high or low threat. The explicit task was designed to isolate the neural correlates of explicit self-relevant threat processing. In the implicit threat processing task, participants saw the same stimuli but were asked to detect if the stimulus display contained a non-threat target object (the presence or absence of a hand). The implicit task was used to investigate brain responses during implicitly processed self-relevant threat information.

We hypothesized that high threat picture processing (explicitly and implicitly) would increase activation in the amygdala and other brain areas of the emotion network, compared to low threat pictures (i.e., threat modulation of brain activity) irrespective of smoking status. Based on previous findings showing stronger amygdala activation during 
explicit processing than during implicit processing, we expected larger threat modulation for the explicit task than for the implicit task (e.g., Gur, Sara et al., 2002; Gur, Schroeder et al., 2002).

Furthermore, we expected that the overall threat effect in the amygdala is modulated by self-relevance. Smokers compared to non-smokers, are expected to show defensive reactions towards self-relevant threat information. We hypothesized that these defensive reactions, reflected in less attention for the information, involve the amygdala. If amygdala shows decreased activation in reaction to self-relevant threatening health information this will subsequently lead to less attention for the information. Therefore, we hypothesized the threat modulation in the amygdala would be smaller for smokers than for non-smokers.

Finally, based on previous research showing defensive reactions when attention was paid to the content of the self-relevant threatening stimuli (Brown \& Locker, 2009) we expected this smaller threat modulation for smokers compared to non-smokers at an explicit level, but not at an implicit level.

\section{Method}

\section{Participants}

Twenty-nine undergraduate students took part in the experiment, fifteen daily smoking (10 females) and fourteen non-smoking students (7 females). Smoking participants smoked at least 5 cigarettes a day $(M=10 ; S D=5.71)$ for at least one year. Non-smoking participants reported never having smoked. Participants were 19 to 29 years of age (Smokers: $M=21.67 ; S D=1.95$; Non-Smokers: $M=23.07 ; S D=3.02 ; t(29)=1.58, p=.12$ ), right handed, neurologically healthy, and had normal or corrected-to-normal visual acuity. Participants gave informed written consent and took part for course credits or were paid for their participation. Just before the start of the experiment smoking participants were asked to smoke a cigarette in order to minimize the urge to smoke.

\section{Stimuli}

We selected smoking-related pictures from a pilot study, in which we presented 120 smoking pictures to 16 smoking and 16 non-smoking individuals (who did not participate in the current study) using Authorware Macromedia 5.0. Participants had to rate each smoking picture according to the perceived levels of threat and arousal on a 9-point scale (threat: $1=$ not at all, $9=$ very much; arousal: $1=$ calm, $9=$ excited). For the imaging experiment, we selected 36 high-threat and 36 low-threat stimuli from the rated picture 
et. Selected high-threat pictures had a minimum score of 3.8 on both rating scales (threat: $M=4.89 ; S D=.47$; arousal: $M=4.76 ; S D=.58$ ), selected low-threat pictures had a maximum score of 3.5 on both scales (threat: $M=2.78 ; S D=.20$; arousal: $M=2.73 ; S D=$ .21). The selected high- and low-threat pictures differed significantly in threat $(t(35)=$ $24.03, p<.01)$ and arousal $(t(35)=18.62, p<.01)$. Furthermore, each set of selected pictures contained 18 pictures with a hand presented in the picture, and 18 pictures without a hand in the picture.

Of the 72 selected pictures, 24 pictures were used for practice trials containing 6 pictures from each category (high-threat with hand, high-threat without hand, low-threat with hand, low-threat without hand). The remaining 48 pictures were used as stimulus material for the main experiment.

\section{Experimental Design}

In the main experiment, participants pressed the left or the right button to indicate whether the currently viewed picture was a high or a low threatening picture (explicit threat task) or whether the picture contained a hand or no hand (implicit threat task; see Figure 1). Trials of the same type of task were presented in blocks that lasted 81 seconds each. In each block, 6 different smoking pictures were presented in the middle of the screen. Each picture was presented for 3 seconds, followed by the presentation of a fixation cross at a variable interval (range, 6,9 or 12 seconds). Prior to each block participants briefly saw an instruction (explicit threat vs. implicit threat) for the fashion of responding of the upcoming block followed by a fixation cross of 3 seconds. The four different picture categories were equally distributed over the implicit and explicit blocks. In one functional run, four explicit and four implicit blocks were presented in a fixed order (E-I-I-E-E-I-E-I; E = Explicit; I = Implicit). All 48 pictures were presented in a random order within one run. Participants completed two functional runs, in which all pictures were equally divided across conditions. Thus, each participant responded to each picture twice, once according to the explicit threat instructions and once according to the implicit threat setting. Between the two runs there was a short break. Accuracy and reaction time data were collected during the scanning sessions. 


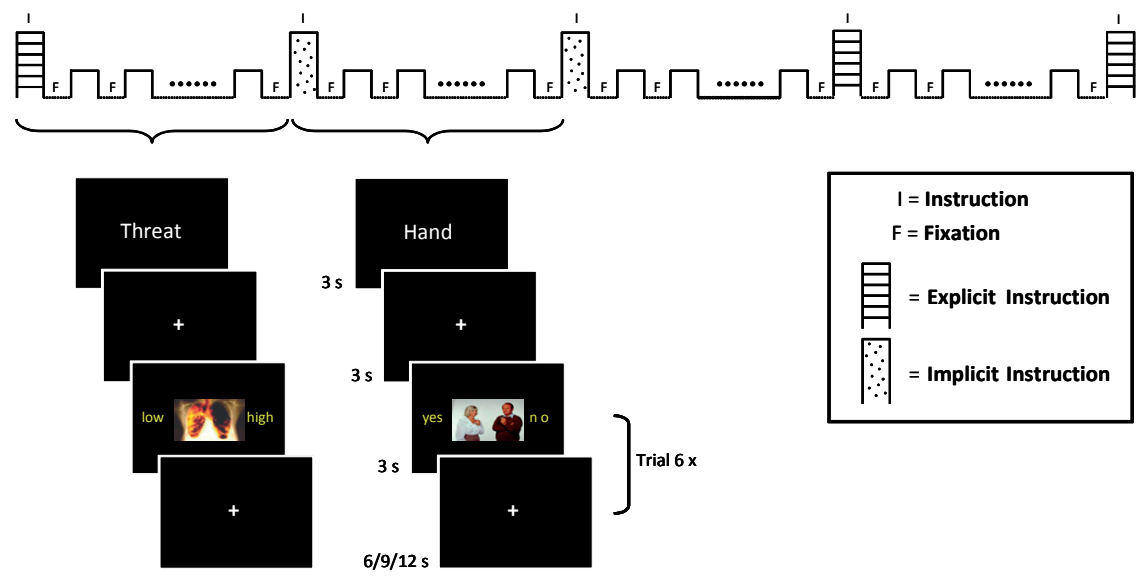

Figure 1. Graphical outline of the stimulation protocol used in this fMRI experiment. Stimuli in this experiment were presented in a mixed design involving two experimental conditions: Implicit (with or without hand) and explicit (low or high threat). Stimuli were presented in the centre of the participants' visual field. At the beginning of each block the task instruction (hand or threat) was presented indicating the task. Left and right button responses were indicated on the left and right side of the picture.

\section{Procedure}

Prior to entering the scanner, each participant assessed the urge to smoke a cigarette on a paper-pencil visual analogue scale (VAS; $100 \mathrm{~mm}$ range, $0=$ no urge, $100=$ maximum urge). Participants were trained on a practice task outside the scanner, which was similar to the experimental task inside the scanner. For the practice trials 42 pictures were presented that were not used in the main experiment. During MR scanning, participants performed two functional runs of the main experiment. After acquisition of the MR images participants left the MRI room and completed the urge to smoke VAS for a second time.

\section{fMRI Data Acquisition}

MR images were acquired using a 3T Siemens Magnetom Allegra Head-only Scanner at the Maastricht Brain Imaging Centre (MBIC). A birdcage volume coil was used for radio frequency (RF) transmission and reception. Each blood-oxygen-level dependent (BOLD) echoplanar volume scan consisted of 45 transverse slices parallel to the intercommissural (AC-PC) line (in plane matrix $=128 \times 96$; pixel size $=2 \mathrm{~mm}^{2}$; slice thickness $=2.5 \mathrm{~mm}$; no 
gap between slices; $\mathrm{TE}=25 \mathrm{~ms} ; \mathrm{TR}=3000 \mathrm{~ms}$ ). Each functional run consisted of 221 whole-brain volumes. In the same scanning session a high-resolution whole brain anatomical T1-weighted scan was acquired: $(T R=2250 \mathrm{~ms}, \mathrm{TE}=2.6 \mathrm{~ms}$, flip angle $=9 \mathrm{deg}, 1$ $\left.\mathrm{mm}^{3}\right)$.

\section{fMRI Data Preprocessing}

Anatomical and functional images were preprocessed and analyzed using Brainvoyager QX (v 1.9; www.brainvoyager.com). The first two volumes of the functional time series were discarded to remove magnetic saturation effects from the analysis. Preprocessing included slice scan timing correction (using cubic spline interpolation), motion correction (using a 3D rigid-body transformation of each volume to the first volume of each run and using trilinear interpolation) and high-pass filtering to remove low-frequency noise (linear trend removal and removal of up to three cycles per time series). Functional images were spatially smoothed with an $8 \mathrm{~mm}$ full-width-at-half-maximum (FWHM) isotropic Gaussian kernel. The anatomical images were resampled in standardized space (Talairach \& Tournoux, 1988) at $1 \mathrm{~mm}^{3}$. Functional images were aligned to the anatomical images and resampled in standardized space at a voxel size of $3 \mathrm{~mm}^{3}$.

\section{Data Analyses}

Urge to Smoke. The mean scores of the urge to smoke VAS measured before and after the MR scanning were entered into one-samples t-tests to test whether smokers and non-smokers reported an urge to smoke before or after the MR scanning. To investigate whether the urge to smoke scores differed between the two time measurements a paired samples t-test was used.

Reaction Times. Reaction time differences as a function of the different task conditions and participant groups were investigated using a mixed model analysis of variance (ANOVA) with task (explicit vs. implicit) and threat (low threat vs. high threat) as withinsubject factors and smoking status (non-smoker vs. smoker) as between-subjects factor.

\section{Functional MRI Data Analysis}

Region-of-interest analysis. The main part of the analysis centred on the investigation of response amplitudes as a function of task conditions and participant group within regions of interest (ROIs) that were modulated by the level of threat of the presented stimuli. We identified ROIs in the following manner: Using the general linear model (GLM) for fMRI analysis (Friston, 1996; Worsley \& Friston, 1995), we calculated for each participant the linear model fits (i.e., $\beta$ values) of high and low threat during implicit and explicit 
tasks. Time series of the two runs of each participant were mean- and variancestandardized and concatenated. For each participant, we calculated threat modulation scores (i.e., $\beta_{\text {mod }}=\beta_{\text {high-threat }}-\beta_{\text {low-threat }}$ ). Group results of all participants (regardless of participant group) were obtained by one-sample t-tests of the $\beta_{\text {mod }}$ values across participants ( $\mathrm{df}=28$ ). Group results were corrected for multiple comparisons using a falsediscovery rate (FDR) of $q=0.03$ (Genovese, Lazar, \& Nichols, 2002) and for a minimum cluster size of 6 contiguous functional voxels (Forman et al., 1995). Clusters of voxel tvalues that survived the correction procedures were used for consecutive ROI analysis (Table 1). For each ROI, mixed model analysis was used to test for effects of task and participant group (and the task $x$ group interaction) on the individual $\beta$ values.

To explore whether brain activation in the amygdala correlated with behavioural responses we computed correlation coefficients between $\beta$ values of the amygdala and reaction times and recognition accuracy (mean percent correct) in the explicit task for smokers and non-smokers. $\beta$ Values for the left and right amygdala were averaged.

To control for sphericity violations in the ANOVAs, we corrected linear model estimates using the Greenhouse-Geisser correction for F-tests with more than one degree of freedom in the numerator. Further, we calculated effect sizes for significant results ( $p \leq$ $0.05)$ using the partial eta squared $\left(\eta_{p}^{2}\right)$ for the ANOVAs and eta squared $\left(\eta^{2}\right)$ for the paired-samples t-tests (i.e., within-subject tests). 
Table 1. Talairach coordinates for high threat vs. low threat smoking pictures

\begin{tabular}{lccccc}
\hline Brain Region & Hemisphere & Tal (x) & Tal (y) & Tal (z) & Size \\
\hline High Threat > Low Threat & & & & & \\
$\quad$ Visual Area & L & -41 & -59 & -11 & 40847 \\
& $\mathrm{R}$ & 37 & -62 & -9 & 40789 \\
Amygdala & $\mathrm{L}$ & -24 & -7 & -9 & 1886 \\
& $\mathrm{R}$ & 24 & -4 & -7 & 548 \\
Inferior Frontal Gyrus & $\mathrm{L}$ & -46 & 21 & 20 & 28801 \\
& $\mathrm{R}$ & 47 & 16 & 25 & 8800 \\
Caudate Nucleus & $\mathrm{R}$ & 10 & 2 & 8 & 408 \\
Inferior Parietal Lobe & $\mathrm{L}$ & -30 & -67 & 36 & 9160 \\
& $\mathrm{R}$ & 29 & -64 & 43 & 192 \\
Insula & $\mathrm{R}$ & 24 & -4 & -7 & 548 \\
Parahippocampal Gyrus & $\mathrm{R}$ & 30 & -1 & -24 & 539 \\
Thalamus & $\mathrm{R}$ & 14 & -10 & 17 & 188 \\
Superior Frontal Gyrus & $\mathrm{L}$ & -7 & 28 & 52 & 7815 \\
Low Threat > High Threat & & & & & \\
Cingulate Sulcus & $\mathrm{L}$ & -14 & -47 & 43 & 190 \\
& $\mathrm{~L}$ & -16 & -37 & 34 & 166 \\
& $\mathrm{~L}$ & -19 & -21 & 37 & 286 \\
Precuneus & $\mathrm{R}$ & 10 & -40 & 42 & 2327 \\
\hline
\end{tabular}

\section{Results}

\section{Self-report Measures}

Independent sample t-tests showed a main effect of smoking status on the reported urge to smoke before the start of the fMRI scanning session, $t(27)=4.58, p<.001, d=1.73$, and at the end of the fMRI scanning session, $t(27)=7.99, p<.001, d=3.03$. Smokers reported a higher urge to smoke $(M=2.17 ; S D=1.74)$ than non-smokers $(M=0.04 ; S D=$ .13) before the start of the $f M R I$ scanning session. The mean levels of the urge to smoke at the end of the fMRI scanning session were also higher for smokers $(M=4.59 ; S D=$ 
2.14) than for non-smokers $(M=.00 ; S D=.00)$. Smokers reported a significant higher urge to smoke at the end of the fMRI scanning session than before the start of the fMRI scanning session, $t(14)=3.36, p<.01$. For non-smokers the level of craving did not differ between both time measurements, $t(13)=1.00, p=.34$.

\section{Reaction Times}

An overview of the mean reaction time scores can be found in Table 2. A mixed ANOVA on the reaction times showed significant main effects of threat, $F(1,27)=8.43, p<.01, \eta_{\mathrm{p}}^{2}$ $=.24$, and task, $F(1,27)=51.92, p<.001, \eta_{p}^{2}=.66$, but not of smoking status, $F(1,27)=$ $2.17, p=.15, \eta_{p}^{2}=.07$. Participants responded slower in reaction to high threat trials than to low threat trials. Furthermore, participants responded slower in the explicit than in the implicit task. Besides the main effects, the overall mixed ANOVA revealed a significant interaction between threat and task, $F(1,27)=5.79, p<.05, \eta_{p}^{2}=.18$. Smoking status showed no significant interactions involving the factors threat and task, $F<3.40, p>.08$, $\eta_{p}^{2}<.11$.

In parsing the interaction effect, separate paired samples t-tests showed that in the implicit task participants responded slower to high threat pictures than to low threat pictures, $t(28)=9.21, p<.001, \eta^{2}=0.75$. In the explicit task reaction times to high and low threat pictures did not differ, $t(28)=-.03, p=.98, \eta^{2}=.00$. In addition, for both high threat pictures and low threat pictures responses were slower in the explicit task than in the implicit task, $t(28)=4.28, p<.001, \eta^{2}=0.40$ and $t(28)=6.46, p<.001, \eta^{2}=0.60$, respectively.

Table 2. Behavioural performance measures as a function of task, threat and smoking status (with means and standard deviations)

\begin{tabular}{lcccccccc}
\hline & \multicolumn{4}{c}{ Explicit } & \multicolumn{7}{c}{ Implicit } \\
& \multicolumn{1}{c}{ Low Threat } & High Threat & Low Threat & High Threat \\
Electrode & $M$ & $S D$ & $M$ & $S D$ & $M$ & $S D$ & $M$ & $S D$ \\
\hline Error & 13 & 23 & 28 & 28 & 2 & 8 & 8 & 7 \\
$\quad$ Smokers & 9 & 15 & 14 & 14 & 2 & 6 & 3 & 7 \\
$\quad$ Non-smokers & & & & & & & & \\
Reaction Time (ms) & 1696 & 424 & 1737 & 374 & 1376 & 223 & 1548 & 266 \\
$\quad$ Smokers & 1562 & 262 & 1522 & 205 & 1302 & 237 & 1386 & 248 \\
$\quad$ Non-smokers & 152 &
\end{tabular}

Note. Unless otherwise indicated, all values are percentages 
Categorisation Analysis

Mean percentages of deviant categorisation frequencies made in the explicit and the implicit task are shown in Table 2. A mixed Threat $x$ Task $x$ Smoking Status ANOVA revealed significant main effects of task, $F(1,27)=18.22, p<.001, \eta_{p}^{2}=.40$, and smoking status, $F(1,27)=3.54, p<.05, \eta_{p}^{2}=.12$. Participants made more deviant categorisations in the explicit task than in the implicit task and smokers made more deviant categorisations than non-smokers. The interaction between task and smoking status was not significant, $F(1,27)=.81, p=.38, \eta_{p}^{2}=.03$, neither were any effects that involved the factor threat, $F s>1.71, p s>.20, \eta_{p}^{2} s<.06$.

\section{Functional MRI Data}

Whole brain analyses for $\mathrm{ROI}$ selection. Brain regions that were significantly positively modulated by threat (i.e., high threat > low threat; pooled for explicit and implicit tasks; $p<.05$ ) included left and right amygdala, the bilateral visual area, the inferior frontal gyrus, the caudate nucleus, the inferior parietal lobe, the right insula, the right parahippocampal gyrus, the right thalamus, and the left superior frontal gyrus (see Table 1). Brain regions that were significantly negatively modulated by threat (i.e., low threat $>$ high threat) included left and right cingulated sulcus and the left precuneus. Together the ROls outlined an emotion processing network, including the amygdala (See Figure 2). Threat modulation scores in these ROls were used in subsequent analyses to further explore effects of task and group. 


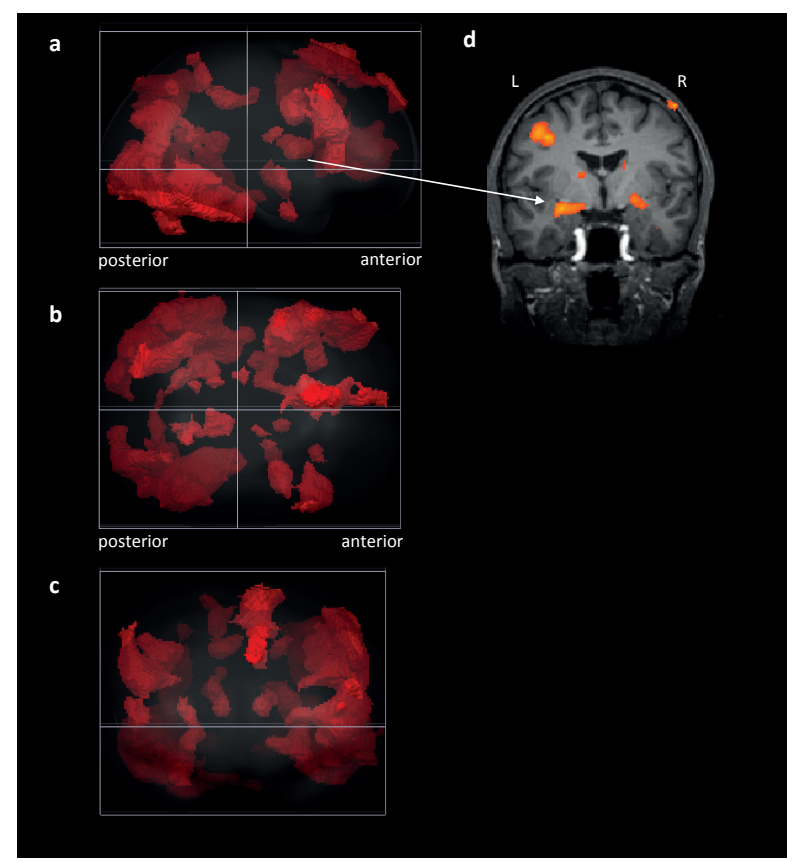

Figure 2. Whole brain activation maps with superimposed F-map [ANOVA F-test: high threat > low threat, $F D R<0.03$, cluster size threshold $>6$ voxels], indicated in red all ROls with significant BOLD activity for the contrast of threat. Standardized anatomical coordinates of the ROIs are presented in Table 1. 3D Views represent: (a) sagittal, (b) tranverse, and (c) coronal view. Coronal view of the left amygdala (d) represents voxels activated for high threat versus low threat picture processing. $\mathrm{L}=$ Left; $\mathrm{R}=$ Right.

ROIs. Within the left amygdala, the mixed ANOVA on the difference scores of threat (high minus low) with the factors task and smoking status revealed no significant main effects of task, $F(1,27)=1.40, p=.25, \eta_{p}^{2}=.05$, and smoking status, $F(1,27)=.81, p=.38, \eta_{p}^{2}$ $=.03$, or a significant interaction between task and smoking status, $F(1,27)=.19, p=.67$, $\eta_{\mathrm{p}}^{2}=.01$. For the right amygdala no significant support was found for a main effect of task, $F(1,27)=1.93, p=.18, \eta_{p}^{2}=.07$, and smoking status, $F(1,27)=1.31, p=.26, \eta_{p}^{2}=.05$, or the interaction between task and smoking status, $F(1,27)=.00, p=.99, \eta_{\mathrm{p}}^{2}=.00$. Hence, threat modulation of activity in the left and right amygdala did not differ between the explicit or implicit task or between smokers and non-smokers (see Figure 3). 


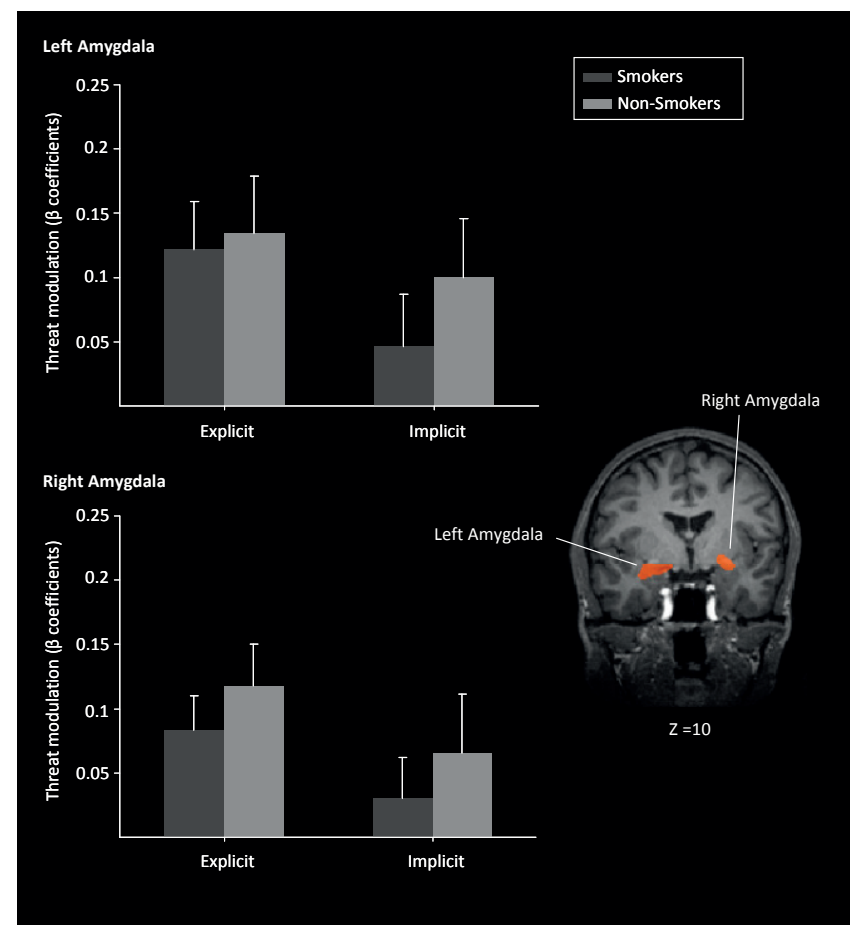

Figure 3. ROI bar plots of the left and right amygdala represent threat modulation scores $\left(\beta_{\bmod }=\right.$ $\beta_{\text {high-threat }}-\beta_{\text {low-threat }}$ ) with standard errors. Coronal view of the selected regions of interest (left and right amygdala) is presented on the right.

Mixed ANOVAs on the difference scores for the other ROls showed a main effect of task for the left inferior parietal lobe, $F(1,27)=6.49, p<.05, \eta_{p}^{2}=.19$, and for the right inferior frontal gyrus, $F(1,27)=4.02, p=.05, \eta_{p}^{2}=.13$. Threat modulation of parietal activity was larger in the implicit task $(M=.15 ; S D=.12)$ than in the explicit task $(M=.08 ; S D=$ .14). Threat modulation of frontal activity was also larger in the implicit $(M=.18 ; S D=$ $.14)$ than in the explicit task $(M=.10 ; S D=.16)$. Figure 4 visualizes these significant effects.

A marginally significant main effect of smoking status was found for the basal ganglia (left caudate nucleus), $F(1,27)=3.40, p=.07, \eta_{\mathrm{p}}^{2}=.11$, with a stronger threat modulation for non-smokers $(M=.12 ; S D=.09)$ than for smokers $(M=.05 ; S D=.11)$ (see Figure 4). Furthermore, separate Mixed ANOVAs for the ROls showed no significant interactions involving the factors smoking status and task. 
Correlation analyses. In the correlation analyses we correlated recognition accuracy of the explicit task with brain activity of the amygdala ROls (see Figure 5). Because task effects were similar in left and right amygdala ROls, activity of these ROIs were averaged. For smokers, recognition accuracy and amygdala activity were marginally significantly correlated $(r=-0.50, p=.06)$. For non-smokers this correlation was not significant $(r=$ $0.06, p=.84)$. Comparing the correlation coefficients between smokers and non-smokers did not reveal a significant difference $(z=1.46 ; p=0.14)$.

Correlation analysis between recognition accuracy and amygdala activity in the implicit task revealed no significant correlations for smokers $(r=-.01, p=.98)$ and nonsmokers $(r=.35, p=.22)$. 


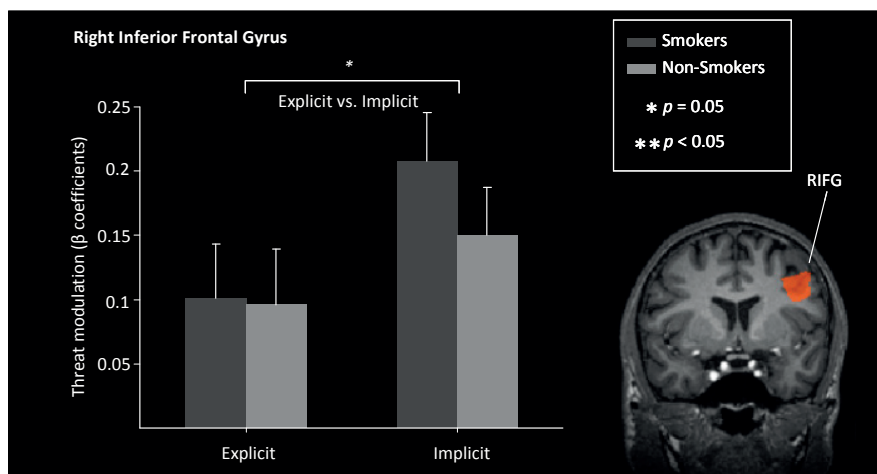

Left Inferior Parietal Lobe
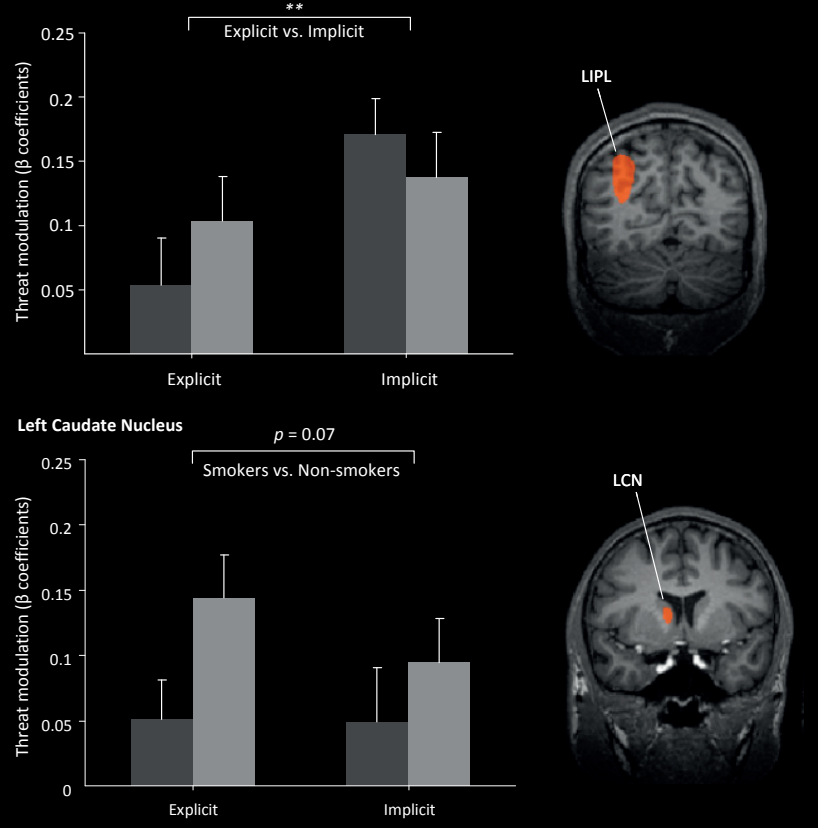

Figure 4. ROI bar plots of the right inferior frontal gyrus, the Left inferior parietal lobe and the left caudate nucleus represent threat modulation scores $\left(\beta_{\text {mod }}=\beta_{\text {high-threat }}-\beta_{\text {low-threat }}\right)$ with standard errors. Coronal views of the selected regions of interest are presented on the right. 

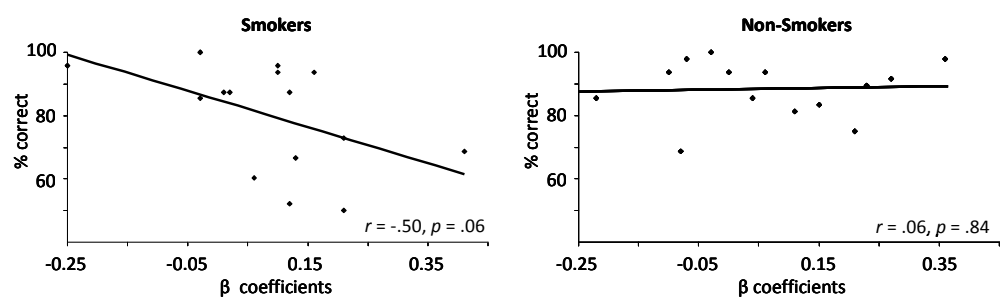

Figure 5. Scatterplot of correlation analysis between $\beta$ coefficients of the amygdala (left and right amygdala averaged) and recognition accuracy for explicit emotion processing across smokers (left) and non-smokers (right) indicating a significant negative correlation between emotion recognition accuracy and amygdala responses for smokers only.

\section{Discussion}

The current neuroimaging study investigated the role of self-relevance during explicit and implicit processing of threatening health information. In a mixed event-related design, our results showed a threat modulation of activation in the amygdala regardless of task context (i.e., explicit versus implicit). Furthermore, amygdala activity correlated with perceived threat in the smokers, but not in the non-smokers. Threat modulation was also observed in other emotion and visual perception areas, including bilateral visual area (including the fusiform gyrus, the middle temporal gyrus and the inferior temporal gyrus), inferior frontal gyrus, caudate nucleus, inferior parietal lobe, right insula, right parahippocampal gyrus, right thalamus, and left superior frontal gyrus. Threat modulation of the left inferior parietal lobe and inferior frontal gyrus was stronger in the implicit task than in the explicit task. Brain regions did not show smaller threat modulations in smokers compared to non-smokers.

Behavioural results showed slower responses and more deviant categorizations in the explicit than in the implicit task. Furthermore, implicit judgments were slower for high threat pictures than for low threat pictures. Finally, smokers made more deviant categorizations than non-smokers.

The results of the ROI analyses suggest that implicit and explicit processing of threat information partly depend on similar neural structures (Scheuerecker et al., 2007). However, the left inferior parietal lobe and the inferior frontal gyrus did show differential activity between the two tasks. These areas have been associated with implicit emotional processing (Price, Wise, \& Frackowiak, 1996; Scheuerecker et al., 2007). Furthermore, the increased activity in left inferior frontal gyrus during the implicit task may be associated with a greater role of attentional selection, compared to the explicit task. According to a 
central thesis of a selection hypothesis the left inferior frontal gyrus serves as a general mechanism for selecting among competing representations (Zhang, Feng, Fox, Gao, \& Tan, 2004). Our implicit task may have induced a larger requirement for visual search and object selection from the visual scene, because participants had to detect a hand in the picture. No particular visual search or object selection was required for the explicit task.

It is possible that threat modulation in the amygdala did not differ between explicit and implicit processing as a result of the repeated viewing of the emotional pictures (Gur, Schroeder et al., 2002). The chance of spontaneously evaluating stimuli increases when training in emotional evaluation (Wright et al., 2008). Consequently, the observed activation patterns in the left and right amygdala could reflect automatic cognitive or associative processing of the pictures even though participants received the implicit task instruction to judge whether a hand was visible.

No support was found for a difference in the amygdala between smokers and nonsmokers when processing high threat information. Although the activation pattern of the amygdala in the explicit and implicit task showed lower $\beta$ coefficients for smokers than for non-smokers, this difference between smokers and non-smokers did not reach significance. Correlation analyses between amygdala activation and recognition accuracy provided support for a difference in amygdala involvement between smokers and nonsmokers. The $\beta$ coefficients of the amygdala and the recognition accuracy in the explicit task showed a significant negative correlation for smokers and a non-significant correlation for non-smokers. The higher level of deviant categorisations when judging high threat pictures compared to low threat pictures could explain this negative correlation among smokers. Although the difference was non-significant, smokers categorized a high threat picture more often as a low threat picture than they judged a low threat picture as a high threat picture. It is possible that a high threat picture that was categorized as a low threat picture still caused an emotional reaction in the amygdala. For non-smokers no significant correlation was found between amygdala response and behavioural responses during explicit processing. These findings for smokers and non-smokers implicate that self-relevance of the information has no influence in the initial evaluation of a smoking stimulus as the amygdala responses showed no significant differences between smokers and non-smokers, but does make a difference during complex processing such as their labelling.

$\mathrm{ROI}$ analyses of other brain areas of the emotion network showed no effects of selfrelevance in threat modulation. This result appears at odds with previous studies that showed the involvement of MPFC, precuneus and dorsomedial PFC in the processing of self-relevant or self-referential information (Lieberman, 2010; Rameson et al., 2010). These studies, however, differed from our study in one important aspect. While previous self-relevance studies utilized paradigms that explicitly asked participants to judge whether a broad variety of adjectives were self-descriptive, in the present study no explicit judgments of self-descriptiveness had to be made. For example, in the study of 
Rameson et al. (2010), participants judged the self-descriptiveness of self-schematic and non-self-schematic material. In contrast, in our study the factor of self-relevance was created through testing smokers and non-smokers while seeing smoking related information. Within these groups, the processing of self-relevance may not be required to ascertain the perceived level of threat of the smoking pictures. Smoking individuals could have processed their perceived levels of threat of the smoking pictures without reverting to explicit judgments of self-reference or self-description. A future study may include selfdescriptive judgments about non-smoking related material to further explore the role of self-relevance during threat processing.

It is possible that our paradigm of explicit and implicit processing was not optimal to measure defensive processing for self-relevant threat information. For example, our paradigm did not include selective attention processes. A previous ERP study showed defensive responses to self-relevant threat information while measuring spatial selective attention processes (Kessels et al., in press). Also, participants were slower to respond in the explicit task than they were in the implicit task, which may indicate that the explicit task was more difficult than the implicit task. The different difficulty levels of the tasks may have influenced the emotional impact of the threat stimuli and consequently influenced amygdala activation (Habel et al., 2007; Pessoa, Japee, Sturman, \& Ungerleider, 2006).

A final limitation was the relatively small sample size, which, especially in the context of between-subject effects, resulted in a relatively low statistical power. For example, regional effects in the amygdala showed lower threat modulations for smokers compared to non-smokers, but this effect did not reach significance. Increasing the number of participants for both groups may increase the significance level in the expected direction.

In conclusion, the current study showed that well-known emotion areas were activated in reaction to threatening smoking pictures. Self-relevance of the information did not make a difference in brain activation in the amygdala. No support was found for a difference between smokers and non-smokers in brain activation in the amygdala, which indicated that smokers did not respond in a more defensive manner than non-smokers. However, non-smokers reported a higher percentage of categorization accuracy than smokers, indicating that personal relevance of the information influenced the complex process of labelling of the information. More research is needed to explore the neural correlates of processing self-relevant threatening information. 



\section{Chapter 6}

I spy with my little eye for help, not for threat: Attention for health messages on cigarette packages

Submitted for publication as: Kessels, L.T.E. \& Ruiter, R.A.C. I spy with my little eye for help, not for threat: Attention for health messages on cigarette packages. 
Introduction

An important goal of health education messages is to encourage and motivate people to engage in health promoting and disease preventive behaviours. A prerequisite for achieving this goal is that people have attention for the persuasive message they are exposed to (Blumberg, 2000; McGuire, 1985). One way to achieve attention for the health information is to explicitly present the severe consequences of risky behaviours performed by the target population, presumably because negative information is believed to attract more attention than positive information (see also Baumeister, Bratslavsky, Finkenauer, \& Vohs, 2001; N. K. Smith, Cacioppo, Larsen, \& Chartrand, 2003; S. E. Taylor, 1991). Nowadays, as a result of the recommendations of the World Health Organisation's Framework Convention on Tobacco Control and - for member states of the European Union - Directive 2003/641/EC of the European Committee, cigarette packages include health warnings (e.g., "Smoking causes fatal long cancer") with the aim to motivate people to refrain from smoking (but see Harris et al., 2007; Ruiter \& Kok, 2005, 2006).

Explanatory models of human decision making and behaviour suggest that increased risk perception is an important determinant of people's motivation to adopt safer and healthier behavioural alternatives (Fishbein et al., 2000; Leventhal, 1970; Maddux \& Rogers, 1983; Witte, 1992). Although threatening health information is often used in health messages to increase risk perceptions (for an overview, see Ruiter, Abraham et al., 2001), the evidence regarding the effectiveness of threatening health information on measures of protection motivation and behaviour change has been mixed (e.g., Barlow \& Wogalter, 1993; Brown \& Locker, 2009; Croyle et al., 1997; Ditto \& Croyle, 1995; Fischer, Richards, Berman, \& Krugman, 1989; Freeman et al., 2001; Keller, 1999; Keller \& Block, 1999; Krugman et al., 1994; Liberman \& Chaiken, 1992; MacKinnon \& Lapin, 1998; D. J. Smith, 1990; Snyder \& Blood, 1992; Thomsen \& Fulton, 2007). While self-relevant information usually attracts attention from the reader (Kreuter et al., 1999; Ruiter et al., 2006), a large body of experimental research suggests that people who are most at risk, have the least attention for the risk information, report the least motivation to change, and subsequently react defensively to the message by means of avoidance and denial. Early empirical support for the counterproductive effects of health messages was reported by Liberman and Chaiken (1992). In an experimental study, they demonstrated that coffee drinkers were less critical of information questioning the link between caffeine and fibrocystic disease and more critical of information supporting the link than non-coffee drinkers (for similar findings, see e.g., Brown \& Locker, 2009; Brown \& Smith, 2007; Croyle et al., 1997; Ditto \& Croyle, 1995; Freeman et al., 2001; Keller, 1999; Keller \& Block, 1999).

To take action, individuals need to know what to do and have to believe that they are capable to perform the action (Bandura, 1997). Self-efficacy refers to a person's belief of being capable to successfully perform a behaviour (Bandura, 1986). For a range of 
health-related behaviours such as smoking cessation, exercise and diet, increases in selfefficacy were strongly associated with behaviour change and maintenance (Forsyth \& Carey, 1998). In addition, meta-analyses of social cognition models of human behaviour, among which the theory of planned behaviour and protection motivation theory have identified self-efficacy (or perceived behavioural control) and not risk perception as a major predictor of protection motivation (de Vries \& Backbier, 1994; Floyd et al., 2000; Godin \& Kok, 1996; Maibach \& Murphy, 1995; Milne et al., 2000; Witte \& Allen, 2000).

While self-efficacy is one of the most widely applied constructs across theories of health behaviour and presenting coping information might increase levels of self-efficacy (Woodgate \& Brawley, 2008), coping information is only rarely presented in health messages in the public domain (Moriarty \& Stryker, 2008). For example, only 2 of the 14 recently introduced graphic warnings labels on cigarette packages in the European Community provide information that might aid smokers with translating intention to quit smoking into quitting behaviour ('Your doctor or pharmacist can help you stop smoking' and 'get help to stop smoking: 0803000000 '),

See also: http://ec.europa.eu/health/ph_determinants/life_style/Tobacco/Documents/ com_1452_a_en.pdf.

\section{Eye-movement registration}

An essential prerequisite for effective communication is attention for the health information (Blumberg, 2000; McGuire, 1985). Although some studies have shown that risk information triggers message avoidance, especially for whom the information is selfrelevant, less is known about attention processes for coping information in mass media campaigns (Moriarty \& Stryker, 2008). In general, the effects of message features and personal characteristics on processes of attention allocation have not been addressed systematically in persuasion research (for an exception, see Ruiter et al., 2006). In the present study, we chose to use the method of eye-movement registration to measure attention processes for health information. Eye-movement registration enables us to measure the course of attention over longer periods of time (Thomsen \& Fulton, 2007). Eye movements, as important indicators of visual attention (Krugman et al., 1994; Wedel \& Pieters, 2000), compromise a sequence of fixations (i.e., discrete periods of immobility of the eye) and saccades (i.e., quick jumps between fixation locations). During fixating, attention is paid to the stimulus and information is extracted, whereas during saccades vision is basically suppressed (Rayner, 1998; Wedel \& Pieters, 2000). In eye-tracking studies the number of fixations is related to the amount of information extracted from a stimulus (Rayner, 1998; Wedel \& Pieters, 2000). Besides the number of fixations, dwell time can also be used as an indicator of the amount of attention paid to a stimulus. Dwell-time represents the total duration (in $\mathrm{ms}$ ) of time that was spent looking at a stimulus (Thomsen \& Fulton, 2007). 
The Present Study

The primary purpose of the present study was to examine the effects of presenting high risk information vs. low risk information vs. coping information on the amount of attention allocation to the health message. We sought evidence for the hypothesis that people for whom the health risk information is self-relevant will react defensively to this information. Therefore we predict that smokers will pay less attention - reflected in fewer fixations and dwell time - to the high risk messages about the negative consequences of smoking than non-smokers.

For the coping information we expect another pattern of results. While coping information contains self-relevant information for smokers, the information does not contain any threat information. Therefore we do not expect that smokers will react defensively to the coping information. Since self-relevant information attracts attention from the reader (Ruiter et al., 2006) we expect that coping messages will attract more attention - reflected in more fixations and dwell time - from smokers than from non-smokers.

\section{Method}

\section{Participants and Design}

In total, 56 psychology undergraduate students took part in the experiment, 28 daily smoking students ( 16 women) and 28 non-smoking students (15 women). Smoking participants smoked somewhat more than 6 cigarettes per day on average $(M=6.40 ; S D=$ 4.30). Participants were recruited in various public places at the university and they took part for course credits or received a gift voucher of 12 Euros for their participation. Participants were 17 to 25 years of age $(M=19.77$; $S D=2.09)$, and reported upon being asked normal or corrected-to-normal vision. The data set of three smoking participants could not be used because of technical problems. Therefore 53 participants remained in the sample and were included in the analyses. The experiment varied the content of the text message (high risk, low risk, coping) as within-subjects factors and smoking status (smoker vs. non-smoker) as between-subjects factor.

\section{Stimulus Materials}

The stimulus materials were twelve self-created posters of cigarette packages (see Figure 1 for examples). The upper part of each cigarette package was held constant, with the texts 'cigarettes' and 'brand' printed in a red and a white rectangle, respectively. Below the middle of each cigarette package twelve different neutral but smoking-related colored photos were presented. At the bottom of each cigarette package we varied the 
content of the text messages. We presented twelve smoking-related health messages in white letters on a black rectangle. These text messages consisted of four low risk messages (i.e. "If you smoke, everyone around you also smokes"), four coping messages (i.e. "You can do it, your doctor or pharmacist can help you stop smoking"), and four high risk messages (i.e. "Smoking causes fatal lung cancer").

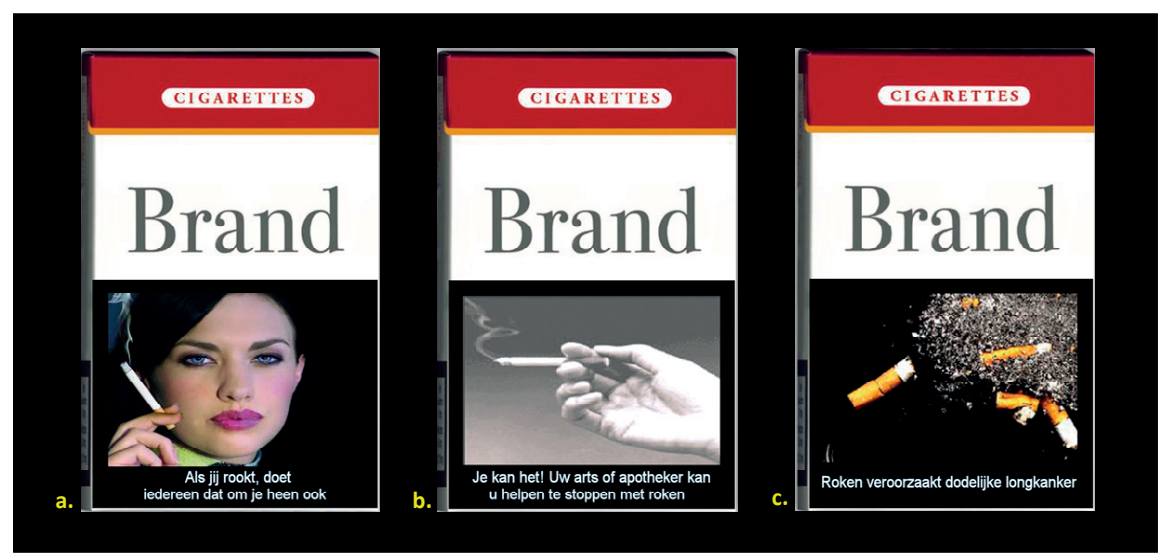

Figure 1. Examples of cigarette packages used in the present study. A cigarette package with a low risk message ('Als jij rookt, doet iedereen dat om je heen ook' - 'If you smoke, everyone around you also smokes'). A cigarette package with a coping message ('Je kan het! Uw arts of apotheker kan u helpen te stoppen met roken' - 'You can do it! Your doctor or pharmacist can help you stop smoking'). A cigarette package with a high risk message ('Roken veroorzaakt dodelijke longkanker' - 'Smoking causes fatal lungcancer').

The messages and photos on the cigarette packages were selected from a pilot study in which we tested twenty-four smoking-related health messages partly based on existing messages on cigarette packages

(http://ec.europa.eu/health/ph_determinants/life_style/Tobacco/Documents/com_1452 _a_en.pdf). Sixteen smoking and fifteen non-smoking undergraduate students rated each message on 7-point scale measuring the perceived level of threat of the message ( $1=$ not at all, 7 = very much) and whether the message contains helpful information regarding quitting smoking (perceived level of coping ability: 'This message provides help for quitting smoking', $1=$ not at all, $7=$ very much). The perceived level of threat was significantly higher for the selected high risk messages $(M=3.10 ; S D=1.14)$ than for the low risk messages $(M=1.46 ; S D=.55)$ and coping messages $(M=1.24 ; S D=.47), F(2,58)=63.66$, $p<.001, \eta_{p}^{2}=.69$. Low risk and coping messages did not differ on the perceived level of threat. In addition, the perceived level of coping ability was higher for the selected coping 
messages $(M=3.50 ; S D=1.21)$ than for the low risk $(M=1.49 ; S D=.49)$ and high risk messages $(M=1.64 ; S D=.84), F(2,58)=53.53, p<.001, \eta_{p}^{2}=.65$. Low risk messages and high risk messages did not differ on the perceived level of coping.

For selecting the photos to be presented on the cigarette packages twenty-four smoking-related photos were found on the website of the European Community presenting the cigarette packages and via a search through the internet using search terms like 'smoking', 'cigarette', or 'causes smoking'. On a 7-point scale participants rated the perceived level of threat ( $1=$ not at all, $7=$ very much) for each photo. Finally, we made a selection of twelve low threat photos with a maximum score of 2 on the perceived level of threat scale.

For creating the twelve cigarette packages for the main experiment each photo was paired to a health message with the result that each smoking package contained a unique combination of photo and health message. The perceived level of threat associated with the photos did not differ among the three groups of cigarette packages, $F(2,58)=2.87, p$ $=.07, \eta_{\mathrm{p}}^{2}=.09$.

All other features of the cigarette packages (e.g., colour, font type) were kept constant across conditions. Furthermore, a mixed ANOVA with condition (low risk message ( $\mathrm{n}$ $=4)$ vs. coping message $(n=4)$ vs. high risk message $(n=4))$ as within-subjects factor showed that the number of words used in the three categories of health messages did not differ significantly, $F(2,6)<1$, ns. The final set of stimulus materials is available from the first author on request.

\section{Apparatus}

Eye movements were registered by the EyeLink I eyetracker from SensoMotoric Instruments (SMI, Germany) and SR Research (Canada), with a $250 \mathrm{~Hz}$ temporal resolution, a $0.005^{\circ}$ gaze and eye position resolution, and a gaze position accuracy with $0.5-1.0^{\circ}$ average error. It is a headband-mounted infrared video-based tracking system that can track both eyes. The system corrects for head-motion by means of an additional infrared camera.

The participant's head rested on a chin-rest at an approximate distance of $57 \mathrm{~cm}$ of a computer monitor (19" flat panel Dell monitor). Monitor resolution was set to 1024 * 768 pixels. A Dell Optiplex GX110 Pentium III computer controlled the stimulus presentation. The cigarette packages were presented in colour format and sized 7 by $13 \mathrm{~cm}$. The presentation of stimuli and analysis of the eye tracking was performed with Matlab 6.5. Although viewing was binocular, only fixations and saccades of the right eye were monitored. 


\section{Procedure}

The experiment took place in a dimly lit, sound-attenuating room. After explaining the procedure of the experiment, participants signed an informed consent, and the Eyelink system was installed on the head. Participants were seated at a table in front of a computer screen, with their head resting on a chin-rest. After calibrating and validating the Eyelink system, the experiment started.

Each of the twelve cigarette packages were randomly presented for 10 seconds. Before a package appeared on the screen, a dot was presented at the centre of the screen. Participants were asked to focus on the dot, so that each participant would start viewing every package in the same way. During exposure to the stimuli, eye movements were registered. After presentation of the twelve different packages, the headset was removed and the participant started with filling out the self-report questionnaires to evaluate the stimuli.

\section{Self-report Measures}

To measure different dimensions of the messages and the photos, we used self-report items with 7-point Likert scales. Each message and photo was evaluated separately. We measured message evaluation with five items ( $\alpha$ 's $>$.79): clearness, credibility, interest, usefulness, acceptability ( $1=$ not at all, $7=$ very much $)$. Newness and perceived personal relevance of the message were both measured with one item $(1=$ not at all, $7=$ very much). Furthermore, participants had to evaluate each message and photo on the perceived level of threat ( $1=$ not at all, $7=$ very much).

\section{Data-Analysis}

We extracted the eye tracking data from Data Viewer (SR Research software) to SPSS. For analyzing the eye-movements we created three areas of interests (i.e. three rectangles) for each cigarette package. The first area of interest contained the health message (low risk vs. coping vs. high risk), the second area of interest contained the photo, and the third area of interest contained the whole cigarette package, including the message and the photo (see Figure 1). For each area of interest we compared the number of fixations and dwell time for the three different conditions after averaging for each condition the responses to the four stimuli within that condition.

For the eye tracking data, with number of fixations and dwell time as outcome measures, and for the self-report measures we used mixed analysis of variances (ANOVA) with the within-subjects factor health message (low risk vs. coping vs. high risk) and the between-subjects factor smoking status (smokers vs. non-smokers). In case of a significant main effect of health message, pairwise comparisons (Bonferroni) were performed 
to test which conditions differed significantly. Significant interactions between health message and smoking status were followed-up by simple effect analyses. To control for sphericity violations in the mixed ANOVAs, we report probability values with GreenhouseGeisser correction for $F$ tests with more than one degree of freedom in the numerator. The reported estimates of the effect size are partial eta squared $\left(\eta_{p}^{2}\right)$ for the analyses of variance.

\section{Results}

\section{Eye Tracking}

Table 1 shows the mean number of fixations and dwell-time in milliseconds for the three areas of interest (health message, photo and cigarette package) for each experimental condition and the two smoking status groups. In case of main effects of health message and smoking status, overall means are provided in the text.

Area of Interest - Health Message. A mixed ANOVA on the number of fixations for the health messages showed a significant main effect of health message, $F(2,102)=$ $20.17, p<.001, \eta_{p}^{2}=.28$. No significant main effect or interaction effect involving the factor smoking status was found, $F s<.81, n s, \eta_{p}^{2} s<.02$. Pairwise comparisons showed more fixations for coping information $(M=12.63 ; S D=4.29)$ than for low risk information $(M=10.39 ; S D=3.86)$ and high risk information $(M=10.52 ; S D=3.54 ; p \mathrm{~s}<.001)$. No significant difference in the number of fixations between low risk and high risk information was found $(p=1.00)$.

A similar pattern of results was found for the dwell time, showing a significant main effect of health message, $F(2,102)=10.17, p<.001, \eta_{p}^{2}=.17$, and no effects for the factor smoking status, $F s<.87, n s, \eta_{p}^{2}<.02$. Pairwise comparisons revealed significantly more dwell time for coping information $(M=2640 ; S D=981.08)$ than for low risk information $(M=2303.42 ; S D=935.25)$ and high risk information $(M=2194.45 ; S D=811.03 ; p s<.02)$. Dwell time for low risk information did not differ significantly from dwell time for high risk information $(p=.76)$. 
Table 1. Means (SD) of Fixations and Dwell Time (in milliseconds) for the AOls Message, Photo and Package for each health message (Low Risk vs. Coping vs. High Risk)

\begin{tabular}{|c|c|c|c|c|c|c|}
\hline \multirow[b]{2}{*}{ AOI } & \multicolumn{2}{|c|}{ Low Risk } & \multicolumn{2}{|c|}{ Coping } & \multicolumn{2}{|c|}{ High Risk } \\
\hline & Smokers & Nonsmokers & Smokers & Nonsmokers & Smokers & Nonsmokers \\
\hline \multicolumn{7}{|l|}{ Message } \\
\hline \multirow[t]{2}{*}{ Fixation } & 10.87 & 9.96 & 12.74 & 12.54 & 10.48 & 10.54 \\
\hline & (4.14) & (3.61) & $(4.40)$ & $(4.27)$ & (3.57) & (3.57) \\
\hline \multirow[t]{2}{*}{ Dwell Time } & 2483 & 2143 & 2742 & 2548 & 2230 & 2162 \\
\hline & (1034) & (823) & (1062) & (912) & (892) & (746) \\
\hline \multicolumn{7}{|l|}{ Photo } \\
\hline \multirow[t]{2}{*}{ Fixation } & 15.78 & 15.57 & 12.87 & 14.46 & 16.75 & 16.61 \\
\hline & (4.67) & (4.11) & (4.05) & (3.74) & $(4.94)$ & (3.79) \\
\hline \multirow[t]{2}{*}{ Dwell Time } & 4813 & 4734 & 4388 & 5231 & 5363 & 5231 \\
\hline & (1074) & (1099) & (910) & (1118) & (854) & (1118) \\
\hline \multicolumn{7}{|l|}{ Package } \\
\hline \multirow[t]{2}{*}{ Fixation } & 31.87 & 31.88 & 30.99 & 32.24 & 32.22 & 31.87 \\
\hline & (5) & $(4.33)$ & $(4.70)$ & $(4.77)$ & $(4.82)$ & $(4.52)$ \\
\hline \multirow[t]{2}{*}{ Dwell Time } & 8598 & 8538 & 8733 & 8549 & 8690 & 8619 \\
\hline & $(672)$ & (677) & (461) & (546) & (499) & (437) \\
\hline
\end{tabular}

Area of Interest - Photo. The mixed ANOVA on the number of fixations for the area of interest of the photo (AOI-photo) showed a significant main effect of health message, $F(2,102)=23.74, p<.001, \eta_{p}^{2}=.32$. No significant support was found for effects involving the factor smoking status, $F_{s}<2.60, n s, \eta_{p}^{2}<.05$. Pairwise comparisons showed that photos presented with low risk information $(M=15.67 ; S D=4.34)$ and high risk information $(M=16.67 ; S D=4.33)$ received significantly more fixations than photos presented with coping information $(M=13.71 ; S D=3.94 ; p s<.001)$. Photos presented with high risk information received marginal significant more fixations than photos presented with low risk information $(p=.054)$.

The dwell time for the AOI-photo showed almost the same pattern of results, with a significant main effect of health message, $F(2,102)=26.44, p<.001, \eta_{p}^{2}=.34$, and no effects for smoking status, $F s<.91, n s, \eta_{p}^{2}<.02$. Pairwise comparisons revealed significantly more dwell time for photos presented with low risk information $(M=4771.64 ; S D=$ $1077.65)$ or high risk information $(M=5293.36 ; S D=995.33)$ than for photos presented with coping information $(M=4472.68 ; S D=881.32 ; p s<.05)$. Presenting photos with high 
risk information revealed more dwell time than presenting photos with low risk information $(p<.001)$.

Area of Interest - Cigarette Package. Mixed ANOVAs on the number of fixations and dwell time for the area of interest of the cigarette package (AOI-package), including the message and the photo, showed no significant main effects or interactions involving the factors health message and smoking status, $F_{s}<1.74, n s, \eta_{p}^{2}<.03$.

\section{Self-report measures}

An overview of the mean scores on the self-report measures of smokers and nonsmokers can be found in Table 2. Again, in case of main effects of health messages and smoking status, aggregated mean scores are provided in the text.

Table 2. Means (SD) of Self-Report Measures for Evaluation, Newness, Relevance and Threat for each health message (Low Risk vs. Coping vs. High Risk). Evaluation, Newness and Relevance was only measured for the AOIs Message, Threat was measured for the AOI Message and the AOI Photo

\begin{tabular}{lcccccc}
\hline & \multicolumn{2}{c}{ Low Risk } & \multicolumn{2}{c}{ Coping } & \multicolumn{2}{c}{ High Risk } \\
AOI & Smokers & Nonsmokers & Smokers & Nonsmokers & Smokers & Nonsmokers \\
\hline Message & & & & & & \\
Evaluation & 4.3 & 4.52 & 4.37 & 4.74 & 5.24 & 5.46 \\
& $(0.99)$ & $(0.92)$ & $(1.14)$ & $(1.09)$ & $(0.98)$ & $(0.84)$ \\
Newness & 3.61 & 4.32 & 3.39 & 3.69 & 2.94 & 3.42 \\
& $(1.14)$ & $(1.02)$ & $(1.51)$ & $(1.26)$ & $(1.13)$ & $(1.35)$ \\
Relevance & 2.85 & 1.47 & 2.46 & 1.21 & 2.73 & 1.38 \\
& $(1.01)$ & $(0.97)$ & $(1.24)$ & $(0.64)$ & $(1.22)$ & $(1.03)$ \\
Threat & 2.47 & 2.54 & 1.86 & 1.33 & 4.13 & 4.23 \\
& $(1.22)$ & $(0.95)$ & $(1.04)$ & $(0.63)$ & $(1.24)$ & $(1.47)$ \\
Photo & & & & & & \\
Threat & 2.67 & 2.31 & 2.71 & 2.43 & 2.42 & 2.27 \\
& $(1)$ & $(0.38)$ & $(0.98)$ & $(0.73)$ & $(1.10)$ & $(1.03)$ \\
\hline
\end{tabular}


Message Evaluation. A mixed ANOVA showed a significant main effect of health message on message evaluation, $F(2,102)=44.60, p<.001, \eta_{p}^{2}=.47$. No significant support was found for a main effect or interaction effect involving the factor smoking status, $F_{s}<1.20, n s, \eta_{p}^{2}<.02$. Pairwise comparisons showed that high risk information was more positively evaluated $(M=5.36 ; S D=.91)$ than low risk $(M=4.42 ; S D=.95)$ and coping information $(M=4.57 ; S D=1.12)$, ( $p$ 's $<.001)$. No significant difference was found between low risk information and coping information $(p=.60)$.

Newness. For the newness scale, a mixed ANOVA showed a significant main effect of health message, $F(2,102)=9.74, p<.001, \eta_{p}^{2}=.16$. No effects involving the factor smoking status was found, $F s<3.28, n s, \eta_{p}^{2}<.06$. Pairwise comparisons showed that low risk information $(M=3.99 ; S D=1.13)$ was perceived as newer than coping information $(M=$ 3.55; $S D=1.38)$ and high risk information $(M=3.19 ; S D=1.26)$, ( $p s<.05)$. Coping information and high risk information did not differ significantly on perceived newness of the information $(p=.14)$.

Personal Relevance. On the perceived level of personal relevance smokers judged the health messages as more personally relevant $(M=2.68, S D=1.04)$ than non-smokers ( $M$ $=1.35, S D=.81), F(1,51)=26.88, p<.001, \eta_{p}^{2}=.35$. In addition, an effect of health message was found, $F(2,102)=5.11, p<.01, \eta_{p}^{2}=.09$. Participants evaluated the low risk information $(M=2.12 ; S D=1.20)$ to be more personally relevant than the coping information $(M=1.80 ; S D=1.15)(p<.01)$. The high risk information $(M=2.02 ; S D=1.30)$ was not evaluated to be more or less personally relevant than the low risk and coping information ( $p s>14$ ).

Threat. A mixed ANOVA showed a significant main effect of health message on perceived threat, $F(2,102)=137.61, p<.001, \eta_{p}^{2}=.73$. No significant support was found for a main effect or interaction effect involving the factor smoking status, $F s<2.55, n s, \eta_{p}^{2}<.05$. Pairwise comparisons showed that high risk information $(M=4.18 ; S D=1.35)$ was judged to be more threatening than low risk information $(M=2.51 ; S D=1.08)$ and coping information $(M=1.58 ; S D=.88)$, ( $p s<.001)$. In addition, low risk information was judged to be more threatening than coping information $(p<.001)$.

A mixed ANOVA on perceived threat of the photos showed no significant main effects or an interaction effect involving the factors health message or smoking status, Fs < $1.95, n s, \eta_{p}^{2}<.04$. The photos were not evaluated differently when presented in combination with low risk information $(M=2.48 ; S D=.75)$, coping information $(M=2.56 ; S D=$ $.86)$ and high risk information $(M=2.34 ; S D=1.06), F(2,102)=1.95, p=.16, \eta_{p}^{2}=.04$. 


\section{Discussion}

The present study examined whether presenting self-relevant high risk information would lead to defensive reactions among smoking participants. We expected that smokers react defensively and thus pay less attention to high risk information than non-smokers. Furthermore, we predicted that smokers pay more attention to coping information compared to non-smokers because the coping information contains self-relevant information without any threat. Contrary to our expectations and the finding that smokers judged the materials as more personal relevant than the non-smokers, smokers and non-smokers did not differ from each other on the amount of fixations and dwell time for the three types of messages. Both smokers and non-smokers allocated more attention - that is more fixations and more dwell time - to coping information than to high risk information, whereas high risk information received the same amount of fixations and dwell-time as low risk information.

With respect to the eye-movement data for the photos, results showed that smokers and non-smokers had less fixations and dwell time for photos presented with a coping message than for photos presented with a high risk or low risk message. Presenting the photo with a high risk message received even more dwell time than presenting the photo with a low risk message. Because participants looked at the whole cigarette package for 10 seconds and the total number of fixations and dwell time for the whole cigarette package did not differ between the three conditions, the pattern of results for the photos confirm the findings for the health messages with more attention allocated to the coping information than to the high risk and low risk information. The finding that coping information received more attention than high and low risk information does not seem to be the result of the newness of the presented information. Although coping information is much less visible on cigarette packages in the EU than threat information - 12 out of 14 health messages containing high risk information and only two messages containing coping information - smokers (and also non-smokers) did not judge the coping information to be more new than the high risk information or low risk information. The low risk was in fact judged as more new than the coping information. Although the coping messages received the most attention, the coping messages also received the least positive message evaluations and were judged to be less personal relevant compared to the high and low risk messages. A possible explanation could be that because the coping information received most attention, the viewers had more time to be critical on the information and subsequently judged the information as less positive and less personal relevant. Another explanation is that risk information is simply more imminent than coping information because referring directly to personal relevant threats and therefore is more positively evaluated and considered to be more personally relevant. Despite these differences it is important to note that coping information was evaluated positively rather than negatively with mean scores situated about the scale midpoints. 
The present study has some limitations. First, we did not include a comparison between low and high levels of coping information. While we created two levels of risk information by adding low and high risk messages, only one level of coping information was presented. Although a comparison between low and high coping information would be useful, low coping messages stating that quitting smoking is difficult would be at odds with the goal of the health message and will therefore raise questions about the relevance and quality of this information and thus may interfere with attention processes under study. Instead of presenting low coping information, we could have chosen to present neutral but smoking-related information (e.g., 'the ashtray is on the table'). However, it would be difficult then to attribute effects of a comparison between coping conditions and non-coping conditions to the presentation of coping information because the non-coping condition would not contain any health related information. Another limitation is that despite the fact that high threatening graphic pictures are already have been introduced on cigarette package in several countries worldwide (e.g., Canada, Brasil, Belgium, Singapore), we only included low threat smoking-related pictures on the packages in the present study. Our interest was foremost on the impact of written health messages on attention allocation processes, but future studies could in addition look at the role of high threatening graphic warnings and their effects on attention processes in combination with presenting coping information. Finally, in the present study we did not measure any recall or behaviour effects of the presented messages. Consequently, we can not make any assumptions about an association between attention and memory or between attention and behaviour for the presented information. It should be noted however that within-subjects designs are preferred in attention research to control for often strong inter-individual differences, but that these designs make comparisons between experimental conditions at the level of recall and behaviour complicated due to possible contamination of experimental conditions.

By recording eye movement, the present study finds evidence that coping messages presented on cigarette packages attract more attention from the viewer, smokers and non-smokers, than high risk or low risk messages. This finding is in line with recent metaanalysis studies into the effectives of behavioural change interventions in the related health domains of HIV/AIDS and nutrion and physical activity. These studies show that providing instructions about how to effectively adopt healthy behaviour could be a more useful tool in health education than providing threat information about the negative consequences of unhealthy behaviour (e.g., Albarracín et al., 2005; Michie, Abraham, Whittington, McAteer, \& Gupta, 2009). The present findings also support meta-analyses of protection motivation theory that suggest that self-efficacy is a stronger determinant of behaviour change than perceptions of threat (Floyd et al., 2000; Milne et al., 2000). Furthermore, empirical studies have shown that threatening health information is met with defensive responses especially among those to whom the health threat is most personally relevant (e.g., Brown \& Smith, 2007). Therefore, the presentation of coping 
information on cigarette packages may be a more fruitful approach to motivate people to refrain from smoking than the current policy that is adopted by leading authorities in tobacco prevention. 


\section{Chapter 7}

General Discussion 
The central focus of the current research project is to improve our knowledge of the underlying working mechanisms of different health education methods. In particular, attention processes in response to personally relevant health messages were investigated. A total of 5 empirical studies explored attention processes for tailored health message and threatening health information. It was assumed that the method of message tailoring increases attention for the information, because personalized information would attract attention from the reader. On the other hand, presenting threatening health information would cause a more complex pattern of results. Specifically, if the threat information is self-relevant defensive reactions were expected to arise because people do not want to be confronted with negative information that concerns their own behaviour (Brown \& Locker, 2009; Croyle et al., 1997; Ditto \& Croyle, 1995; Freeman et al., 2001; Harris \& Napper, 2005; Keller, 1999; Keller \& Block, 1999; Liberman \& Chaiken, 1992; Sherman et al., 2000; Taubman - Ben-Ari et al., 2000). Defensive reactions should be reflected in less attention for threatening health information among those for whom the information is self-relevant. For those for whom the information is not self-relevant no decrease in attention for threatening health information was expected because of the absence of defensive responses. This thesis investigated these hypotheses by applying the research methods of EEG, $\mathrm{FMRI}$, eye tracking and reaction times using experimental study designs.

\section{Overview}

In Study 1 (chapter 2) attention processes for tailored versus non-tailored nutrition education messages were examined. In an oddball-task participants read the messages while EEG and RT were measured. In a between-subject design it was shown that tailored nutrition information leads to more attention for the message than non-tailored nutrition information. This positive attention effect was found on the P300 ERP measure, but not on the reaction times and the self-report measure of perceived attention. The reaction times however were in the predicted direction. Additionally, more participants were motivated to change their diet / eating behaviour after reading tailored information than after reading non-tailored information. These findings provide support for the dual process models of attitude change that hold that personal relevant information is more systematically processed than information that is less self-relevant (e.g., Petty \& Cacioppo, 1986).

Previous research suggests that self-relevance leads to more systematic processing of the information, but only if this information is non-threatening. When the information contains high threat information, less attention will be paid to the self-relevant health information (see also Harris et al., 2007; Harris \& Napper, 2005; Sherman et al., 2000). The main goal of study 2 (chapter 3 ) was to investigate these defensive reactions through measuring attention processes for self-relevant health information in combination with 
threatening health information. In study 2 (chapter 3) tailored health information was combined with either high or low threatening health information. In addition, tailored and non-tailored nutrition education messages were presented in a within-subjects design. The use of a within-subjects design, in contrast with the between-subjects design of our first ERP study (Study 1; chapter 2), may reduce the interperson variability and increase the chance of significant results on the reaction times. Significant result on the reaction time data would indicate that the attention is modulated by message relevance not only early on in the cognitive processing of health information, as was indicated by the ERP results, but also at the end of the cognitive process (during motor preparation). A combination of measuring reaction times and ERPs thus provides useful timing information of measured attention processes.

In Study 2 (chapter 3), attention effects on the combination of message tailoring and threatening health information were investigated by using the same oddball paradigm as in Study 1 (chapter 2). While message tailoring was presented as a within-subjects factor, threat information was presented as a between-subjects factor. Both tailored and nontailored messages were supplemented with high threat or low threat nutrition information in order to investigate the effects of message tailoring in combination with health threat information on attention allocation processes.

Threat information was presented as a between-subjects factor because we thought that participants would discover the purpose of the threat manipulation when they read both parts of high and low threat information. Besides a replication of our first ERP study, showing positive attention effects for message tailoring, the results showed also more attention for low threat information compared with high threat information. In addition to the first ERP study, attention enhancement for tailored information was also found on the reaction time data. This suggests that not only at the beginning, but also at the end of the cognitive process (during motor preparation) attention is modulated by message relevance.

Interestingly, the results on the self-report measure of perceived attention did not support the results on the ERP and the reaction times data in both studies. Both ERP studies showed no significant differences between the two tailoring conditions in subjective estimates of the extent to which respondents read the information carefully. These findings implicate the usefulness of more objective measures (e.g., ERPs) when studying important psychological processes underlying the effectiveness of health communications. Although participants might not consciously experience their relative attention gain for certain information, measures of ERPs and reaction times are able to surface these positive effects in an objective way. More general, the findings support the hypothesis put forward in several basic publications of the working mechanisms of message tailoring that refers to the relative gain in attention for individualized health information to explain the positive effects of message tailoring on indices of behaviour change (Brug et al., 2003; Kreuter \& Holt, 2001; Noar et al., 2007). 
However, the result of the second study did not reveal the expected interaction between threat and tailoring indicating defensive responses when personal relevant health information is threatening. While the ERP waves indicated most attention for tailored low threat information and least attention for non-tailored high threat information, this pattern was not supported by a significant interaction effect, but reflected a main effect of threat manipulation. A possible explanation for the lack of a significant interaction effect is the relatively low sample size, with only 17 participants in each group. Unfortunately 7 participants from the original sample size were lost, due to technical problems or too many mistakes.

Apart from a low sample size, an alternative explanation for the missing interaction effect could be the creation of the threat manipulation. Both tailored and non-tailored messages had three short sections, about 225 words each, containing either high or low threat information. The remainder of the messages ( \pm 875 words) contained information about how to improve nutrition behaviour. In total, less than $50 \%$ of the message contained a threat manipulation. Although self-report measures showed higher threat judgements for the high threat messages than for the low threat messages, the overall mean was very low (i.e., 3.04 on a 7-point scale). It is possible that the message did not have enough impact to induce a significant interaction effect between threat and tailoring.

Building on the findings of Study 2 (chapter 3 ) and our interest in the attention effects of threatening health information, the other studies primarily focused on presenting threatening health information. Study 3 (chapter 4) explored attention processes for threatening health information (i.e., smoking pictures) that was self-relevant or non-selfrelevant. In contrast with the method of message tailoring used in the first two studies, the factor of self- relevance was created through testing smokers (self-relevant) and nonsmokers (non-self-relevant). In a variant of the Posner cueing task, ERPs and reaction times were measured for attention capture and attention disengagement processes. Among smokers, the ERP results showed more efficient disengagement processes for high threat compared to low threat smoking pictures. Furthermore, both smokers and nonsmokers revealed more attention capture processes for high threat compared to low threat smoking pictures. Unfortunately, reaction times did not support these ERP findings.

While the tailoring $x$ threat ERP study (Study 2; chapter 3) showed less attention processes for high threat information irrespective of the self-relevance of the information, in the cueing ERP study (Study 3; chapter 4) evidence was found for the hypothesis that high threat information causes defensive reactions when the information is selfrelevant. For the first time neuroscientific support was found for the previous self-report findings that showed defensive responses for self-relevant threat information.

Consistent with the tailoring study (Study 1; chapter 2), the reaction time data of the cueing study (Study 3; chapter 4) did not significantly support the ERP data. Although the 
reaction times of Study 1 were in the predicted direction and a large effect size was reported, the reaction times of Study 3 did not show the expected pattern of results. In Study 1 , the non-significant effect of tailoring on the reaction times was probably caused by a lack of power. Regarding Study 3, the non-significant interaction between threat and self-relevance on the reaction times could indicate that defensive responses occur early on in the cognitive processing of health information. These early processes are visible in ERP responses, but not in the reaction times. At the end of the cognitive process (during motor preparation) any influence of the combination of threat and self-relevance was probably cancelled out. At a more general level, these findings implicate the usefulness of high temporal resolution methods like ERP when studying important psychological processes underlying the effectiveness of health communications.

Although the ERP results provided detailed timing information about the two streams of attention processes, no information can be implied about the brain areas involved in these attention processes. Therefore, in Study 4 (chapter 5) the high spatial resolution method of $\mathrm{fMRI}$ was used as study instrument to measure brain activation while processing high and low threat health smoking pictures. To study optimal levels of attention modulation in the amygdala, smokers and non-smokers made explicit and implicit judgments of each smoking picture. The results demonstrated that threat modulation was visible in well-known emotion-related regions, including the amygdala. No support was found for a difference between smokers and non-smokers in brain activation patterns of the amygdala when processing high threat self-relevant information. Although the activation pattern of the amygdala showed the expected lower $\beta$ coefficients for smokers than for non-smokers, this effect did not reach significance.

Although the brain activation patterns of the amygdala showed no effect of selfrelevance, correlation analyses provided support for a difference in amygdala involvement between smokers and non-smokers. Among smokers, the amygdala responses in the explicit task correlated with behavioural performances. These findings suggest that self-relevance of the information made a difference during complex processing such as its labelling. However, because of the correlational nature of the findings no conclusions could be drawn whether self-relevance of the information had a positive or a negative effect on message attention.

In the cueing ERP study (Study 3; chapter 4) and the fMRI study (Study 4; chapter 5) smoking related pictures were presented to smokers and non-smokers. Although the pictures were related to smoking, these pictures provided health information about smoking in an indirect way, by visually presenting the negative health consequences of smoking in photos. In the last study (Study 5; chapter 6) we wanted to investigate attention processes for stimuli which are more directly related to health advices. Therefore we forged cigarette packages containing three different kinds of health messages. The health messages presented either high risk, low risk or coping information about smoking behaviour. The factor of personal relevance was created through testing smokers and non- 
smokers. Eye movements were recorded during message exposure because it enabled us to measure overt attention processes when participants viewed the whole cigarette packages, including the reading of the information. Three different health education messages were tested on the amount of fixations and dwell time. The results showed that smokers and non-smokers tend to spend less time looking at the low risk and high risk information than at the coping information. In contrast, coping information was less positively evaluated than high threat information, although the coping information was still evaluated positively with a mean score of 4.6 on a 7-point scale.

For the first time, attention processes for coping information versus high threat information were compared. The results implicated less overt attention processes for high threat information compared to coping information irrelevant of the self-relevance of the information. This study thus showed attention preferences for coping information irrespective of whether the person already follows the recommended behaviour or not. Unfortunately we did not measure recall performances for the health messages. This measure would have been interesting, because the self-report measures showed more positive evaluations for the high threat information while the eye tracking measures showed more attention preferences for the coping information. With recall performances we could have tested whether heightened attention or more positive evaluations correlated with higher recall for the written information.

The last study showed that the method of eye tracking is a useable tool to evaluate health education materials. Objective information can be provided on how information is processed by viewers. Second, while in all other studies covert attention processes were measured, the method of eye tracking enabled us to measure overt attention processes.

In conclusion, based on the attention studies presented in this thesis the following conclusions can be drawn:

(1) Message tailoring and coping information are potentially effective tools to increase attention for health information.

(2) Investigating the relation between self-relevance, threatening health information and attention reveals a complex pattern of results. When measuring covert attention processes two different patterns of results were detected. First, threatening health information automatically captures attention irrespective of the self-relevance of the information. Second, threatening health information causes more efficient attention disengagement when the information is self-relevant. Furthermore, divided attention and overt attention measures showed less attention for threatening health information irrespective of the self-relevance of the information. Overall, threatening health information can cause defensive reaction, but the influence of self-relevance on attention is dependent on the type of attention under study.

(3) To measure attention processes for health information it is recommended to apply neuroscience techniques to obtain non-invasive and objective measures of attention during message processing. 


\section{Social Neuroscience}

In the present thesis neuroscience methods were used to investigate social psychological processes. Neuroscience methods can provide information that would be impossible to gather with other techniques such as self-report questionnaires. Social neuroscience is a growing field of research. To get a more complete understanding of human behaviour, psychology needs neuroscience and neuroscience needs psychology (Harmon-Jones \& Beer, 2009). Through integrating neuroscience into social psychology we gathered a more complex understanding of attention processes for different health education messages.

Besides the important advantage of measuring attention processes more objectively, we also came across some barriers while using different neuroscience research methods that complicated the progress of the present thesis. Some of these barriers will be mentioned as they can be helpful for social neuroscience practitioners.

First, using neuroscience research methods is time consuming, expensive and requires many skills. Requiring those skills for three different techniques (i.e., EEG, fMRI and Eye Tracking) used in the present thesis was time consuming. Furthermore, testing the participants took a lot of time. For example, an EEG measurement of one participants took us about 2,5 hour. Next to the time constraint, using the apparatus for measuring $E E G$, eye tracking or $\mathrm{fMRI}$ is much more expensive than using printed questionnaires.

Second, social neuroscience is a relatively new research field. The first two social neuroscience journals, SCAN and Social Neuroscience, originated only a few years ago in 2006. While attention for complex social stimuli (e.g., IAPS pictures) has been investigated for many years by using EEG and reaction times, only relatively few neuroscience studies used fMRI as research method. Therefore, especially in our fMRI study it was difficult to make choices for experimental design, timing of the stimuli and fMRI data acquisition parameters. Contrary to the other four studies, the fMRI study had a more explorative character.

Third, the results of ERPs, BOLD activation, number of fixations and dwell time showed very large standard deviations. These large standard deviations may have been caused by the complexity of the stimuli. For example, our smoking pictures varied from black lunges to skeletons holding a cigarette. These differences in complexity, colours, or even the content of the stimuli may have influenced brain responses and may have caused the large standard deviations. When using the high sensitive research methods it is therefore advisable to use a well validated stimulus set containing less complex stimuli. However, in the present thesis this was impossible because no such stimulus set exists. On the other hand, using social neuroscience methods in studying applied research questions asks for socially relevant stimuli. Finding a good balance between having a homogenous set of stimuli and using real-world examples has been a great challenge throughout the current research project. 
Limitations

Although the previous paragraph discussed some practical limitations of social neuroscience, the present thesis has also some more general limitations that should be mentioned.

First, attention processes for health communication materials were not measured in a natural environment. Although participation was on a voluntary basis, participants were instructed to read or view the materials in an artificial environment. Exposure to the materials in a daily life setting may have other attention effects on the target population. However, objective measures of attention processes can only be tested in lab settings.

Second, in all studies the sample size was relatively low. In some studies marginal significant effects were observed. The reason for our low number of participants was the use of the time consuming and expensive methods of EEG and fMRI. Unfortunately, the very large standard deviations especially in the ERP and fMRI data may have caused nonsignificant interactions involving the factor self-relevance. At the same time, small effect sizes were reported. A further consequence of the low sample sizes is a rather small external validity. Therefore, generalizing our findings to other materials or populations is difficult.

A third limitation is that the participants in our studies mainly included higher educated young adults. This limits the generalizability of our conclusions to other groups with, for example, different educational level or ages. It would be interesting to know whether habituation of the information influenced attention processes for the information. In other words, do elderly people who have often been exposed to health education messages show the same attention responses as young adolescents who have hardly been exposed to health education messages? More research is needed to explore attention processes for health related materials for a broader audience.

A fourth point is the use of smoking related pictures in two of the five studies. These pictures only indirectly provided health advices by showing the negative consequences of unhealthy behaviour. The written messages in the other three studies provided also direct advice for behaviour change. In real life, an effective element of health education material information about how to change unhealthy behaviour, next to a risk communication component. Therefore, the threat pictures used in Study 3 and 4 do not fully reflect real life settings. In future research it would be interesting to explore attention processes for a combination of both aspects of health education materials.

Furthermore, for the first time a stimulus set of high threat and low threat smoking pictures was created. Although the smoking pictures were pretested several times, the picture set was not validated by large samples of participants. Furthermore, our search through the internet revealed a limited amount of useful smoking related pictures. Therefore, we were restricted to use a picture set that was not optimal in the reported range of perceived level of threat. On a 9-point scale the high threat pictures scored on average 4.9 on the perceived level of threat $(1=$ not at all, $9=$ very much). Although our first 
intention was to create three levels of threat (low level of threat, medium level of threat, high level of threat) the limited amount of pictures and the relative low level of perceived threat of the pictures restricted us to use only two levels of threat (low threat and medium threat). It would have been interesting to investigate attention effects for low, medium and high threat pictures to study linear and possible non-linear processes.

A sixth limitation is the use of between-subjects designs in the present thesis. Although we mentioned the advantages of using a within-subjects design in our second study, it was not always possible to create a full within-subjects design when investigating the interaction of self-relevance and threatening health information. The factor selfrelevance was created through testing smokers and non-smokers in one experimental setting. A possibility for creating a full within-subjects design was to present high and low threat smoking versus non-smoking pictures to smokers only. It was however very difficult to create two different picture sets (e.g., smoking pictures and IAPS pictures) that were equal in complexity. Another disadvantage could be that the content of the smoking pictures have an influence on the perception of the non-smoking stimuli. That is, the combination of presenting non-smoking related and smoking-related pictures may confound attention processes for both sets of pictures. Non-smoking related pictures may be more easily perceived as smoking-related pictures while processing both types of pictures and vice versa. For example, when viewing a non-smoking related picture containing a burning car, participants could interpret the cigarette as cause of the fire.

Finally, the studies presented in the current thesis did not include behavioural measures at follow up level. The reason for this lack of follow up measures is the use of withinsubjects factors in the experimental design (e.g., high and low threat pictures). Consequently, no behaviour change effects can be measured if a proper behavioural measure is not possible immediately following the experimental manipulation, which is the case for health-related behaviours such as smoking and nutrition. Accordingly, no conclusions can be drawn about the relation between attention processes and actual behaviour change.

\section{Conclusion and Implications}

The goal of the present thesis was to increase our understanding of the underlying working mechanisms of different health education methods to induce behaviour change. More specifically, we aimed to measure attention processes for the methods of message tailoring and threatening health information.

Based on the findings of our first two studies we may conclude that message tailoring increases attention for the information. People direct more attention to tailored than to non-tailored nutrition education messages. Communicating personal relevant information is a promising strategy to increase attention from the reader for the health information. 
Presenting threatening health information shows a more complex pattern of results. When measuring selective attention processes, high threat health information increases attention capture irrespective of the self-relevance of the information. However, high threat health information that is self-relevant also induces defensive responses. Participants confronted with self-relevant high threat information showed more efficient disengagement from the information than when receiving non self-relevant high threat information.The measures of divided and overt attention processes show less attention for threatening health information irrespective of the self-relevance of the information. Providing coping information or self-relevant low threat information instead of high threat information seems preferable to increase attention for persuasive information.

Providing high threat health information seems to induce defensive reactions reflected in less attention for the information. Our thesis thus shows that it is necessary to thoroughly pretest health communication materials in experimental studies even when some strategies seem obviously more effective or better than others. They may cause unexpected and unwanted side effects. More research on factors that trigger defensive reactions or increase attention for the information and subsequently whether these attention effects lead to behaviour change is desirable and necessary. It should be noted that these patterns of results were not supported when measuring brain regions involved in processing threatening health information. The emotion-related brain regions showed no differences in brain activation between smokers and non-smokers towards threatening health information suggesting that processing of threatening health information was not influenced by self-relevance of the information.

In sum, providing tailored health education materials and coping information are strategies that increase attention for health information. Threatening health information can cause defensive responses. The use of non-invasive measurement techniques (e.g., $E E G, f M R I$ or eye-tracking) allowed us to measure attention processes during message exposure. The integration of neuroscience in health psychology led to a more complete understanding of the underlying attention processes of different persuasive techniques. Therefore, applying neuroscience techniques in future health education research can provide useful information on the underlying working mechanisms of health education materials. 
References 
Abraham, C. S., Sheeran, P., Abrams, D., \& Spears, R. (1994). Exploring teenagers' adaptive and maladaptive thinking in relation to the threat of HIV infection. Psychology \& Health, 9, 253-272.

Aggleton, J. P., \& Mishkin, M. (1986). The amygdala: Sensory gateway to the emotions. In R. Plutchik (Ed.), Biological foundations of emotion (pp. 281-299). New York: Academic Press.

Albarracín, D., Gillette, J. C., Earl, A. N., Glasman, L. R., Durantini, M. R., \& Ho, M.-H. (2005). A test of major assumptions about behavior change: A comprehensive look the effects of passive and active HIV-prevention interventions since the beginning of the epidemic. Psychological Bulletin, 131, 856-897.

Anderson, J. R. (2004). Cognitive psychology and its implications (6th ed.). New York: Worth Publisher.

Bandura, A. (1986). Social foundations of thought and action: A social cognitive theory. Englewood Cliffs, NJ: Prentice-Hall.

Bandura, A. (1997). Self-efficacy: The exercise of control. New York: W. H. Freeman.

Barlow, T., \& Wogalter, M. S. (1993). Alcoholic Beverage Warnings in Magazine and Television Advertisements. The Journal of Consumer Research, 20, 147-156.

Baron, R. S., Inman, M. L., Kao, C. F., \& Logan, H. (1992). Negative emotion and superficial social processing. Motivation and Emotion, 16, 323-346.

Baron, R. S., Logan, H., Lilly, J., Inman, M., \& Brennan, M. (1994). Negative emotion and message processing. Social Psychology Quarterly, 30, 181-201.

Baumeister, R. F., Bratslavsky, E., Finkenauer, C., \& Vohs, K. D. (2001). Bad is stronger than good. Review of General Psychology, 5, 323-370.

Bentin, S., Mouchetant-Rostaing, Y., Giard, M. H., Echallier, J. F., \& Pernier, J. (1999). ERP manifestations of processing printed words at different psycholinguistic levels: Time course and scalp distribution. Journal of Cognitive Neuroscience, 11, 235-260.

Beringer, J. (1987). Experimental Run Time System (Version 3.32c). Frankfurt, Germany: Berisoft Cooperation.

Blair, R. J. R., Morris, J. S., Frith, C. C., Perrett, D. I., \& Dolan, R. J. (1999). Dissociable neural responses to facial expressions of sadness and anger. Brain: A Journal of Neurology, 122, 883-893.

Blumberg, S. J. (2000). Guarding against threatening HIV prevention messages: An informationprocessing model. Health Education and Behavior, 27, 780-795.

Breiter, H. C., Etcoff, N. L., Whalen, P. J., Kennedy, W. A., Rauch, S. L., Buckner, R. L., et al. (1996). Response and habituation of the human amygdala during visual processing of facial expression. Neuron, 17, 875-887.

Britton, J. C., Taylor, S. F., Sudheimer, K. D., \& Liberzon, I. (2006). Facial expressions and complex IAPS pictures: Common and differential networks. Neurolmage, 31, 906-919.

Brown, S., \& Locker, E. (2009). Defensive responses to an emotive anti-alcohol message. Psychology \& Health, 24, 517-528.

Brown, S., \& Smith, E. Z. (2007). The inhibitory effect of a distressing anti-smoking message on risk perceptions in smokers. Psychology and Health, 22, 255-268.

Brug, J., \& De Vries, H. (1999). Computer-tailored education [special issue]. Patient Education and Counseling, 36 (2).

Brug, J., Glanz, K., Van Assema, P., Kok, G., \& Van Breukelen, G. J. P. (1998). The impact of computertailored feedback and iterative feedback on fat, fruit, and vegetable intake. Health Education \& Behavior, 25, 517-531. 
Brug, J., Oenema, A., \& Campbell, M. K. (2003). Past, present, and future of computer-tailored nutrition education. American Journal of Clinical Nutrition, 77, 1028S-1034S.

Brug, J., Steenhuis, I., Van Assema, P., \& De Vries, H. (1996). The impact of a computer-tailored nutrition intervention. Preventive Medicine, 25, 236-242.

Campbell, M. K., De Vellis, B. M., Strecher, V. J., Ammerman, A. S., De Vellis, R. F., \& Sandler, R. S. (1994). Improving dietary behavior: The effectiveness of tailored messages in primary care settings. American Journal of Public Health, 84, 783-787.

Chaicken, S. (1980). Heuristic versus systematic information processing and the use of source versus message cues in persuasion. Journal of Personality and Social Psychology, 39, 752-766.

Chaicken, S., Liberman, A., \& Eagly, A. H. (1989). Heuristic and systematic processing within and beyond the persuasion context. In J. S. Uleman \& J. A. Bargh (Eds.), Unintended thought (pp. 212-252). New York: The Guilford Press.

Chaicken, S., \& Trope, Y. (1999). Dual-process theories in social psychology. New York: The Guilford Press.

Cohen, J. (1998). Statisitical power analysis for the behavioral sciences (2nd ed.). Hillsdale, NJ: Erlbaum.

Compton, R. J. (2003). The Interface Between Emotion and Attention: A Review of Evidence From Psychology and Neuroscience. Behavioral and Cognitive Neuroscience Reviews, 2, 115-129.

Correa, Á., Lupiáñez, J., Madrid, E., \& Tudela, P. (2006). Temporal attention enhances early visual processing: A review and new evidence from event-related potentials. Brain Research, 1076, 116-128.

Costafreda, S. G., Brammer, M. J., David, A. S., \& Fu, C. H. Y. (2008). Predictors of amygdala activation during the processing of emotional stimuli: A meta-analysis of 385 PET and $\mathrm{AMRI}$ studies. Brain Research Reviews, 58, 57-70.

Coull, J. T. (1998). Neural correlates of attention and arousal: Insights from electrophysiology, functional neuroimaging and psychopharmacology. Progress in Neurobiology, 55, 343-361.

Croyle, R. T., Sun, Y., \& Hart, M. (1997). Processing risk factor information: Defensive biases in health-related judgments and memory. In K. J. Petrie \& J. A. Weinman (Eds.), Perceptions of health and illness: Current research and applications (pp. 267-290). Amsterdam: Harwood Academic.

Darley, W. K., \& Lim, J. (1991). Personal relevance as moderator of the effect of public service advertising on behavior. Advances in Consumer Research, 18, 303-309.

Das, E. H. H. J., de Wit, J. B. F., \& Stroebe, W. (2003). Fear appeals motivate acceptance of action recommendations: Evidence for a positive bias in the processing of persuasive messages. Personality and Social Psychology Bulletin, 29, 650-664.

De Vries, H., \& Backbier, E. (1994). Self-efficacy as an important determinant of quitting among pregnant women who smoke: The $\varnothing$-pattern. Preventive Medicine: An International Journal Devoted to Practice and Theory, 23, 167-174.

Dijkstra, A., \& De Vries, H. (1999). The development of computer-generated tailored interventions. Patient Education and Counseling, 36, 193-203.

Ditto, P. H., \& Croyle, R. T. (1995). Understanding the impact of risk factor test results: Insights from a basic research program. In R. T. Croyle (Ed.), Psychosocial effects of screening for disease prevention and detection (pp. 144-181). New York: Oxford University Press.

Eagly, A. H., \& Chaicken, S. (1993). The psychology of attitudes. Fort Worth, TX: Harcourt Brace Jovanovich. 
Eriksen, C. W., \& Yeh, Y. Y. (1985). Allocation of attention in the visual field. Journal of Experimental Psychology: Human Perception and Performance, 11, 583-597.

Ewbank, M. P., Barnard, P. J., Croucher, C. J., Ramponi, C., \& Calder, A. J. (2009). The amygdala response to images with impact. Social, Cognitive and Affective Neuroscience, 4, 127-133.

Eysenck, M. W., \& Keane, M. T. (2005). Cognitive psychology: A student's handbook (5th ed.). New York: Psychology Press.

Fabiani, M., Gratton, G., \& Coles, M. G. H. (2000). Event-related brain potentials. In J. T. Cacioppo, L. G. Tassinary \& G. G. Berntson (Eds.), Handbook of psychophysiology (2nd ed., pp. 53-84). New York: Cambridge University Press.

Festinger, L. (1957). A theory of cognitive dissonance. Stanford: Stanford University Press.

Fichtenholtz, H. M., Hopfinger, J. B., Graham, R., Detwiler, J. M., \& LaBar, K. S. (2007). Happy and fearful emotion in cues and targets modulate event-related potential indices of gaze-directed attentional orienting. Social Cognitive and Affective Neuroscience, 2, 323-333.

Fischer, P. M., Richards, J. W., Jr., Berman, E. J., \& Krugman, D. M. (1989). Recall and Eye Tracking Study of Adolescents Viewing Tobacco Advertisements. JAMA, 261, 84-89.

Fishbein, M., Triandis, H. C., Kanfer, F. H., Becker, M., \& Middlestadt, S. E. (2000). Factors influencing behavior and behavior change. In A. S. Baum, T. A. Revenson \& J. E. Singer (Eds.), Handbook of health psychology (pp. 1-17). Mahwah, New Jersey: Lawrence Erlbaum.

Floyd, D. L., Prentice-Dunn, S., \& Rogers, R. W. (2000). A meta-analysis of research on protection motivation theory. Journal of Applied Social Psychology, 30, 407-429.

Forman, S. D., Cohen, J. D., Fitzgerald, M., Eddy, W. F., Mintun, M. A., \& Noll, D. C. (1995). Improved assessment of significant activation in functional magnetic resonance imaging (fMRI): use of a cluster-size threshold. Magnetic Resonance in Medicine 33, 636-647.

Forsyth, A. D., \& Carey, M. P. (1998). Measuring self-efficacy in the context of HIV risk reduction: Research challenges and recommendations. Health Psychology, 17, 559-568.

Freeman, M. A., Hennessy, E. V., \& Marzullo, D. M. (2001). Defensive evaluation of antismoking messages among college-age smokers: The role of possible selves. Health Psychology, 20, 424433.

Friston, K. J. (1996). Statistical parametric mapping and other analysis of functional imaging data. In A. W. Toga \& J. C. Mazziotta (Eds.), Brain mapping: The methods (pp. 363-385). San Diego, CA: Academic Press.

Fusar-Poli, P., Placentino, A., Carletti, F., Landi, P., Allen, P., Surguladze, S., et al. (2009). Functional atlas of emotional faces processing: A voxel-based meta-analysis of 105 functional magnetic resonance imaging studies. Journal of Psychiatry \& Neuroscience, 34, 418-432.

Gazzaniga, M., Ivry, R., \& Mangun, G. (2002). Cognitive neuroscience: The biology of the mind (2nd ed.). New York: Norton \& Company Inc.

Genovese, C. R., Lazar, N. A., \& Nichols, T. (2002). Thresholding of statistical maps in functional neuroimaging using the false discovery rate. Neurolmage, $15,870-878$.

Gleicher, F., \& Petty, R. E. (1992). Expectations of reassurance influence the nature of fearstimulated attitude change. Journal of Experimental Social Psychology, 28, 86-100.

Godin, G., \& Kok, G. (1996). The theory of planned behavior: A review of its applications to healthrelated behaviors. American Journal of Health Promotion, 11, 87-98.

Gur, R. C., Sara, R., Hagendoorn, M., Marom, O., Hughett, P., Macy, L., et al. (2002). A method for obtaining 3-dimensional facial expressions and its standardization for use in neurocognitive studies. Journal of Neuroscience Methods, 115, 137-143. 
Gur, R. C., Schroeder, L., Turner, T., McGrath, C., Chan, R. M., Turetsky, B. I., et al. (2002). Brain activation during facial emotion processing. Neurolmage, 16, 651-662.

Habel, U., Windischberger, C., Derntl, B., Robinson, S., Kryspin-Exner, I., Gur, R. C., et al. (2007). Amygdala activation and facial expressions: Explicit emotion discrimination versus implicit emotion processing. Neuropsychologia, 45, 2369-2377.

Hale, J. L., Lemieux, R., \& Mongeau, P. A. (1995). Cognitive processing of fear-arousing message content. Communication Research, 22, 459-474.

Harmon-Jones, E., \& Beer, J. S. (2009). Introduction to social and personality neuroscience methods. In E. Harmon-Jones \& J. S. Beer (Eds.), Methods in social neuroscience (pp. 1-9). New York: The Guilford Press.

Harris, P. R., Mayle, K., Mabbott, L., \& Napper, L. (2007). Self-affirmation reduces smokers' defensiveness to graphic on-pack cigarette warning labels. Health Psychology, 26, 437-446.

Harris, P. R., \& Napper, L. (2005). Self-Affirmation and the Biased Processing of Threatening HealthRisk Information. Personality and Social Psychology Bulletin, 31, 1250-1263.

Hawkins, R. P., Kreuter, M. W., Resnicow, K., Fishbein, M., \& Dijkstra, A. (2008). Understanding tailoring in communicating about health. Health Education Research, 23, 454-466.

Hillyard, S. A., Mangun, G. R., Woldorff, M. G., \& Luck, S. J. (1995). Neural systems mediating selective attention. In M. S. Gazzaniga (Ed.), The cognitive neurosciences (pp. 665-681). Cambridge, MA: MIT Press.

Hoffman, J. E., \& Nelson, B. (1981). Spatial selectivity in visual search. Perception \& Psychophysics, 30, 283-290.

Huettel, S. A., Song, A. W., \& McCarthy, G. (2004). Functional magnetic resonance imaging. Sunderland, MA.: Sinauer Associates, Inc.

Ito, T. A., Larsen, J. T., Smith, N. K., \& Cacioppo, J. T. (1998). Negative information weighs more heavily on the brain: The negativity bias in evaluative categorizations. Journal of Personality and Social Psychology, 75, 887-900.

James, W. (1890). The principles of psychology. New York: Holt.

Jepson, C., \& Chaiken, S. (1990). Chronic issue-specific fear inhibits systematic processing of persuasive communications. Journal of Social Behavior \& Personality, 5, 61-84.

Joffe, H. (2000). Adherence to health messages: A social psychological perspective. International Dental Journal, 295-303.

Johnson, R. (1993). On the neural generators of the P300 component of the event-related potential. Psychophysiology, 30, 90-97.

Jonides, J., \& Mack, R. (1984). On the cost and benefit of cost and benefit. Psychological Bulletin, 96, 29-44.

Keller, P. A. (1999). Converting the unconverted: The effect of inclination and opportunity to discount health-related fear appeals. Journal of Applied Psychology, 84, 403-415.

Keller, P. A., \& Block, L. G. (1999). The effect of affect-based dissonance versus cognition-based dissonance on motivated reasoning and health-related persuasion. Journal of Experimental Psychology: Applied, 5, 302-313.

Kessels, L. T. E., Ruiter, R. A. C., \& Jansma, B. M. (in press). Increased attention but moer efficient disengagement: Neuroscientific evidence for defensive processing of threatening health information. Health Psychology.

Killgore, W. D., \& Yurgelun-Todd, D. A. (2004). Activation of the amygdala and anterior cingulate during nonconscious processing of sad versus happy faces. Neurolmage, 21, 1215-1223. 
Kim, H., Somerville, L. H., Johnstone, T., Alexander, A. L., \& Whalen, P. J. (2003). Inverse amygdala and medial prefrontal cortex responses to surprised faces. NeuroReport: For Rapid Communication of Neuroscience Research, 14, 2317-2322.

Klein, R. M. (2004). On the control of visual orienting. In M. I. Posner (Ed.), Cognitive neuroscience of attention (pp. 29-44). New York: The Guilford Press.

Klein, W. M. P., \& Harris, P. R. (2009). Self-affirmation enhances attentional bias toward threatening components of a persuasive message. Psychological Science, 20, 1463-1467.

Kok, A. (1997). Event-related potential (ERP) reflections of mental resources: A review and synthesis. Biological Psychology, 45, 19-56.

Koster, E. H. W., Crombez, G., Van Damme, S., Verschuere, B., \& De Houwer, J. (2004). Does Imminent Threat Capture and Hold Attention? Emotion, 4, 312-317.

Koster, E. H. W., Crombez, G., Verschuere, B., \& De Houwer, J. (2004). Selective attention to threat in the dot probe paradigm: differentiating vigilance and difficulty to disengage. Behaviour Research and Therapy, 42, 1183-1192.

Kramer, A. F., Wickens, C. D., \& Donchin, E. (1985). The processing of stimulus properties: Evidence for dual task integrality. Journal of Experimental Psychology: Human Perception and Performance, 11, 393-408.

Kreuter, M. W., Bull, F. C., Clark, E. M., \& Oswald, D. L. (1999). Understanding how people process health information: A comparison of tailored and nontailored weight-loss materials. Health Psychology, 18, 487-494.

Kreuter, M. W., Farrell, D., Olevitch, L., \& Brennan, M. (2000). Tailored health messages: Customizing communication with computer technology. Mahwah, NJ: Lawrence Erlbaum.

Kreuter, M. W., \& Holt, C. L. (2001). How do people process health information? Applications in an age of individualized communication. Current Directions in Psychological Science, 10, 206-209.

Kreuter, M. W., Oswald, D. L., Bull, F. C., \& Clark, E. M. (2000). Are tailored health education materials always more effective than non-tailored materials? Health Education Research, 15, 305-315.

Kroeze, W., Werkman, A., \& Brug, J. (2006). A Systematic Review of Randomized Trials on the Effectiveness of Computer-Tailored Education on Physical Activity and Dietary Behaviors. Annals of Behavioral Medicine, 31, 205-223.

Krugman, D. M., Fox, R. J., Fletcher, J. E., \& Fischer, P. M. (1994). Do adolescents attend to warnings in cigarette advertising? An eye-tracking approach. Journal of Advertising Research, 34, 39-52.

Kunda, Z. (1990). The case for motivated reasoning. Psychological Bulletin, 108, 480-498.

Kuppens, M., de Wit, J., \& Stroebe, W. (1996). Angstaanjagendheid in gezondheidsvoorlichting: een dual process analyse [Fear-arousing health persuasion: A dual-process analysis]. Gedrag \& Gezondheid: Tijdschrift voor Psychologie en Gezondheid, 24, 241-248.

LaBerge, D., Carlson, R. L., Williams, J. K., \& Bunney, B. G. (1997). Shifting attention in visual space: Tests of moving-spotlight models versus an activity-distribution model. Journal of Experimental Psychology: Human Perception and Performance, 23, 1380-1392.

Lane, R. D., Reiman, E. M., Bradley, M. M., Lang, P. J., Ahern, G. L., Davidson, R. J., et al. (1997). Neuroanatomical correlates of pleasant and unpleasant emotion. Neuropsychologica, 35, 14371444.

Lawrence, T. (1999). A stage-based approach to behaviour change. In E. R. Perkins, I. Simnett \& L. Wright (Eds.), Evidence-based health promotion (pp. 64-75). West Sussex, England: Wiley \& Sons.

Lazarus, R. S., \& Folkman, S. (1984). Stress, appraisal and coping. New York: Springer. 
Leippe, M. R., \& Elkin, R. A. (1987). When motives clash: Issue involvement and response involvement as determinants of persuasion. Journal of Personality and Social Psychology, 52, 269-278.

Leventhal, H. (1970). Findings and theory in the study of fear communication. In L. Berkowitz (Ed.), Advances in experimental social psychology (Vol. 5, pp. 119-186). New York: Academic Press.

Leventhal, H. (1971). Fear appeals and persuasion: The differentiation of a motivational construct. American Journal of Public Health, 61, 1208-1224.

Levy, M. R., \& Windahl, S. (1985). The concept of audience activity. In K. E. Rosengren, L. A. Wenner \& P. Palmgreen (Eds.), Media gratifications research: Current perspectives (pp. 109-122). Beverly Hills, CA: Sage.

Liberman, A., \& Chaiken, S. (1992). Defensive processing of personally relevant health messages. Personality and Social Psychology Bulletin, 18, 669-679.

Liberzon, I., Phan, K. L., Decker, L. R., \& Taylor, S. F. (2003). Extended amygdala and emotional salience: A PET activation study of positive and negative affect. Neuropsychopharmacology, 28, 726-733.

Lieberman, M. D. (2010). Social cognitive neuroscience. In S. Fiske, D. T. Gilbert \& G. Lindzey (Eds.), Handbook of social psychology (5th ed., pp. 143-193). New York: McGraw-Hill.

MacKinnon, D. P., \& Lapin, A. (1998). Effects of alcohol warnings and advertisements: A test of the boomerang hypothesis. Psychology \& Marketing, 15, 707-726.

MacLeod, C., Mathews, A., \& Tata, P. (1986). Attentional bias in emotional disorders. Journal of Abnormal Psychology, 95, 15-20.

Maddux, J. E., \& Rogers, R. W. (1983). Protection motivation and self-efficacy: A revised theory of fear appeals and attitude change. Journal of Experimental Social Psychology, 19, 469-479.

Maibach, E., \& Murphy, D. A. (1995). Self-efficacy in health promotion research and practice: Conceptualization and measurement. Health Education Research, 10, 37-50.

Mangun, G. R., \& Hillyard, S. A. (1995). Mechanisms and models of selective attention. In M. D. Rugg \& M. G. H. Coles (Eds.), Electrophysiology of mind: Event-related brain potentials and cognition (pp. 40-85). Oxford, England: Oxford University Press.

McGuire, W. J. (1985). Attitude and attitude change. In G. Lindzey \& E. Aronson (Eds.), The handbook of social psychology (pp. 233-346). New York: Random House.

Meijnders, A. L., Midden, C. J. H., \& Wilke, H. A. M. (2001). Communications about environmental risks and risk-reducing behavior: The impact of fear on information processing. Journal of $A p$ plied Social Psychology, 31, 754-777.

Melara, R. D., \& Algom, D. (2003). Driven by information: A tectonic theory of Stroop effects. Psychological Review, 110, 422-471.

Michie, S., Abraham, C., Whittington, C., McAteer, J., \& Gupta, S. (2009). Effective techniques in health eating and physical activity interventions: A meta-regression. Health Psychology, 28, 690701.

Milne, S., Sheeran, P., \& Orbell, S. (2000). Prediction and intervention in health-related behavior: A meta-analytic review of protection motivation theory. Journal of Applied Social Psychology, 30, 106-143.

Moriarty, C. M., \& Stryker, J. E. (2008). Prevention and screening efficacy messages in newspaper accounts of cancer. Health Education Research, 23, 487-498.

Morris, J. S., Friston, K. J., Büchel, C., Frith, C. D., Young, A. W., Calder, A. J., et al. (1998). A neuromodulatory role for the human amygdala in processing emotional facial expressions. Brain: $A$ Journal of Neurology, 121, 47-57. 
Morris, J. S., Frith, C. D., Perrett, D. I., Rowland, D., Young, A. W., \& Calder, A. J. (1996). A differential neural response in the human amygdala to fearful and happy facial expressions. Nature, 383, 812-815.

Näätänen, R. (1992). Attention and brain function. Hillsdale, NJ: Erlbaum.

Noar, S. M., Benac, C. N., \& Harris, M. S. (2007). Does tailoring matter? Meta-analytic review of tailored print health behavior change interventions. Psychological Bulletin, 133, 673-693.

Norton, L. (1998). Health promotion and health education: What role should the nurse adopt in practice. Journal of Advanced Nursing, 28, 1269-1275.

Ochsner, K. N., Ray, R. R., Hughes, B., McRae, K., Cooper, J. C., Weber, J., et al. (2009). Bottom-up and top-down processes in emotion generation: Common and distinct neural mechanisms. Psychological Science, 20, 1322-1331.

Parrott, R. L. (1995). Motivation to attend to health messages: Presentation of content and linguistic considerations. In E. Maibach \& R. L. Parrott (Eds.), Designing health messages: Approaches from communication theory and public health practice (pp. 7-23). Thousand Oaks, CA: Sage.

Perchet, C., \& Garcia-Larrea, L. (2000). Visuospatial attention and motor reaction in children: An electrophysiological study of the "Posner" paradigm. Psychophysiology, 37, 231-241.

Pessoa, L., Japee, S., Sturman, D., \& Ungerleider, L. G. (2006). Target visibility and visual awareness modulate amygdala responses to fearful faces. Cerebral Cortex, 16, 366-375.

Petty, R. E., \& Cacioppo, J. T. (1986). Communication and persuasion: Central and peripheral routes to attitude change. New York: Springer-Verlag.

Petty, R. E., Cacioppo, J. T., \& Schumann, D. (1983). Central and peripheral routes to advertising effectiveness: The moderating role of involvement. Journal of Consumer Research, 10, 135-146.

Phan, K. L., Taylor, S. F., Welsh, R. C., Ho, S. H., Britton, J. C., \& Liberzon, I. (2004). Neural correlates of individual ratings of emotional salience: A trial-related fMRI study. Neurolmage, 21, 768-780.

Phillips, M. L., Young, A. W., Senior, C., Brammer, M., Andrews, C., Calder, A. J., et al. (1997). A specific neural substrate for perceiving facial expressions of disgust. Nature, 389, 495-498.

Polich, J. (2007). Updating P300: An integrative theory of P3a and P3b. Clinical Neurophysiology, 118, 2128-2148.

Pollak, S. D., \& Tolley-Schell, S. A. (2003). Selective attention to facial emotion in physically abused children. Journal of Abnormal Psychology, 112, 323-338.

Posner, M. I. (1980). Orienting of attention. Quarterly Journal of Experimental Psychology, 32, 3-25.

Posner, M. I. (2004). Progress in attention research. In M. I. Posner (Ed.), Cognitive neuroscience of attention (pp. 3-9). New York: The Guilford Press.

Posner, M. I., Inhoff, A. W., Friedrich, F. J., \& Cohen, A. (1987). Isolating attentional systems: A cognitive-anatomical analysis. Psychobiology, 15, 107-121.

Posner, M. I., Walker, J. A., Friedrich, F. A., \& Rafal, R. D. (1984). Effects of parietal injury on covert orienting of attention. The Journal of Neuroscience, 4, 1863-1874.

Price, C. J., Wise, R. J. S., \& Frackowiak, R. S. J. (1996). Demonstrating the implicit processing of visually presented words and pseudowords. Cerebral Cortex, 6, 62-70.

Rabbitt, P. (1982). Visual search. In C. R. Puff (Ed.), Handbook of research methods in human memory and cognition. New York: Academic Press.

Rameson, L. T., Satpute, A. B., \& Lieberman, M. D. (2010). The neural correlates of implicit and explicit self-relevant processing. Neurolmage, 50, 701-708.

Rayner, K. (1998). Eye movements in reading and information processing: 20 years of research. Psychological Bulletin, 124, 372-422. 
Reynolds, J. H. (2004). Attention and contrast gain control. In M. I. Posner (Ed.), Cognitive neuroscience of attention (pp. 127-143). New York: The Guilford Press.

Rimer, B. K., \& Glassman, B. (1999). Is there a use for tailored print communication in cancer risk communication? Journal of the National Cancer Institute Monographs, 25, 140-148.

Rippetoe, P. A., \& Rogers, R. W. (1987). Effects of components of protection-motivation theory on adaptive and maladaptive coping with a health threat. Journal of Personality and Social Psychology, 52, 596-604.

Rogers, R. W. (1975). A protection motivation theory of fear appeals and attitude change. Journal of Psychology: Interdisciplinary and Applied, 91, 93-114.

Rogers, R. W. (1983). Cognitive and physiological processes in fear appeals and attitude change: A revised theory of protection motivation. In J. T. Cacioppo \& R. E. Petty (Eds.), Social psychophysiology: A sourcebook (pp. 153-176). New York: The Guilford Press.

Ruiter, R. A. C., Abraham, C., \& Kok, G. (2001). Scary warnings and rational precautions: A review of the psychology of fear appeals. Psychology and Health, 16, 613-630.

Ruiter, R. A. C., Kessels, L. T. E., Jansma, B. M., \& Brug, J. (2006). Increased attention for computertailored health communications: An event-related potential study. Health Psychology, 25, 300306.

Ruiter, R. A. C., \& Kok, G. (2005). Saying is not (always) doing: Cigarette warning labels are useless. European Journal of Public Health, 15, 329-330.

Ruiter, R. A. C., \& Kok, G. (2006). Response to Hammond et al. Showing leads to doing, but doing what? The need for experimental pre-testing. European Journal of Public Health, 16, 225.

Ruiter, R. A. C., Kok, G., Verplanken, B., \& Brug, J. (2001). Evoked fear and effects of appeals on attitudes to performing breast self-examination: An information-processing perspective. Health Education Research, 16, 307-319.

Sanders, A. F. (1997). A summary of resources theories from a behavioral perspective. Biological Psychology, 45, 5-18.

Scheuerecker, J., Frodl, T., Koutsouleris, N., Zetzsche, T., Wiesmann, M., Kleemann, A. M., et al. (2007). Cerebral differences in explicit and implicit emotional processing--An fMRI study. Neuropsychobiology, 56, 32-39.

Sherman, D. A. K., Nelson, L. D., \& Steele, C. M. (2000). Do messages about health risks threaten the self? Increasing the acceptance of threatening health messages via self-affirmation. Personality and Social Psychology Bulletin, 26, 1046-1058.

Sivacek, J., \& Crano, W. D. (1982). Vested interest as a moderator of attitude-behavior consistency. Journal of Personality and Social Psychology, 43, 210-221.

Skinner, C. S., Campbell, M. K., Rimer, B. K., Curry, S., \& Prochaska, J. O. (1999). How effective is tailored print communication? Annals of Behavioral Medicine, 21, 290-298.

Skinner, C. S., Strecher, V. J., \& Hospers, H. (1994). Physician recommendations for mammography: Do tailored messages make a difference? American Journal of Public Health, 84, 43-49.

Smith, D. J. (1990). The impact of product usage warnings in alcoholic beverage advertising. journal of Public Policy and Marketing, 9, 16-29.

Smith, N. K., Cacioppo, J. T., Larsen, J. T., \& Chartrand, T. L. (2003). May I have your attention, please: Electrocortical responses to positive and negative stimuli. Neuropsychologia, 41, 171-183.

Snyder, L. B., \& Blood, D. J. (1992). Caution: Alcohol advertising and the Surgeon General's alcohol warnings may have adverse effects on young adults. Journal of Applied Communication Research, 20, 37-53. 
Sperling, G., \& Weichselgartner, E. (1995). Episodic theory of the dynamics of spatial attention. Psychological Review, 102, 503-532.

Srinivasan, R. (2004). High-Resolution EEG: Theory and Practice. In T. C. Handy (Ed.), Event-Related potentials: A methods handbook (pp. 167-188). Cambridge, MA: The MIT press.

Swanson, J. M., Posner, M. I., Potkin, S. G., Bonforte, S., Youpa, D., Fiore, C., et al. (1991). Activating tasks for the study of visual-spatial attention in ADHD children: A cognitive anatomic approach. Journal of Child Neurology, 6, 119-127.

Talairach, J., \& Tournoux, P. (1988). Co-planar stereotaxic atlas of the human brain. New York: Thieme Medical.

Taubman - Ben-Ari, O., Florian, V., \& Mikulincer, M. (2000). Does a threat appeal moderate reckless driving? A terror management theory perspective. Accident Analysis and Prevention, 32, 1-10.

Taylor, S. E. (1991). Asymmetrical effects of positive and negative events: The mobilizationminimization hypothesis. Psychological Bulletin, 110, 67-85.

Taylor, S. E. (2008). Current issues and new directions in Psychology and Health: Bringing basic and applied research together to address underlying mechanisms. Psychology \& Health, 23, 131-134.

Taylor, S. F., Phan, K. L., Decker, L. R., \& Liberzon, I. (2003). Subjective rating of emotionally salient stimuli modulates neural activity. Neurolmage, 18, 650-659.

Thomsen, S. R., \& Fulton, K. (2007). Adolescents' attention to responsibility messages in magazine alcohol advertisements: An eye-tracking approach. The Journal of Adolescent Health 41, 27-34.

van Assema, P., Brug, J., Ronda, G., Steenhuis, I., \& Oenema, A. (2002). A short dutch questionnaire to measure fruit and vegetable intake: relative validity among adults and adolescents. Nutrition and Health, 16, 85-106.

Van Koningsbruggen, G. M., \& Das, E. (2009). Don't derogate this message! Self-affirmation promotes online type 2 diabetes risk test taking. Psychology \& Health, 24, 635-649.

Van Koningsbruggen, G. M., Das, E., \& Roskos-Ewoldsen, D. R. (2009). How self-affirmation reduces defensive processing of threatening health information: Evidence at the implicit level. Health Psychology, 28, 563-568.

Vuilleumier, P. (2005). How brains beware: Neural mechanisms of emotional attention. Trends in Cognitive Sciences, 9, 585-594.

Wedel, M., \& Pieters, R. (2000). Eye fixations on advertisements and memory for brands: A model and findings. Marketing Science, 19, 297-312.

Whitehead, D., \& Russell, G. (2004). How effective are health education programmes--resistance, reactance, rationality and risk? Recommendations for effective practice. International Journal of Nursing Studies, 41, 163-172.

Wilder, D. A., \& Shapiro, P. (1989). Effects of anxiety on impression formation in a group context: An anxiety-assimilation hypothesis. Journal of Experimental Social Psychology, 25, 481-499.

Wilson, T. D. (2002). Strangers to ourselves: Discovering the adaptive unconscious. Cambridge, MA: The Belknap Press of Harvard University Press.

Wilson, T. D., \& Dunn, E. W. (2004). Self-knowledge: Its limits, value and potential for improvement. Annual Review of Psychology, 55, 493-518.

Winston, J. S., O'Doherty, J., \& Dolan, R. J. (2003). Common and distinct neural responses during direct and incidental processing of multiple facial emotions. Neurolmage, 20, 84-97.

Witte, K. (1992). Putting the fear back into fear appeals: The extended parallel process model. Communication Monographs, 59, 329-349. 
Witte, K., \& Allen, M. (2000). A meta-analysis of fear appeals: Implications for effective public health campaigns. Health Education \& Behavior, 27, 591-615.

Witte, K., Berkowitz, J. M., Cameron, K. A., \& McKeon, J. K. (1998). Preventing the spread of genital warts: Using fear appeals to promote self-protective behaviors. Health Education \& Behavior, 25, 571-585.

Woodgate, J., \& Brawley, L. R. (2008). Use of an efficacy-enhancing message to influence the selfregulatory efficacy of cardiac rehabilitation participants: A field experiment. Rehabilitation Psychology, 53, 153-161.

Worsley, K. J., \& Friston, K. J. (1995). Analysis of fMRI time-series revisited--again. Neurolmage, 15, 173-181.

Wright, P., Albarracin, D., Brown, R. D., Li, H., He, G., \& Liu, Y. (2008). Dissociated responses in the amygdala and orbitofrontal cortex to bottom-up and top-down components of emotional evaluation. Neurolmage, 39, 894-902.

Zhang, J. X., Feng, C., Fox, P. T., Gao, J., \& Tan, L. H. (2004). Is the left inferior frontal gyrus a general mechanism for selection? Neurolmage, 23, 596-603. 

Summary 
Health education messages have the goal to encourage and motivate people to engage in health promoting and disease preventive behaviours and thus reduce health problems and costs in our society. Evidence shows however that health messages often fail to bring about a successful behavioural change (Parrott, 1995). Changing people's health-related behaviour is a difficult and complex task (Joffe, 2000; Lawrence, 1999; Norton, 1998; Whitehead \& Russell, 2004). Partly, this failure can be attributed to the ways that people process the information they have been exposed to (Levy \& Windahl, 1985).

The current research project was meant to improve our knowledge of the underlying working mechanisms of different health education methods. In particular, attention processes in response to personally relevant threatening health messages were investigated. Five empirical studies explored attention processes for tailored health messages and threatening health information by applying the methods of EEG, fMRI, eye tracking and reaction times.

Following Chapter 1, which provides a general introduction, Chapter 2 describes an experimental study in which attention processes for tailored versus non-tailored nutrition education messages were compared. In an oddball-task participants read the messages while EEG and reaction times were measured. The results showed that tailored nutrition information leads to more attention for the message than non-tailored nutrition information. This positive attention effect was found on the P300 ERP measure, but not on the reaction times and the self-report measure of perceived attention. The reaction times however were in the predicted direction. Additionally, more participants were motivated to change their diet / eating behaviour after reading tailored information than after reading non-tailored information. It was concluded that these findings provided support for the dual process models of attitude change that hold that personal relevant information is more systematically processed than information that is less self-relevant (e.g., Petty \& Cacioppo, 1986).

Chapter 3 describes an experimental study (study 2 ) in which the attention processes for self-relevant health information in combination with threatening health information was investigated. Tailored and non-tailored health information messages were combined with either high or low threatening health information. Attention effects on the combination of message tailoring and threatening health information were investigated by using the same oddball paradigm as in study 1 . EEG and reaction times were measured while reading the health messages. Results showed positive attention effects for message tailoring, reflected in the P300 ERP measure and on the reaction times. The results on the P300 ERP measure showed also more attention for low threat information compared to high threat information, irrespective of the personal relevance of the health information. The results on the self-report measure of perceived attention did not support the results on the ERP and the reaction times data. The findings confirm that tailoring is an effective means to draw attention to health messages, whereas threat information seems to result in a loss in message attention. 
Chapter 4 presents study 3 in which attention capture and attention disengagement processes for self-relevant threatening health information were investigated. High threat and low threat smoking pictures were presented among participant for whom the information was self-relevant (i.e., smokers) or non-self-relevant (i.e., non-smokers). While performing a variant of the Posner's cueing task EEG and RT were measured. Smokers showed lower P300 amplitudes in response to high as opposed to low threatening pictures when moving their attention to a target in the opposite visual field, indicating more efficient attention disengagement processes. Furthermore, both smokers and nonsmokers showed increased P300 amplitudes in response to the presentation of high as opposed to low threatening pictures when the target was presented in the same virtual field, indicating threat-induced attention capture processes. Reaction time measures did not support the ERP data. The ERP findings provided support for the hypothesis that threatening health information causes more efficient disengagement among those for whom the health threat is self-relevant.

Chapter 5 focuses on the brain regions involved in processing self-relevant threatening health information. The high spatial resolution method of fMRI was used as an instrument to measure brain activation while processing high and low threat health smoking pictures. Smokers and non-smokers made explicit and implicit judgments of each smoking picture. The results demonstrated that threat modulation was visible in wellknown emotion-related regions, including the amygdala. No support was found for a difference between smokers and non-smokers in brain activation patterns of the amygdala and reaction times when processing high threat self-relevant information. Although the brain activation patterns of the amygdala showed no effect of self-relevance, correlation analyses provided support for a difference in amygdala involvement between smokers and non-smokers. Among smokers, the amygdala responses in the explicit task correlated with behavioural performances. These findings suggest that self-relevance of the information made a difference during complex processing such as its labelling. No conclusions could be drawn whether self-relevance of the information had a positive or a negative effect on message attention.

Chapter 6 presents the last study (study 5) in which we explored attention processes for cigarette packages containing three different health related messages. Smoking cigarette packages were created containing either high threat information about the negative consequences of smoking, coping information referring smokers to ways to effectively quit smoking or low threat information about smoking. Eye movements were recorded while smokers and non-smokers viewed the different smoking cigarette packages. The aim of this study was to investigate which kind of (written) information (low risk, coping information or high risk) attracts most attention from smokers and non-smokers. The results of the eye movement data showed that smokers and non-smokers tend to spend less time looking (i.e., less unique fixations and less dwell time) at the low risk and high risk information than at the coping information. Smoking status did not tend to influence 
attention processes to the health messages. In contrast, coping information was less positively evaluated than high threat information. This study thus showed attention preferences for coping information irrespective of whether the person already follows the recommended behaviour or not.

Finally, in chapter 7 the findings of the studies are provided and discussed. This thesis showed that message tailoring and coping information are potentially effective tools to increase attention for health information. Although investigating the relation between self-relevance, threatening health information and attention reveals a complex pattern of results, presenting threatening health information can cause defensive reactions. Finally, to measure attention processes for health information it is recommended to apply neuroscience techniques to obtain non-invasive and objective measures of attention during message processing. 


\section{Samenvatting}


Het doel van gezondheidsvoorlichtingsboodschappen is het aanmoedigen en het motiveren van mensen om deel te nemen aan gezondheidsbevorderende en ziektepreventieve gedragingen om gezondheidsproblemen en kosten in onze samenleving te reduceren. Empirisch onderzoek laat echter zien dat gezondheidsboodschappen er vaak niet in slagen een succesvolle gedragsverandering tot stand te brengen (Parrott, 1995). Het realiseren van gedragsverandering via voorlichting is een moeilijke en complexe taak (Joffe, 2000; Lawrence, 1999; Norton, 1998; Whitehead \& Russell, 2004). Gedeeltelijk is deze complexiteit toe te schrijven aan de wijze waarop mensen gezondheidsinformatie verwerken (Levy \& Windahl, 1985).

Het huidige onderzoeksproject heeft als doel tot een beter inzicht te komen in de onderliggende werkingsmechanismen van verschillende gezondheidsvoorlichtinsmethodieken. In het bijzonder werden de aandachtsprocessen voor persoonlijk relevante en bedreigende gezondheidsboodschappen onderzocht. Vijf empirische studies onderzochten aandachtsprocessen voor advies-op-maat boodschappen en bedreigende gezondheidsinformatie door gebruik te maken van de methodes van EEG, $\mathrm{FMRI}$, oogbewegingen en reactietijden.

Na de algemene introductie op het uitgevoerde onderzoek in dit proefschrift (Hoofdstuk 1) wordt in Hoofdstuk 2 een empirische studie beschreven waarin aandachtsprocessen voor advies-op-maat en algemene voedingsvoorlichtingsboodschappen met elkaar werden vergeleken. In een oddball-taak lazen de deelnemers voorlichtingsboodschappen over gezonde voeding terwijl EEG en reactietijden werden gemeten. De resultaten toonden aan dat advies-op-maat voedingsinformatie tot meer aandacht leidt voor de boodschap dan algemene voedinsinformatie. Dit positieve aandachtseffect werd wel gevonden op de P300 hersenpotentiaal maar niet op de reactietijden en de zelfrapportage vraag naar de mate van aandacht die deelnemers voor de boodschap hadden. De scores op de reactietijden waren echter wel in de voorspelde richting. Aanvullend werd gevonden dat meer deelnemers gemotiveerd waren hun eetgedrag te veranderen na het lezen van een advies-op-maat dan na het lezen van een algemeen advies. Geconcludeerd werd dat deze bevindingen steun geven voor informatieverwerkingsmodellen die aangeven dat persoonlijk relevante informatie meer systematisch wordt verwerkt dan informatie die minder zelf-relevant is (bijv. Petty \& Cacioppo, 1986).

Hoofdstuk 3 beschrijft een experimentele studie (studie 2) waarin aandachtsprocessen voor zelf-relevante bedreigende gezondheidsinformatie werden onderzocht. Adviesop-maat en algemene gezondheidsinformatieboodschappen werden gecombineerd met hoog of laag bedreigende gezondheidsinformatie. Effecten van aandacht werden onderzocht door gebruik te maken van het oddball-paradigma van studie 1 . EEG en reactietijden werden gemeten tijdens het lezen van de gezondheidsboodschappen. Resultaten op de P300 ERP-maat en de reactietijden toonden positieve aandachtseffecten voor adviesop-maat. De resultaten op de P300 ERP maat toonden verder meer aandacht voor laag bedreigende informatie dan voor hoog bedreigende informatie, ongeacht, de persoonlij- 
ke relevantie van de gezondheidsinformatie. Op de mate van zelfgerapporteerde aandacht werden geen effecten van beide typen voorlichtingsboodschappen gevonden. De bevindingen bevestigen dat advies-op-maat een effectieve methode is voor het trekken van aandacht naar gezondheidsboodschappen, terwijl bedreigende informatie lijkt te resulteren in verminderde aandacht voor de boodschap.

Hoofdstuk 4 beschrijft studie 3 waarin processen van het vangen van aandacht voor zelf-relevante bedreigende gezondheidsinformatie en de loskoppeling van diezelfde aandacht werden onderzocht. Hoog en laag bedreigende foto's over roken werden getoond aan deelnemers voor wie de informatie zelf-relevant (rokers) en niet zelf-relevant (niet rokers) was. Tijdens het uitvoeren van een variant van de Posner cueing taak werden EEG en reactietijden gemeten. In tegenstelling tot niet rokers, scoorden rokers lagere P300 amplitudes in reactie op hoog in plaats van laag bedreigende foto's tijdens het verschuiven van de aandacht naar een doelstimulus in het tegenovergestelde gezichtsveld. Deze bevinding duidt op meer efficiënte processen van loskoppeling van aandacht bij rokers dan bij niet rokers. Tevens werden bij zowel rokers als niet-rokers hogere P300 amplitudes in reactie op de presentatie van hoog bedreigende in plaats van laag bedreigende foto's gevonden als de doelstimulus in het zelfde gezichtsveld als de foto's verscheen. Deze bevinding suggereert dat bedreigende informatie van nature de aandacht trekt. Reactietijden gaven geen steun voor de ERP bevindingen. De ERP bevindingen bieden steun voor de hypothese dat bedreigende gezondheidsinformatie voor een meer efficiënte loskoppeling van aandacht zorgt bij die mensen voor wie de gezondheidsdreiging zelf-relevant is.

Hoofdstuk 5 richt zich op de hersengebieden die betrokken zijn bij de verwerking van bedreigende gezondheidsinformatie. fMRI werd als hoog-spatiële resolutie methode gebruikt voor het meten van hersenactiviteit tijdens het verwerken van hoog en laag bedreigende informatie over roken. De resultaten toonden aan dat dreiging tot verschillende mate van activiteit leidde in bekende emotie-gerelateerde hersengebieden, inclusief de amygdala. Er werd geen steun gevonden voor een verschil tussen rokers en nietrokers in de mate van hersenactiviteit in de amygdala en op de reactietijden tijdens het verwerken van hoog en laag bedreigende zelf-relevante gezondheidsinformatie. Hoewel er geen effect van zelfrelevantie van de gezondheidsinformatie op de mate van activiteit in de amygdala werd gevonden, boden correlatie-analyses steun voor een verschil tussen rokers en niet-rokers in de betrokkenheid van de amygdala bij de verwerking van bedreigende informatie. Alleen voor rokers werden significante correlaties gevonden tussen de mate van activiteit in de amygdala en de reactietijden in de gedragstaak. Deze bevindingen suggereren dat de mate van zelf-relevantie van gezondheidsinformatie invloed heeft op de complexe verwerking van die informatie zoals bijvoorbeeld tijdens processen van categorisatie en benoeming. In hoeverre deze effecten positief of negatief zijn kon niet worden vastgesteld. 
Hoofdstuk 6 beschrijft de laatste empirische studie (studie 5). Hierin hebben we aandachtsprocessen voor sigarettenpakjes met drie verschillende gezondheidsgerelateerde boodschappen onderzocht. Er werden sigarettenpakjes gecreëerd met ofwel hoog-bedreigende informatie met betrekking tot de negatieve gevolgen van rokers, aanbevelingsinformatie die rokers wijst op manieren om effectief te stoppen met roken, ofwel laag-bedreigende informatie over roken. Terwijl rokers en niet-rokers verschillende sigarettenpakjes bekeken werden oogbewegingen gemeten. Het doel van deze studie was te onderzoeken welke soort (geschreven) informatie (laag risico, aanbeveling, of hoog risico) de meest aandacht trekt van rokers en niet-rokers. De resultaten van de oogbewegingsdata - in het bijzonder het aantal unieke fixaties en de duur waarin deelnemers naar een uniek punt keken - toonden aan dat rokers en niet-rokers minder tijd spendeerden aan het kijken naar laag-risico en de hoog-risico informatie dan naar de aanbevelingsinformatie. Rookstatus had geen invloed op de aandachtsprocessen voor de gezondheidsboodschappen. Een opvallende bevinding was verder dat aanbevelingsinformatie minder positief werd geëvalueerd dan hoog bedreigende informatie. Deze studie toonde dus een aandachtsvoorkeur aan voor aanbevelings informatie ongeacht of de persoon het ongezonde gedrag wel of niet vertoonde.

Tot besluit worden in hoofdstuk 7 de bevindingen van de verschillende studies besproken. Geconcludeerd wordt dat gepersonaliseerde gezondheidsinformatie en aanbevelingsinformatie effectieve instrumenten kunnen zijn om de aandacht voor gezondheidsinformatie te verhogen. Hoewel de verschillende onderzoeken naar de relatie tussen zelfrelevantie, bedreigende gezondheidsinformatie en aandacht een complex patroon van resultaten laten zien, kan het presenteren van bedreigende gezondheidsinformatie defensieve reacties veroorzaken. Tot slot, voor het meten van aandachtsprocessen voor gezondheidsinformatie wordt het gebruik van non-invasieve neurowetenschappelijke technieken ten zeerste aanbevolen om zo tot een objectieve meting van aandacht tijdens de verwerking van gezondheidsinformatie te komen. 


\section{Curriculum Vitae}





\section{Curriculum Vitae}

Loes Kessels was born on July 25, 1981, in Montfort, The Netherlands. In June 1999, she graduated from secondary school (Bisschoppelijk College Echt). She started studying Psychology at Maastricht University in September 1999. In 2004, she graduated in cognitive psychology and biological psychology. Before starting her PhD Research in January 2006 at the Department of Work \& Social Psychology, Maastricht University, she was a research assistant for one year at the Department of Experimental Psychology. Currently, she is a postdoctoral fellow at the Department of Work \& Social Psychology, Maastricht University. 
The "Kurt Lewin Institute Dissertation Series" started in 1997. Since 2008 the following dissertations have been published:

2008-1: Marijke van Putten: Dealing with missed opportunities. The causes and boundary conditions of inaction inertia

2008-2: Marjolein Maas: Experiential Social Justice Judgment Processes

2008-3: Lonneke de Meijer: Ethnicity effects in police officer selection: Applicant, assessor, and selection-method factors

2008-4: Frederike Zwenk: Voice by Representation

2008-5: Margreet Reitsma: The Impact of Linguistically Biased Messages on Involved Receivers

2008-6: Marcus Maringer: Feeling one thing, seeing another: Emotion comparison effects in person judgments

2008-7: Hanneke Heinsman: The competency concept revealed: Its nature, relevance, and practice

2008-8: Joris Lammers: Toward a more social social psychology of power

2008-9: Daniël Fockenberg: Between Good and Evil: Affective Priming in Dynamic Context

2008-10: Arne van den Bos: Why we stereotype influences how we stereotype: selfenhancement and comprehension effects on social perception

2008-11: Lidewij Niezink: Considering Others in Need: On Altruism, Empathy and Perspective Taking

2008-12: Aad Oosterhof: Better together: Antecedents and consequences of perceived expertise dissimilarity and perceived expertise complementarity in teams

2008-13: Femke ten Velden: Negotiation in dyads and groups: The effects of social and epistemic motives

2008-14: Maike Wehrens: How did YOU do? Social comparison in secondary education

2008-15: Kyra Luijters: Making Diversity Bloom: Coping Effectively with Cultural Differences at Work

2008-16: llona de Hooge: Moral emotions in decision making: Towards a better understanding of shame and guilt

2008-17: Lindred L. Greer: Team Composition and Conflict: The Role of Individual Differences

2008-18: Sezgin Cihangir: The Dark Side of Subtle Discrimination: How targets respond to different forms of discrimination

2008-19: Giel Dik: On the contagiousness of others' goals: The role of perceiving effort

2008-20: Lotte van Dillen: Dealing with negative feelings: The role of working memory in emotion regulation 
2008-21: Marijn Poortvliet: Information exchange examined: An interpersonal account of achievement goals

2008-22: Sjoerd Pennekamp: Dynamics of disadvantage: Uncovering the role of groupbased anger

2008-23: Chris Reinders Folmer: Cooperation and communication: Plastic goals and social roles

2009-1: Marijke Leliveld: Ethics in Economic Decision-Making

2009-2: Monique Pollmann: Accuracy and Bias in Person Perception

2009-3: Krispijn Faddegon: Regulatory Focus in Group Contexts

2009-4: Lieven Brebels: Mirror, mirror on the wall... Procedural fairness as an evaluative and regulatory looking-glass self

2009-5: Daphne Wiersema: Taking it personally: Self-esteem and the protection of selfrelated attitudes

2009-6: Judith D.M. Grob: Dial E for Emotion: Context and Consequences of Emotion Regulation

2009-7: Katherine Stroebe: Is this about me? Responding to subtle discrimination beyond an individual versus group perspective

2009-8: Menno Vos: Identity patterns in diverse work groups: Improving social integration outcomes through relational identities

2009-9: Lennart Renkema: Facing Death Together: Understanding The Consequences of Mortality Threats

2009-10: Michael Vliek: Group-based social comparison processes: An intragroup level of analysis

2009-11: Karlijn Massar: Unconscious rivals: The automatic evaluation of rivals in jealousy-evoking situations

2009-12: Bart Terwel: Origins and consequences of public trust: Towards an understanding of public acceptance of carbon dioxide capture and storage

2009-13: Emma ter Mors: Dealing with information about complex issues: The role of source perceptions

2009-14: Martijn Veltkamp: On the Instigation of Implicit Motivation: How Deprivation and Positive Affect Cause Motivated Behavior

2009-15: Marret K. Noordewier: Consistency and the unexpected

2009-16: Sytske van der Velde: Imitation of Emotion: How meaning affects the link between imitation and liking

2009-17: Jacomijn Hofstra: Attaching Cultures: The role of attachment styles in explaining majority members' acculturation attitudes

2009-18: Jacqueline Tanghe: Affect in Groups: Convergence, Conditions and Consequences

2009-19: Anne Marike Lokhorst: Using Commitment to Improve Environmental Quality

2009-20: Jonathan van 't Riet: Framing Health Communication Messages 
2009-21: Suzanne Pietersma: Persuasive Health Communication: A Self-Perspective

2009-22: Remco Wijn: A functional perspective on the justice judgment process and its consequences

2009-23: Niels van de Ven: The bright side of a deadly sin: The psychology of envy

2009-24: Anthon Klapwijk: The Power of Interpersonal Generosity

2010-1: Maarten Wubben: Social Functions of Emotions in Social Dilemmas

2010-2: Joyce Rupert: Diversity faultlines and team learning

2010-3: Daniel Lakens: Abstract Concepts in Grounded Cognition

2010-4: Luuk Albers: Double You? Function and Form of Implicit and Explicit Self-Esteem

2010-5: Matthijs Baas: The Psychology of Creativity: Moods, Minds, and Motives

2010-6: Elanor Kamans: When the Weak Hit back: Studies on the Role of Power in Intergroup Conflict

2010-7: Skyler Hawk: Changing Channels: Flexibility in Empathic Emotion Processes

2010-8: Nailah Ayub: National Diversity and Conflict: The Role of Social Attitudes and Beliefs

2010-9: Job van der Schalk: Echoing Emotions: Reactions to Emotional Displays in Intergroup Context

2010-10: Nevra Cem: Organizational citizenship behavior and counterproductive work behavior: Cross-cultural comparisons between Turkey and the Netherlands

2010-11: Ron Broeders: On Situated and Embodied Knowledge Regarding Moral Issues

2010-12: Margriet Braun: Dealing with a deviant group member

2010-13: Dennis Bleeker: Representing or defecting? The pursuit of individual upward mobility in low status groups

2010-14: Petra Hopman: Group Members Reflecting on Intergroup Relations

2010-15: Janneke Oostrom: New Technology in Personnel Selection: The Validity and Acceptability of Multimedia Tests

2010-16: Annefloor Klep: The Sharing of Affect: Pathways, Processes, and Performance

2010-17: Geertje Schuitema: Priceless policies. Factors influencing the acceptability of transport pricing policies

2010-18: Femke van Horen: Breaking the mould on copycats: What makes product imitation strategies successful?

2010-19: Niek van Ulzen: Exploring affective perception and social action

2010-20: Simon Dalley: Women's body dissatisfaction and restrictive eating behaviour: $A$ tyranny of a thin-ideal or a fear of fat?

2010-21: Paul Preenen: Challenge at Work: A matter of give and take

2010-22: Katarzyna Ewa Kubacka: The Rules of Attraction: Trust, Anxiety and Gratitude

2010-23: Loes Kessels: May I have your attention please? A neuroscientific study into message attention for health information 